$$
\text { DOE/PC/90546--T13 }
$$

\title{
Confined Zone Dispersion Project Final Technical Report
}

\author{
Prepared by \\ Bechtel Corporation
}

Prepared for

U.S. Department of Energy Pittsburgh Energy Technology Center P.O. Box 10940 Pittsburgh, Pennsylvania 15236-0940

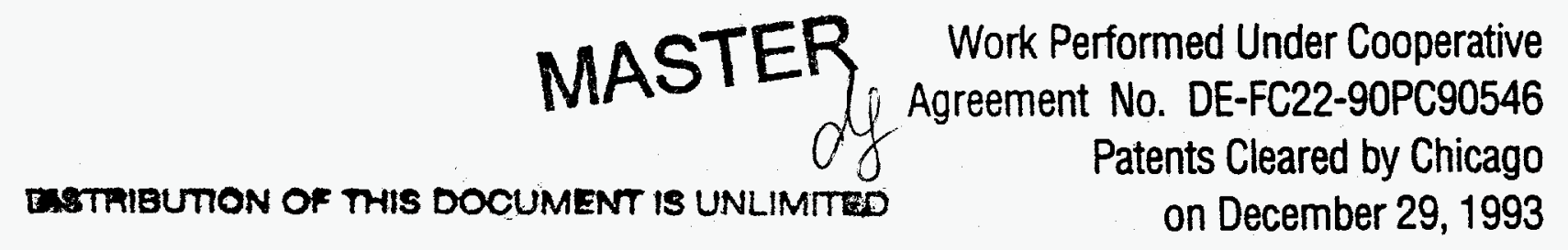




\section{DISCLAIMER}

Portions of this document may be illegible electronic image products. Images are produced from the best available original document. 


\section{LEGAL NOTICE}

This report was prepared by Bechtel Corporation, pursuant to a Cooperative Agreement partially funded by the U.S. Department of Energy, and neither Bechtel Corporation, nor any of its subcontractors nor the U.S. Department of Energy, nor any person acting on behalf of either:

(A) Makes any warranty or representation, express or implied, with respect to the accuracy, completeness, or usefulness of the information contained in this report, or that the use of any information, apparatus, method, or process disclosed in this report may not infringe privately-owned rights; or

(B) Assumes any liabilities with respect to the use of, or for damages resulting from the use of, any information, apparatus, method, or process disclosed in this report.

Reference herein to any specific commercial product, process, or service by trade name, trademark, manufacturer, or otherwise, does not necessarily constitute or imply its endorsement, recommendation, or favoring by the U.S. Department of Energy. The view and opinions of authors expressed herein do not necessarily state or reflect those of the U.S. Department of Energy.

\section{PENNSYLVANIA ENERGY DEVELOPMENT AUTHORITY DISCLAIMER}

This report summarizes the results of research supported by the Commonwealth of Pennsylvania through a research grant from the Pennsylvania Energy Development Authority. The report is made available as a public service for informational purposes only. Neither the Commonwealth of Pennsylvania nor the Pennsylvania Energy Development Authority guarantees the accuracy of the research results, nor assumes any responsibility for reliance thereon by third parties. 


\begin{abstract}
This Final Technical Report is executed in compliance with Cooperative Agreement DE-FC22-90PC90546 with the U.S. Department of Energy (DOE) and Venture Capital Grant Agreement 893-4002 with the Pennsylvania Energy Development Authority (PEDA). It describes the performance of the confined zone dispersion (CZD) flue gas desulfurization (FGD) system in removing sulfur dioxide $\left(\mathrm{SO}_{2}\right)$ from flue gas in the coal-fired boiler.
\end{abstract}

The CZD-FGD system, installed at Pennsylvania Electric Company's (Penelec's) Seward Power Station, was designed to remove $50 \%$ of the $\mathrm{SO}_{2}$ from one-half of Unit No. 5's flue gas when the boiler is fired with $1.5 \%$ sulfur coal. Unit No. 5 has a 147 MWe capacity.

The project had three phases:

Phase 1: Design and Permitting

Phase 2: Construction and Startup

Phase 3: Operation and Disposition

This report covers all project activities up to the end of June 1993 when the demonstration program, under the cooperative agreement with DOE, was terminated. Bechtel is continuing the demonstration at its own cost, with an inkind contribution from Penelec, until the CZD process is commercially proven.

The operation of the CZD-FGD system at Seward Station consisted of parametric and continuous runs. It demonstrated that under favorable boiler operating conditions a $50 \% \mathrm{SO}_{2}$ removal could be attained, and that sustained operation at lower removal rates could be maintained over long periods without significant problems. However, sustained operation at $\mathrm{SO}_{2}$ removal rates of 40 to $50 \%$ was not accomplished during this program; therefore, the demonstration did not succeed in proving the process commercially.

Section 1, Introduction, discusses the significance of CZD, the purpose of this report, the history of the project, and the role of DOE in the project. Section 1 
also describes the project organization and lists the six design areas involving proprietary information.

Section 2, Project Description, presents project location, objectives, and phases, and discusses the test program.

Section 3, CZD System Description, explains the process flow diagram, piping and instrumentation diagrams and operating controls, site plan, equipment layouts, and process equipment.

Section 4, Analysis of Test Program Results, provides an integrated discussion of all the test results obtained during the test program, backed by tabulations and graphics.

Section 5, Critical Component Failure Report, describes the testing failures and corrective actions taken. It also offers recommendations for future designs.

Section 6, Reliability/Availability/Maintainability Analysis Data of Major Equipment, covers the following systems:

- Atomizing

- Sootblowing

- Lime

- Flue gas

- Controls and Instrumentation

Section 7, Plant Cost Data and Economics, summarizes the capital cost requirements for the Seward CZD demonstration unit and discusses the capital and operating costs of installing the process at plants with various unit capacities. This section also compares the CZD-FGD process with those of competing technologies.

Section 8, Future Plans and Marketing Program, discusses Bechtel's and Penelec's plans to continue the CZD demonstration to achieve longer term continuous operation at $\mathrm{SO}_{2}$ removals of $50 \%$. It also discusses the technological and 
economical merits of the CZD system, plans for commercialization, and Bechtel's intended flexible marketing approach.

Section 9, Conclusions and Recommendations, presents the principal findings of the CZD demonstration and recommends additional testing to explore the limits of the lime injection rate and $\mathrm{SO}_{2}$ removal, clarify the performance of $\mathrm{CL}$ and PHDL under continuous operation, and assess the effect of long-term, continuous lime injection on ESP performance.

The Bibliography appended to this report lists sources of additional project information.

Appendix A contains the analyses of the limes and coals used in the demonstration program. 


\section{CONTENTS}

Section

Executive Summary

ES-1

1.0 Introduction

1.1 Significance of CZD

1.2 Purpose of the Final Technical Report

1.3 Project Background

1.4 Organization of the Project

1.5 DOE Role in the Project

1.5.1 Cooperative Agreement

1.5.2 Legal Basis for Authority to Expend Funds

1.6 Proprietary Information

2.0 Project Description

2.1 Project Location

2.2 Project Objectives

2.3 Project Phases

2.4 Test Program

2.4.1 Parametric Testing

2.4.2 Continuous Testing

3.1 Process Description 3-1

3.2 Process Flow Diagrams and Stream Properties 3-3

3.3 Process Equipment 3-3

3.3.1 Lime Slurry Preparation 3-7

3.3.2 Lime Slurry Feed 3-7

3.3.3 Lime Slurry Injection 3-8

3.3.4 Flue Gas Desulfurization 3-9 


\section{CONTENTS (cont'd)}

3.4 Piping and Instrumentation Diagram, Including Operating Controls

3.4.1 Lime Slurry Preparation

3.4.2 Lime Slurry Feed

3.4.3 Lime Slurry Injection

\subsubsection{Flue Gas Desulfurization}

3.5 Site Plan

4.0 Analysis of Test Program Results

4.1 Objectives

4.2 Atomizer Testing

4.2.1 Selection and Calibration

4.2.2 In-Duct Water Injection

4.3 $\mathrm{SO}_{2}$ Removal Testing

4.3.1 Dolomitic Lime

4.3.1.1 Parametric Testing

4.3.1.2 Continuous Testing

4.3.2 Calcitic Lime

4.3.2.1 Hydrated Calcitic Lime

4.3.2.2 Freshly Slaked Calcitic Lime

4.3.2.3 Comparison with PHDL Results

4.3.3 High-Sulfur Coal

4.3.4 Approach to Adiabatic Saturation Temperature

4.3.5 Waste Product Analysis

4.3.6 Duct Deposits

4.4 ESP Performance

4.5 Automated Continuous Operation 


\section{CONTENTS (cont'd)}

Section

5.0 Critical Component Failure Report 5-1

5.1 Lime Slurry Preparation System 5-1

5.1.1 Failure Identification:

Drive Belts for Lime Silo Blower 5-1

5.1.2 Failure Identification: Lime Silo Screw Conveyor 5-1

5.1.3 Failure Identification:

Pipe Elbow on Recirculation Lime 5-2

5.2 Lime Slurry Storage and Handling System 5-2

5.2.1 Failure Identification: Lime Slurry Transfer Pump 5-2

5.2.2 Failure Identification: Gum-Rubber Sleeve for Control Valves FCV-10 and LCV-25 5-3

5.3 Sootblowing System - Rotary and Retractable Sootblowers 5-4

5.3.1 Failure Identification: Limit Switches for Retractable Sootblowers $\quad 5-4$

5.3.2 Failure Identification: Sootblower Mechanical Stops 5-5

5.3.3 Failure Identification: Sootblower Drive Chain 5-5

5.3.4 Failure Identification: Traveling Carriage 5-6

5.3.5 Failure Identification:

Steam Valves for Rotary Sootblowers $\quad 5-6$

5.3.6 Failure Identification: Air/Steam Check Valves for Rotary Sootblowers

5.4 Leeds \& Northrup (L\&N) Chart Recorders 5-8

5.4.1 Failure Identification: Chart Recorders 5-8

5.5 Continuous Emissions Monitoring System (CEMS) 5-9

5.5.1 Failure Identification: Lear Siegler In Situ Monitors 5-9

6.0 Reliability, Availability, and Maintainability Analysis

of Major Equipment

6.1 Atomizing System 6-1

6.1.1 Plugging of the Atomizers 6-1 
CONTENTS (cont'd)

Section

Page

6.1.2 Atomizer Tip Deposits

6.2 Sootblower System Limitations

6-2

6.3 Lime System

6-3

6.3.1 Surface Deposits

6-3

6.3.2 Valve Failures

6-4

6.3.3 Pump Failures

6-4

6.4 Flue Gas System

6.4.1 Uneven Gas Flow

6.4.1.1 Non-Uniformity of Gas Velocity

6.4.1.2 Non-Uniformity of Gas Temperature

\subsubsection{Variation in the Cross-Sectional}

Temperature at Section C

6.4.2 Duct Deposits

6.4.3 Opacity Problems

6.4.4 Corrective Actions

6-6

6.4.5 Current Status

6.5 Controls and Instrumentation - L\&N Recorders

7.0 Plant Cost Data and Economics

7.1 Demonstration Project

7.2 Commercial Projections

7.3 Comparison with Competing Technologies

8.0 Future Plans and Marketing Program

9.0 Conclusions and Recommendations

Bibliography

Appendix A 


\section{TABLES}

Table

Page

4-1 Summary of the CZD Parametric Test Program Using Pressure Hydrated Dolomitic Lime

4-2 Summary of the CZD Continuous Test Program Using Pressure Hydrated Dolomitic Lime

4-3 Summary of the CZD Parametric Test Program Using Hydrated Calcitic Lime

4-4 Summary of the CZD Parametric Test Program Using Freshly Slaked Calcitic Lime

4-5 Comparison of Daily CZD Summaries of Operating Data with Regular Sulfur Coal Versus Higher Sulfur Coal

4-6 Solid Waste Product Analyses Samples Collected from B Duct ESP Hopper

4-7 Lime Slurry Injection in the B Duct on November 15 Followed by Water Injection on November 16

4-8 Data Recorded With No Injection in the B Duct at 7:30 a.m. and 9:30 a.m. on November 19

4-9 Lime Slurry Injection in the B Duct on November 19

4-10 Water Injection in the B Duct on November 19 After Completion of Lime Injection

7-1 CZD Demonstration Unit Cost Summary 7-3

7-2 Design Basis $7-5$

7-3 Cost of $\mathrm{SO}_{2}$ Removal with CZD (500 MW Plant Size) $7-6$

A-1 Typical Chemical Analysis of Lime Used During the CZD Project A-1

A-2 Ultimate Analyses for Normal and Higher Sulfur Coal A-2 


\section{ILLUSTRATIONS}

Figure

Page

1-1 Project Organization and Participants

1-2 Relationship Between Participants

1-3 Contractor and Subcontractors

3-1 Confined Zone Dispersion Diagram

3-2 CZD Test Equipment Additions

3-3 Process Flow Diagram

3-4 Material Balance and Energy Consumption

3-5 Simplified Overall P\&ID Diagram

3-6 Plan View of Duct with Thermocouple Locations

3-7 Typical Thermocouple Section

(6 Thermocouples per Thermowell $=24$ per Section)

3-8 Site Plan

4-1 Temperature Profile Before Water Injection at the B Cross Section

4-2 Temperature Profile Before Water Injection at the C Cross Section

4-3 Temperature Profile with $50 \mathrm{gpm}$ Water Injection at the B Cross Section

4-4 Temperature Profile with $50 \mathrm{gpm}$ Water Injection at the C Cross Section

4-5 Average Temperatures During Water Injection of 18 to $45 \mathrm{gpm}$ at B, C, D, and E Cross Sections

4-6 Low Temperatures During Water Injection of 18 to $45 \mathrm{gpm}$ at B, C, D, and E Cross Sections

4-7 $\mathrm{SO}_{2}$ Removal versus PHDL Lime Slurry Injection Rate Based on Parametric Test Data Taken Between November 1991 through February 1992 


\section{ILLUSTRATIONS (cont'd)}

Figure

Page

4-8 $\mathrm{SO}_{2}$ Removal versus PHDL Lime Slurry Injection Rate Based on Continuous Test Data Taken Between

August 17, 1992 and September 3, 1992

4-9 $\mathrm{SO}_{2}$ Removal versus PHDL Lime Slurry Injection Rate for Parametric and Continuous Test Data

4-10 Lime Flow and Flue Gas Temperature versus Time August 17 to December 16, 1992

4-11 $\mathrm{SO}_{2}$ Reduction, Lime Flow and Slurry Solids versus Time August 17 to December 16, 1992

4-12 $\mathrm{SO}_{2}$ Removal versus Lime Slurry Concentration August 17 to December 16, 1992

4-13 Lime Utilization and Lime Slurry Concentration versus Time - August 17 to December 16, 1992

4-14 Lime Utilization versus Lime Slurry Concentration August 17 to December 16, 1992

4-15 $\mathrm{SO}_{2}$ Removal versus Hydrated Calcitic Lime Slurry Injection Rate

4-16 $\mathrm{SO}_{2}$ Removal versus Freshly Slaked Calcitic Lime Slurry Injection Rate

4-17 Effect of Lime Type on $\mathrm{SO}_{2}$ Removal

4-18 C Cross Section Approach to Saturation, Lime Flow and

$\mathrm{SO}_{2}$ Removal versus Time - November 17 to December 16, 1992

4-19 $\mathrm{SO}_{2}$ Removal versus C Cross Section Approach to Saturation - November 17 to December 16, 1992

4-20 Recording of Opacity on November 15, 1991

4-21 Recording of Opacity on November 19, 1991

4-22 CZD Performance Summary - October 17 to November 16, 1992 4-52

7-1 CZD Generic Retrofit Capital Costs for Various Unit Sizes 7-8

7-2 Cost of $\mathrm{SO}_{2}$ Removal for Various Unit Sizes

Based on $50 \%$ Removal 


\section{LIST of ABBREVIATIONS}

BOD

CCT

CEMS

CFR

$\mathrm{CL}$

CZD

CZD-FGD

DCS

DOE

EMP

EMS

EMV

EPRI

ESP

FGD

FRP

$I \& C$

ID fan

I/O

L\&N

MCC

MCS

MFP

NLL

NPDES

NPT

OIU

O\&M

PaDER

P\&ID

PCV

PEDA

Penelec

PHDL
Biochemical oxygen demand

Clean coal technology

Continuous emissions monitoring system

Code of Federal Regulations

Calcitic lime

Confined zone dispersion

Confined zone dispersion flue gas desulfurization

Distributed Control System

Department of Energy

Environmental Monitoring Plan

Environmental Monitoring System

Effective migration velocity

Electric Power Research Institute

Electrostatic precipitator

Flue gas desulfurization

Fiberglass reinforced plastic

Instrumentation and control

Induced draft fan

Input/output

Leeds \& Northrup

Motor control center

Management control system

Multifunction processor

Normal low level

National Pollution Discharge Elimination System

National Pipe Thread

Operator interface unit

Operations and Maintenance

Pennsylvania Department of Environmental Resources

Piping and instrumentation diagram

Process control valve

Pennsylvania Energy Development Authority

Pennsylvania Electric Company

Pressure-hydrated dolomitic lime 


\section{LIST of ABBREVIATIONS (cont'd)}

POC

PV

R-C

RF

SCA

SEM

SS

TAG

TSS

UPS

VSD
Proof of concept

Process variable

Research-Cottrell

Radio frequency

Specific collection area

Scanning electron micrograph

Stainless steel

Technical Assessment Guide

Total suspended solids

Uninterruptible power supply

Variable-speed drive 


\section{LIST of UNITS}

A

acf

acfm

bhp

Btu

Btu/lb

cfm

dia.

${ }^{\circ} \mathrm{F}$

$\mathrm{ft}$

$\mathrm{ft} / \mathrm{sec}$

gpm

gr

gr/scf

hr

hp

$\mathrm{Hz}$

kW

kWh

$\mathrm{lb}$

$\mathrm{lb} / \mathrm{ft}^{3}$

$\mathrm{mA}$

mgd

MV

MW

pph

ppm

psi

psig

scfm

tpd

tph

$\mu$

V

Wh

yr
Amperes

Actual cubic feet

Actual cubic feet per minute

Brake horsepower

British thermal unit

British thermal unit per pound

Cubic feet per minute

Diameter

Degrees Fahrenheit

Feet

Feet per second

Gallons per minute

Grains

Grains per standard cubic foot

Hour

Horsepower

Hertz

Kilowatt

Kilowatt-hour

Pound

Pounds per cubic foot

Milliamperes

Million gallons per day

Megavolts

Megawatts

Pounds per hour

Parts per million

Pounds per square inch

Pounds per square inch gauge

Standard cubic feet per minute

Tons per day

Tons per hour

Micron

Volts

Watt-hours

Year 


\section{GLOSSARY of TERMS}

Chemical Symbols

$\mathrm{Ca}$

$\mathrm{CaCO}_{3}$

$\mathrm{Ca}(\mathrm{OH})_{2}$

$\mathrm{CaSO}_{4}$

$\mathrm{CaSO}_{4} \cdot 2 \mathrm{H}_{2} \mathrm{O}$

$\mathrm{CaSO}_{3} \cdot 1 / 2 \mathrm{H}_{2} \mathrm{O}$

$\mathrm{CO}_{2}$

$\mathrm{H}_{2} \mathrm{O}$

$\mathrm{Mg}$

$\mathrm{Mg}(\mathrm{OH})_{2}$

$\mathrm{N}_{2}$

$\mathrm{NO}_{x}$

$\mathrm{O}_{2}$

$\mathrm{SO}_{2}$

Technical Terms

Absorption waste

Fly ash

Grit

Humidity

Lime feed ratio

Lime slurry

Lime utilization
Calcium

Calcium carbonate

Calcium hydroxide - lime

Calcium sulfate

Gypsum

Calcium sulfite hemihydrate

Carbon dioxide

Water - liquid or vapor

Magnesium

Magnesium hydroxide

Nitrogen

Nitrogen oxides

Oxygen

Sulfur dioxide

A mixture of fly ash, sulfur dioxide removal products, and unreacted reagent

Entrained residue from the combustion of coal

Residue of unreacted lime and inerts from slaking lime Water vapor content of air or flue gas, expressed in pounds of water per pound of dry gas

Moles of lime fed (includes the magnesium hydroxide portion of the dolomitic lime) divided by the moles of $\mathrm{SO}_{2}$ entering Aqueous suspension of lime Percent $\mathrm{SO}_{2}$ removal divided by the lime feed ratio 


\section{EXECUTIVE SUMMARY}

\section{INTRODUCTION}

The Confined Zone Dispersion Flue Gas Desulfurization (CZD-FGD) process was conceived for the low-cost removal of one-half of the sulfur dioxide $\left(\mathrm{SO}_{2}\right)$ content of flue gas from existing coal-fired utility boilers. The low cost of $\mathrm{SO}_{2}$ removal results from using the existing power plant equipment with minimal modifications for the operation of the CZD system.

The CZD process involves injecting a finely atomized slurry of reactive lime into the flue gas ductwork of a coal-fired utility boiler. The principle of the confined zone is to form a wet zone of slurry droplets in the middle of the duct, confined in an envelope of hot gas between the wet zone and the duct walls. The lime in the slurry droplets reacts with part of the $\mathrm{SO}_{2}$ in the gas, and the reaction products dry to form solid particles. An electrostatic precipitator (ESP) downstream from the point of injection captures the reaction products, along with the fly ash entrained in the flue gas.

The CZD project at Penelec's (Pennsylvania Electric Company) Seward Station is the first full-scale demonstration of Bechtel's CZD technology for reducing $\mathrm{SO}_{2}$ emissions. When implemented, the CZD process will allow coal-burning plants to comply with the Clean Air Act standards at a minimum of cost. Because of its low capital cost, low operating cost, and relatively minor space requirements, CZD is a feasible option for installation on older generating stations.

The CZD process is technically simple and has a significant economic advantage over other FGD processes. Because of these characteristics, its demonstration at Seward Station attracted U.S. Government, state government, and industrial sponsors who contributed the following amounts: 
- U.S. Department of Energy

- Pennsylvania Electric Company

- Bechtel Corporation

- The Pennsylvania Energy Development Authority

- New York State Electric and Gas Corporation

- Rockwell Lime Company

Total
$\$ 5,200,000$

$3,600,000$

$2,500,000$

750,000

100,000

23,000

$\$ 12,173,000$

DOE sponsorship was based on Cooperative Agreement DE-FC22-90PC 90546 between Bechtel and DOE. This agreement defined the cost-sharing basis, project schedule, and reporting requirements of the project, which was scheduled to last from June 1990 to June 1993 and to terminate with the final technical report.

As a result of various operating problems, the demonstration schedule had to be extended. The project will continue into early 1994 but without further DOE sponsorship. Bechtel will provide financing. Penelec will provide electricity, steam, and water to operate the CZD system, and it will dispose of the $\mathrm{SO}_{2}$ absorption waste.

This is the final technical report on the work performed under DOE and PEDA sponsorship in accordance with the requirements of the cooperative agreement and venture-capital grant agreement, respectively. It contains the description of the investigations undertaken and the results achieved; it also includes an analysis of Bechtel's plan for marketing, commercialization and technical readiness of the demonstrated technology. It presents tabulated data, figures, and bibliographic citations in support of the investigations undertaken and conclusions reached, and it summarizes all topical and technical progress reports.

\section{PROJECT BACKGROUND}

Bechtel conceived the CZD process 10 years ago. In 1986, DOE selected this process for proof-of-concept (POC) testing on a $5 \mathrm{MW}$ scale. These tests were performed on a slipstream of flue gas from Consumers Power Company's 
260 MW J.H. Campbell Station Unit 1 in Michigan. The test results indicated $\mathrm{SO}_{2}$ removal in excess of $50 \%$ was possible.

Following the Campbell tests, large-scale POC tests, funded by PEDA Grant Agreement 486-009, were performed at Penelec's Seward Station Unit No. 5 (147 MW) in Pennsylvania, where the CZD system was retrofitted on one of two twin flue gas ducts to treat one-half of the flue gas from the unit. The results of the large-scale POC tests confirmed that a true confined zone operation could be maintained and that duct deposits could be prevented by limiting the injection rates. The short distance between the injection point and the duct turning vanes limited the volume of lime slurry that could be injected into the duct and evaporated before it hit the turning vanes. Consequently, the actual amount of $\mathrm{SO}_{2}$ removal was low.

The results of both POC tests convinced Bechtel that the CZD process was ready for commercial demonstration in a duct of proper length. Bechtel's 1989 proposal for an 18-month CZD demonstration project was accepted by DOE during Round 3 of the Clean Coal Technology Program. The proposed project entailed replacement of one of two ducts (Duct B) of Unit No. 5 with a 211-footlong duct having a 120-foot-long straight test section and retrofit of this duct with the CZD system.

\section{PROJECT LOCATION}

The CZD-FGD demonstration system described in this report was located at Penelec's Seward Power Station. This power plant is located in western Pennsylvania, approximately 12 miles northwest of Johnstown on the southern bank of the Conemaugh River in East Wheatfield Township, Indiana County.

The pressure-hydrated dolomitic lime (PHDL), supplied from Wisconsin by Rockwell Lime Company, was shipped by rail in lime cars that were stored in Pittsburgh. From there, it was delivered to Seward Station in road trucks.

The freshly slaked calcitic lime was obtained from the Conemaugh Power Plant located approximately 3 miles away and operated and maintained by Penelec. 
The absorption wastes were deposited, together with the fly ash, in the landfill near Conemaugh Power Plant.

\section{PROJECT OBJECTIVES}

The goal of this project was to prove the technical and economic feasibility of CZD technology on a commercial scale. The process is expected to achieve $50 \%$ $\mathrm{SO}_{2}$ removal at lower capital and O\&M costs than other FGD systems.

Technical objectives of the project included the evaluation of different atomizers, different absorbents (dolomitic and calcitic limes), low- and highsulfur coals, and the effects of the CZD system on the performance of the electrostatic precipitator and stack gas opacity. These objectives were accomplished using a parametric test program. After the parametric test program, the CZD system was revamped for fully automatic, continuous operation, integrated with the regular power plant operation. The specific objectives of the project were to:

- Demonstrate the applicability of the CZD-FGD process for use in utility boiler flue gas operations, which are derived from low- and high-sulfur coal combustion

- Evaluate/quantify the CZD-FGD process variable effects and determine the optimum operating requirements for long-term continuous testing

- Determine the operability and reliability of CZD-FGD during long-term testing and its impact on downstream operations - e.g., ESP performance and stack emissions

- Demonstrate a reduction of utility boiler flue gas $\mathrm{SO}_{2}$ emissions by 40 to $50 \%$

- Verify that the CZD-FGD process has no detrimental impact on waste streams

- Determine the cost of CZD-FGD, with the aim of achieving $\mathrm{SO}_{2}$ removal costs (capital and operating) in the range of $\$ 300 /$ ton or less

- Document this CZD-FGD test effort sufficiently to inform the public about the capability of the process and its applicability to the U.S. utility industry 
The CZD-FGD project was carried out in 3 phases:

Phase 1: Design and permitting

Phase 2: Construction and startup

Phase 3: Operation and disposition

Phase 1 work was completed on January 31,1991. During this phase, Bechtel developed a process design, prepared piping and instrumentation diagrams (P\&IDs), and performed detailed engineering for a new extended duct to be used in the CZD demonstration on one-half of Unit No. 5 at Penelec's Seward Station. Bechtel wrote all the specifications for equipment and instruments, and started procurement activities. Interface with the appropriate environmental agencies was accomplished through Penelec, with Bechtel providing assistance as needed.

Phase 2 work was substantially completed by July 31,1991. This phase included equipment acquisition and installation, facility construction, and startup operations. Bechtel completed procurement of the equipment, instruments, materials, and fabrication of the new long duct. Penelec performed construction and installation of these items in accordance with specifications prepared by Bechtel. At completion of construction, using Penelec operating and maintenance personnel, Bechtel trained the operators, started all major elements of the CZD system, and verified that the installation and control system functioned according to requirements.

Phase 3 was conducted in two parts - parametric testing and continuous testing. The purpose of the parametric tests was to characterize the system's process performance and to select optimum operating conditions for continuous tests. Parametric testing lasted 6 months and was carried out on day shifts, only 5 days a week.

Continuous testing started in August 1992 and continued until June 1993. The purpose of the continuous tests was to verify the operation of the CZD system on automatic control and to determine the long-term effects of lime injection on system performance. Bechtel supervised the continuous demonstration, carried out various performance tests, managed the data acquisition, and arranged for chemical analyses. 


\section{CZD SYSTEM DESCRIPTION}

The flue gas is treated in approximately 120 feet of a straight ductwork section, 8 feet wide $\times 11$ feet high. The ductwork section is located between two existing ESPs. At a nominal flue gas velocity of $60 \mathrm{ft} / \mathrm{sec}$, the duct section has approximately 2 seconds of residence time. After slurry injection, the dried reaction products and fly ash are collected in the second existing ESP.

PHDL is received in self-unloading trucks and pneumatically transferred to a lime silo. The dry lime is slurried with water in a 5,000-gallon lime sump equipped with an agitator. The slurry is pumped from the sump to a vibrating screen to remove fine grit and then stored in either of two 10,000-gallon agitated lime feed tanks.

A centrifugal feed pump pumps lime from the feed tanks through a pumparound loop passing close to a valved manifold that distributes lime to the atomizing nozzles. A separate valved manifold distributes atomizing air to the nozzles.

On-line measurements include the following:

- Gas velocity and temperature upstream of lime injection

- Gas temperature before and after the downstream ESP

- Sulfur dioxide $\left(\mathrm{SO}_{2}\right)$ and carbon dioxide $\left(\mathrm{CO}_{2}\right)$ concentrations upstream of the spray nozzles and downstream of the ESP and the induced draft (ID) fan

- Flow of lime slurry and atomizing air

- Temperature profiles in the duct cross section at several distances downstream of the injection point

Startup, operation, and monitoring of the CZD equipment is accomplished by a combination of actions performed locally or in the control room (remote operation). Once the equipment is in operation, monitoring its condition and changing the system setpoints can be done remotely in the control room, or locally through panel-mounted switches and controllers. 


\section{TEST RESULTS}

The atomizers selected for CZD testing were developed and calibrated at the University of California at Davis to determine their pressure/flow characteristics for very fine mist formation. It was determined that standard, off-the-shelf atomizers were not suitable. Standard nozzles were modified to provide the desired atomization characteristics. Then the atomizers, assembled in lances, were tested both outside and inside the duct to verify their pressure/flow characteristics at different water flow rates, the effect of the impact between the mists of adjacent atomizers, and the atomizers' configuration to avoid wetting the duct and the turning vanes. Temperature profiles taken in the duct cross section at several distances from the injection point confirmed that a true confined zone, a moist interior surrounded by hot gas, could be obtained. It was also confirmed that the straight length of ductwork was adequate to allow the evaporation of $50 \mathrm{gpm}$ of water from the injected lime slurry without the formation of deposits on the turning vanes.

Parametric slurry injection testing was conducted with PHDL and two types of calcitic lime - hydrated and freshly slaked. The parametric tests normally lasted for several hours with conditions kept as constant as possible during that time. However, because the temperature of the inlet gas and the concentration of $\mathrm{SO}_{2}$ in the gas were affected by the boiler operation and could not be controlled, test conditions often varied to some extent. All three reagents show the same trends in $\mathrm{SO}_{2}$ removal performance:

- The percentage of $\mathrm{SO}_{2}$ removed is directly proportional to the lime slurry feed rate.

- By maintaining a constant lime slurry feed rate to the flue gas duct and increasing the lime slurry concentration, the percentage of $\mathrm{SO}_{2}$ removed increases until it reaches a peak, after which any increase in lime slurry concentration does not increase the percentage of $\mathrm{SO}_{2}$ removed.

Plots of the percentage of $\mathrm{SO}_{2}$ removal versus the slurry injection rate with a least-squares, straight-line fit to the data for the parametric tests were made for the three lime types. The PHDL data show the best performance; the freshly slaked calcitic data are somewhat lower and the hydrated calcitic data significantly lower. The very low performance for the hydrate is likely due to 
operating at significantly higher approach to saturation temperatures than the other tests although a loss in reactivity due to aging may have contributed.

Continuous slurry injection was conducted with PHDL. During periods when the temperature of the flue gas to the CZD system was in the design range of 300 to $310^{\circ} \mathrm{F}$, it was possible to inject sufficient slurry to achieve $\mathrm{SO}_{2}$ removals approaching $50 \%$. However, for a significant portion of the continuous test period the inlet flue gas temperatures were lower than $300^{\circ} \mathrm{F}$, which limited both injection rates and the percentage of $\mathrm{SO}_{2}$ removal.

A comparison of the PHDL continuous and parametric test data apparently indicates that a higher injection rate is required in continuous testing to achieve a given percentage of $\mathrm{SO}_{2}$ removal.

CZD treatment of the flue gas resulting from burning a higher sulfur coal was tested for a 15-day period. The results show that $\mathrm{SO}_{2}$ removal and the lime utilization were slightly higher during the period when higher sulfur coal was burned. These results could be expected because the higher $\mathrm{SO}_{2}$ concentration creates a higher partial pressure of $\mathrm{SO}_{2}$, leading to the faster reaction with water and $\mathrm{SO}_{2}$ absorbent.

During normal CZD operations, duct deposits were not significant, as confirmed by duct inspections during outages. On a few occasions, deposits accumulated in the duct and had to be manually removed. These deposits resulted from equipment failures that produced excessive slurry feed rates, improper atomization or leaks, and sootblower maloperations. These equipment failures were identified and corrected. Increased skill of the operators at maintaining proper nozzle atomization and the improved failure-detection techniques that were implemented are expected to control duct deposit formation.

In general, CZD system operation has a beneficial effect on ESP performance and during the lime slurry in-duct injection, the stack opacity is lower than without injection. The explanation for the increase in ESP removal efficiency during the water and lime slurry injection in the flue gas duct is as follows: 
- The cooling of the flue gas during the lime slurry injection (from about 300 to $180^{\circ} \mathrm{F}$ ) decreases the flue gas volume and gas velocity, thereby increasing the flue gas residence time inside the ESP.

- The ash resistivity and that of reacted products (calcium sulfite and sulfate) varies with the temperature. For some ashes, the lower temperature reduces resistivity, allowing a higher electric current that improves ESP performance.

- It is known that the water vapor is a conditioning agent for improving ESP performance.

- It was demonstrated that during lime slurry injection, an agglomeration of fly ash particles with lime and reacted products occurred, creating larger particles that can be more easily removed by the ESP.

Once the CZD system is set in operation, monitoring the condition of equipment and the changing of system setpoints can occur remotely at the control room. On automatic control, the injection rate (lime slurry or water) is automatically regulated to maintain the lowest temperature in a section of the duct at a chosen setpoint. As the flue gas temperature or flow rate to the CZD system varies, the automatic controls vary the injection rate to maintain this set temperature. The automatic controls have provided excellent operability and availability during the CZD system continuous demonstration period.

\section{PLANT COSTS AND ECONOMICS}

The total capital costs required to provide a complete and operable CZD system at Seward Station was $\$ 4.4$ million. These costs include all proprietary or "business-sensitive" equipment such as atomizer lances (included as piping), nozzles, and associated headers, piping, instrumentation, and other parts of the slurry injection atomizer array system.

Since earlier CZD proof-of-concept work was done at Seward Station, certain items of equipment did not need to be purchased and installed. These included the lime slurry feed and storage tanks, the grit tanks, the vibrating screen, and the water booster pump. In addition, Seward Station had an existing lime silo and lime preparation sump, as well as space in its existing buildings for installation of air compressors and a receiver. If the existing equipment and 
space were not available, the cost of the Seward Station CZD installation would increase to $\$ 5.1$ million.

It is expected that there will be some cost improvement in future plants, based on design maturity and plant operating experience, because the Seward Station CZD system is the first commercial installation. Although most of the CZD equipment is of standard off-the-shelf design, the atomizer nozzles are expensive, special prototypes. As the market for CZD installations develops and increased quantities of nozzles are required, the nozzle cost will decrease.

\section{COMMERCIAL PROJECTIONS}

The CZD process may be scaled as necessary to fit a variety of plant capacity requirements. The lime slurry preparation and feed areas offer no scaleup problems, and the lime slurry injection scaleup is a function of the site-specific plant characteristics. If existing plant ductwork is inadequate to provide the residence time and cross-sectional area needed, new ductwork similar to the retrofit at Seward Station can be designed so that the injection requirements can be met. Consequently, duct size and length can be adjusted to satisfy the lime injection rates necessary to achieve the desired level of $\mathrm{SO}_{2}$ removal.

A preliminary assessment has been made of the capital and operating costs for CZD installations at various unit capacities. The costs were derived from analysis of the retrofit cost for Seward Station. It was assumed that no existing equipment or space was available and a complete lime receiving, preparation, and storage system would need to be provided. An allowance was also made for replacement of an equivalent amount of ductwork similar to that at Seward Station. Costs for larger or smaller units were factored, using appropriate exponents for individual items of equipment. The individual costs were then summed to give the total direct costs. Appropriate percentages were then applied for field distributables, home office costs, fees, and paid-up royalties to arrive at the total capital costs.

The total capital cost for plants in the range from $150 \mathrm{MW}$ to $500 \mathrm{MW}$ varies from about $\$ 38 / \mathrm{kW}(500 \mathrm{MW})$ to $\$ 62 / \mathrm{kW}(150 \mathrm{MW})$. The capital costs rise sharply below $150 \mathrm{MW}$. 
Levelized O\&M costs were derived using the Electric Power Research Institute's (EPRI's) Technical Assessment Guide (TAG). Annual O\&M costs were derived on the same basis, but exclude any capital charges and represent the actual costs before application of carrying charges and levelization factor. The annual O\&M costs for a plant burning $4 \%$ sulfur coal vary from $\$ 332$ per ton of $\mathrm{SO}_{2}$ removed from a $50 \mathrm{MW}$ unit, to $\$ 185$ per ton of $\mathrm{SO}_{2}$ removed from a $500 \mathrm{MW}$ unit. Similarly, the levelized costs vary from $\$ 486$ per ton of $\mathrm{SO}_{2}$ removed from a 50 MW unit, to $\$ 240$ per ton of $\mathrm{SO}_{2}$ removed from a $500 \mathrm{MW}$ unit.

\section{FUTURE PLANS AND MARKETING PROGRAM}

At the conclusion of the DOE-funded CZD demonstration project at Seward Station, reliable operation of the CZD process when integrated with a power station was demonstrated, but longer term continuous operation at higher $\mathrm{SO}_{2}$ removals was not. Bechtel and Penelec will continue to cooperate in the CZD demonstration to achieve continuous operation at $\mathrm{SO}_{2}$ removals of $50 \%$. Bechtel intends to commercialize the CZD process when the demonstration is successfully concluded.

The CZD-FGD process is particularly suited for retrofitting onto existing boilers and is not dependent on boiler type, age, size, type of coal burned, or sulfur content of the coal. The acid rain provisions of the 1990 Clean Air Act Amendments give utilities the option to select the most cost-effective approach to maintain $\mathrm{SO}_{2}$ emissions at the required levels. A large number of candidate plants in the United States are suitable for application of the CZD process. There is also a significant international marketing potential. Many areas, such as Central Europe, could benefit from a low capital cost method of reducing $\mathrm{SO}_{2}$ emissions.

Following a successful CZD demonstration, Bechtel will initiate business discussions with domestic utilities, including Penelec, which might potentially benefit from CZD. After the CZD system is commercialized in the United States, commercialization in Eastern Europe and developing countries will be pursued.

\section{CONCLUSIONS}

The following conclusions can be drawn from the CZD demonstration results: 
- The integration of the fully automated system with the power plant operation proved that the CZD process responds very well to automated control operations.

- CZD system availability and mechanical operation of the process are very good.

- Overall $\mathrm{SO}_{2}$ removals above $50 \%$ are possible under favorable boiler operating conditions when the flue gas inlet temperature is above $300^{\circ} \mathrm{F}$. However, demonstration of sustained operation at $\mathrm{SO}_{2}$ removal rates of $50 \%$ was not accomplished during this program.

- Lime utilizations of $50 \%$ are possible with lime concentrations of $5 \%$ but fall off to the low 30 s when concentrations increase to $10 \%$.

- The injection of atomized lime slurry in a large duct can be controlled in a confined zone that minimizes duct deposition while enhancing $\mathrm{SO}_{2}$ removal performance.

- Injected lime slurry has to dry before contacting any surfaces inside the duct; otherwise, deposits will form. Slurry injection rates high enough to cause wet deposits must be avoided.

- During normal CZD operations, no deposits of fly ash and reaction products took place in the flue gas duct.

- At Seward Station, stack opacity is not detrimentally affected by the CZD system.

- The CZD process can achieve costs of less than $\$ 300 /$ ton of $\mathrm{SO}_{2}$ removed when operating a $500 \mathrm{MW}$ unit burning $4 \%$ sulfur coal. Based on a 500 MW plant retrofitted with CZD for a $50 \%$ rate of $\mathrm{SO}_{2}$ removal, the total capital cost is estimated to be about $\$ 38 / \mathrm{kW}$. 


\section{Section 1}

\section{INTRODUCTION}

\subsection{SIGNIFICANCE OF CZD}

The Confined Zone Dispersion Flue Gas Desulfurization (CZD-FGD) process was conceived for the low-cost removal of one-half of the sulfur dioxide $\left(\mathrm{SO}_{2}\right)$ content of flue gas from older coal-fired utility boilers. The low cost of $\mathrm{SO}_{2}$ removal results from using the existing power plant equipment with minimal modifications for the operation of the CZD system.

The CZD process involves injecting a finely atomized slurry of reactive lime into the flue gas ductwork of a coal-fired utility boiler. The principle of the confined zone is to form a wet zone of slurry droplets in the middle of the duct, confined in an envelope of hot gas between the wet zone and the duct walls. The lime slurry reacts with part of the $\mathrm{SO}_{2}$ in the gas, and the reaction products dry to form solid particles. An electrostatic precipitator (ESP) downstream from the point of injection captures the reaction products, along with the fly ash entrained in the flue gas.

The CZD project at Penelec's (Pennsylvania Electric Company) Seward Station is the first full-scale demonstration of Bechtel's CZD technology for reducing $\mathrm{SO}_{2}$ emissions. When implemented, the CZD process will allow coal-burning plants to comply with the Clean Air Act standards at a minimum of cost. Because of its low capital cost, low operating cost, and relatively minor space requirements, CZD is a feasible option for installation on older generating stations.

CZD will significantly affect the economy of the surrounding area, which depends on these stations for their economic survival. For example, without an economical solution for the removal of $\mathrm{SO}_{2}$ from the discharged stack gas, most of the smaller and older plants would have to cease operations in 1995 because of noncompliance with environmental laws. 


\subsection{PURPOSE OF THE FINAL TECHNICAL REPORT}

This final technical report presents the technical account of all work performed by Bechtel under Cooperative Agreement DE-FC22-90PC90546 with the U.S. Department of Energy (DOE). It contains a comprehensive description of the investigations undertaken and results achieved, and includes an analysis of Bechtel's plans for marketing, commercialization, and technical readiness of the demonstrated technology. It also includes tabulations of data, figures, and bibliographic citations in support of the investigations undertaken and conclusions reached. It summarizes all topical and technical progress reports.

The purpose of the final technical report is to provide the public with all pertinent, nonproprietary information on the clean coal technology being demonstrated.

\subsection{PROJECT BACKGROUND}

Bechtel conceived the CZD process 10 years ago. In 1986, Bechtel's CZD process was selected by DOE for proof-of-concept (POC) testing at a $5 \mathrm{MW}$ scale. These initial tests were performed using a slipstream of flue gas from Consumers Power Company's 260 MW J.H. Campbell Station Unit No. 1 in Michigan. Test results showed that $\mathrm{SO}_{2}$ removal in excess of 50 percent was achieved. In addition, the process did not cause any corrosion in the flue gas duct downstream of the injection point or in the ESP.

Following these tests, large-scale POC tests were performed at Penelec's Seward Station Unit No. 5 (147 MW) in Pennsylvania, where the CZD system was retrofitted to one of two parallel flue gas ducts to treat one half of the flue gas from the Unit. The results of the large-scale POC tests confirmed that a true confined zone could be obtained and that duct deposits could be prevented by limiting injection rates. The short distance between the injection point and the duct turning vanes limited the quantity of lime slurry that could be injected into the duct and consequently limited the percent of $\mathrm{SO}_{2}$ removal.

The results of both POC tests convinced Bechtel that the CZD process was ready for commercial demonstration in a duct of proper length. Bechtel's proposal, in 
1989, for a CZD demonstration project was accepted by DOE during Round 3 of the Clean Coal Technology Program.

The purpose of the proposed project was to demonstrate the CZD technology over an 18-month period. It was proposed that one of the two flue gas ducts leading from Seward Station's Unit No. 5 be retrofitted for the project. The installation of the CZD process requires the replacement of one of two ducts (the west duct called B duct) with a 211-foot-long duct. This includes a 120-foot-long straight section to permit the addition of atomizers and provide adequate lime slurry injection rates with sufficient residence time.

\subsection{ORGANIZATION OF THE PROJECT}

The CZD process is very simple technically and has significant economic advantages over other FGD processes. Because of these characteristics, its demonstration at the Seward Power Plant attracted the following sponsors:

- The U.S. Department of Energy $\$ 5,200,000$

- The Pennsylvania Electric Company $3,600,000$

- Bechtel Corporation $2,500,000$

- The Pennsylvania Energy Development Authority 750,000

- New York State Electric and Gas Corporation 100,000

- Rockwell Lime Company 23,000

Total $\$ 12,173,000$

The CZD-FGD project organization and participants are shown in Figure 1-1. The relationship between the participants is shown in Figure 1-2.

The main contractor, Penelec (the host site's owner), and the four construction subcontractors are shown in Figure 1-3, along with their areas of responsibilities. 


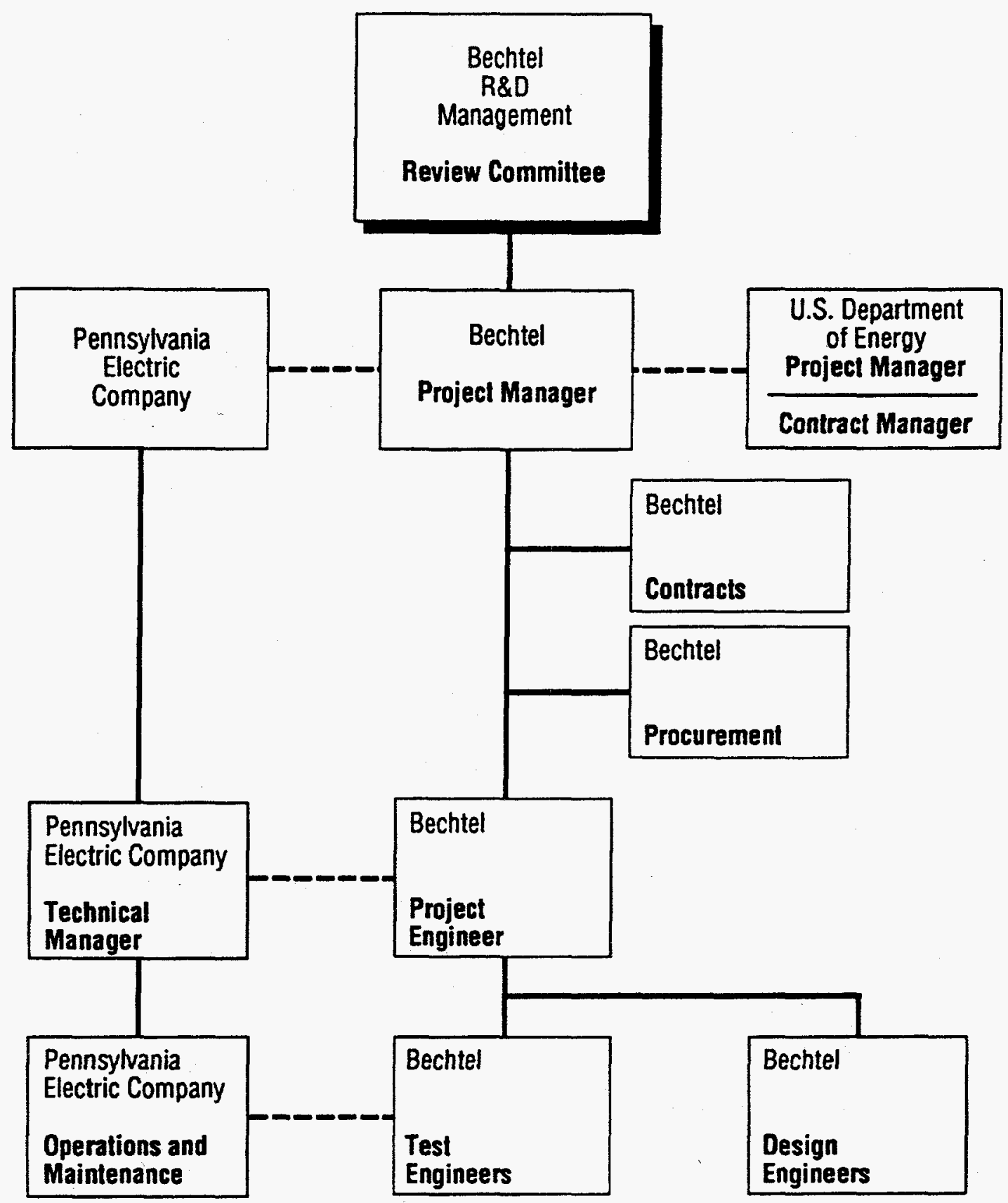

94-1702b.001

Figure 1-1 Project Organization and Participants 


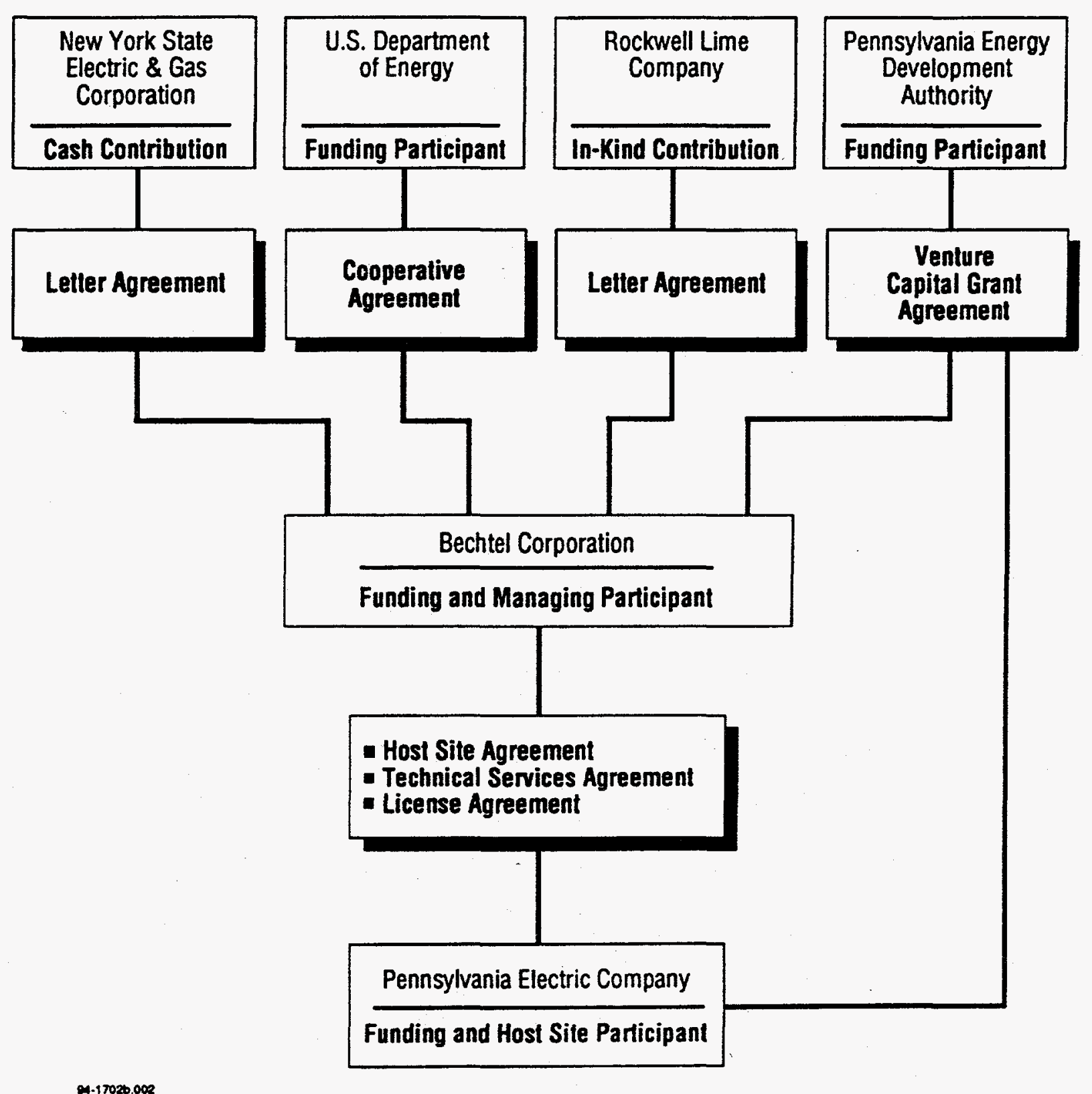

Figure 1-2 Relationship Between Participants 


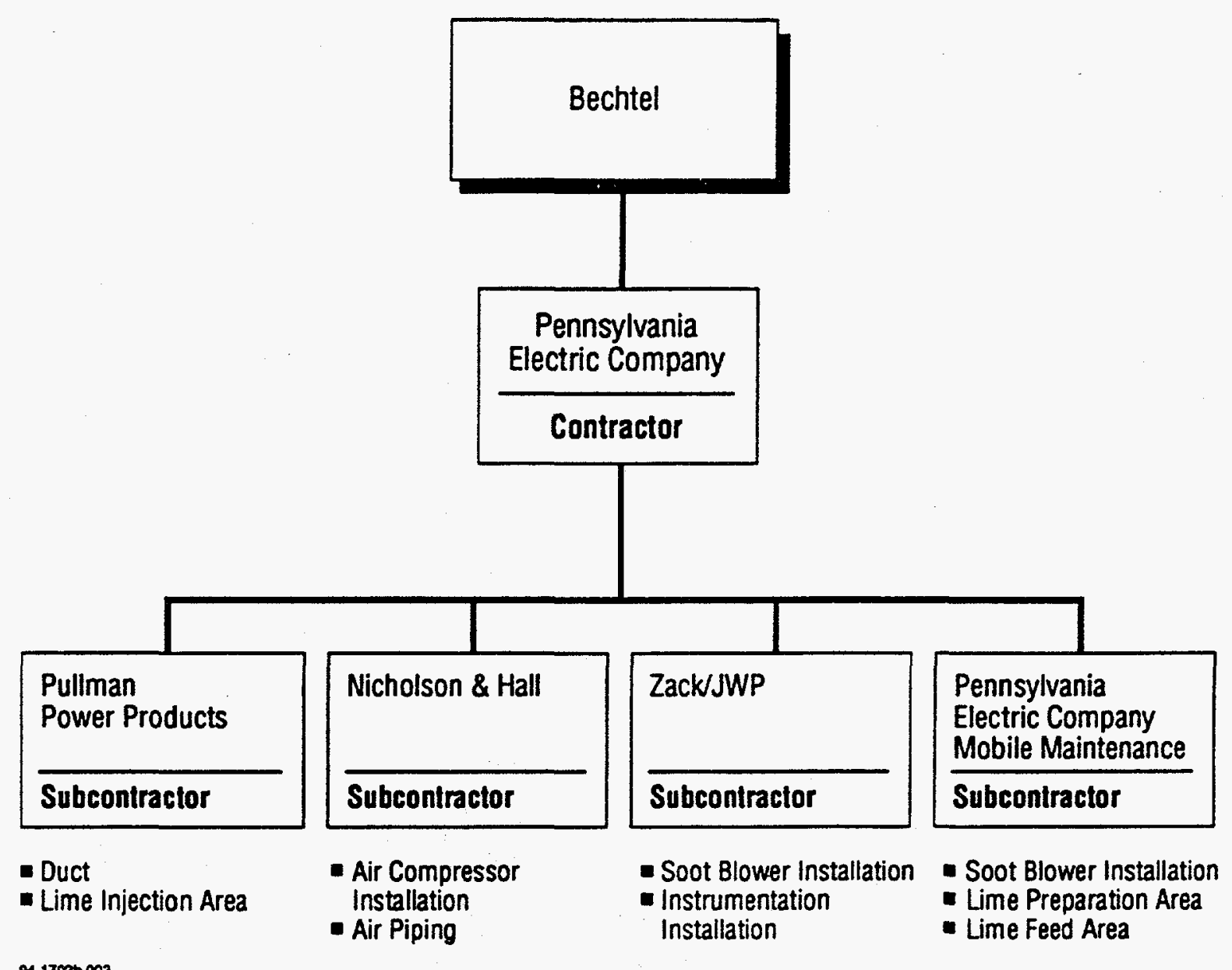

Figure 1-3 Contractor and Subcontractors 


\subsection{DOE ROLE IN THE PROJECT}

This project was carried out under a cooperative agreement between DOE's Pittsburgh Energy Technology Center and Bechtel, the major participant.

\subsubsection{Cooperative Agreement}

The primary objective of the cooperative agreement was to conduct a cost-shared project that would demonstrate Bechtel's CZD-FGD technology. The parties envisioned that if the demonstration project were successful, the technology could be commercialized during the 1990 s. It would be capable of (1) significantly reducing the emissions of $\mathrm{SO}_{2}$ from existing facilities to minimize environmental impacts such as transboundary and interstate pollution and/or (2) providing for future energy needs in an environmentally acceptable manner.

\subsubsection{Legal Basis for Authority to Expend Funds}

The expenditure of DOE funds under the cooperative agreement was subject to the requirements of Public Law 100-446. Except as otherwise expressly provided in Public Law $100-446$ or by terms of this cooperative agreement, the parties complied with the applicable provisions of Subparts A, B, and C of the DOE Financial Assistance Rules, 10 CFR Part 600.

\subsection{PROPRIETARY INFORMATION}

Bechtel considers certain process data to be proprietary and confidential. These data cover the following six design areas:

- Piping arrangement for the lime slurry supply and return

- Modifications to standard nozzles to adapt them for use in the CZD system

- Arrangement of the nozzles in the duct

- Longitudinal and transverse temperature profiles in the duct when the nozzles are operational

- Material flow rates and operating pressures

- Instrumentation, control, and arrangement of the control system 
Process flow diagrams, piping and instrument diagrams, sketches, tables, graphs, and other illustrations showing information relating to any of the above six design areas are considered to be Bechtel proprietary technical information. As appropriate, Bechtel has excluded any proprietary information from this Final Technical Report. 


\section{Section 2}

\section{PROJECT DESCRIPTION}

\subsection{PROJECT LOCATION}

The CZD-FGD system described in this report was located at Penelec's Seward power station. The plant is located in western Pennsylvania, approximately 12 miles northwest of Johnstown on the southern bank of the Conemaugh River in East Wheatfield Township, Indiana County.

The hydrated dolomitic lime for $\mathrm{SO}_{2}$ absorption was supplied by Rockwell Lime Company from Manitowoc, Wisconsin. The shipments were made by rail in lime cars to Pittsburgh and then in road trucks to the Seward power plant.

The freshly slaked calcitic lime was supplied from the Conemaugh power plant located approximately 3 miles away and operated and maintained by Penelec.

Disposal of the absorption waste, together with fly ash, was made in the landfill near Conemaugh power plant.

\subsection{PROJECT OBJECTIVES}

The goal of this project was to prove the technical and economic feasibility of CZD technology on a commercial scale. The process was expected to achieve $50 \%$ $\mathrm{SO}_{2}$ removal at lower capital and O\&M costs than other FGD systems.

The CZD process involves the injection of finely atomized sprays of lime slurry into the flue gas duct ahead of the ESP solids collector. An objective of the project was to evaluate different types of atomizers, the injection of different types of absorbents (dolomitic, calcitic, etc.) and a varying coal sulfur content (low- and medium-sulfur coals) to determine the effects on $\mathrm{SO}_{2}$ removal and on the capability of the ESP to control particulate emissions and opacity.

The demonstration was carried out at Penelec's Seward Station on the 147 MW Unit No. 5 in a modified duct between the first and second ESP. After the parametric test program, a long-term, continuous, fully automated and 
integrated test (with the regular power plant operation) was performed. The specific objectives of this project were to:

- Demonstrate the applicability of the CZD-FGD process for use in utility boiler flue gas operations which are derived from low- and high-sulfur coal combustion

- Evaluate/quantify the CZD-FGD process variable effects and determine the optimum operating requirements for long-term continuous testing

- Determine the operability and reliability of CZD-FGD during long-term testing and its impact on downstream operations - e.g., the ESP, particulate emissions, and opacity percentages

- Demonstrate reduction of utility boiler flue gas $\mathrm{SO}_{2}$ emissions by 40 to $50 \%$

- Verify that the CZD-FGD process has no detrimental impact on waste streams

- Determine the cost of CZD-FGD with the aim of achieving $\mathrm{SO}_{2}$ removal costs (capital and operating) in the range of $\$ 300 /$ ton or less

- Sufficiently document the CZD-FGD test effort to inform the public about the capability of the process and its applicability to the U.S. utility industry

For its low capital, operating, and maintenance costs, the CZD system depends on utilizing the existing power plant equipment for its operation. Consequently, the demonstration of the technical and economic feasibility of the CZD system included a demonstration of its compatibility with power plant operations. It was necessary that the system be capable of fully automatic operation, monitored and controlled from the power plant control room, and that it have no adverse effects on the performance of existing power plant equipment such as the electrostatic precipitator, and fly ash and lime handling systems.

\subsection{PROJECT PHASES}

To achieve its objectives the project was divided into three phases:

Phase 1: Design and permitting

Phase 2: Construction and startup

Phase 3: Operation and disposition 
- Phase 1 work was completed on January 31, 1991. During this phase, Bechtel developed a process design, P\&IDs, and performed detailed engineering for a new extended duct to be used in the CZD demonstration in Unit No. 5 at Penelec's Seward Station. Bechtel wrote all the specifications for equipment and instruments, and started procurement activities. Interface with the appropriate environmental agencies was accomplished through Penelec, with Bechtel providing assistance as needed.

- Phase 2 work was substantially completed by July 31,1991. This phase included equipment acquisition and installation, facility construction, and startup operations. Bechtel completed procurement of the equipment, instruments, materials, and fabrication of the new long duct. Penelec performed construction and installation of these items in accordance with specifications prepared by Bechtel. At completion of construction, using Penelec operating and maintenance personnel, Bechtel trained the operators, started all major elements of the CZD system, and verified that the installation and control system functioned according to requirements. During this phase, the installation of equipment and instrumentation was limited to that necessary for parametric testing to be accomplished in Phase 3.

- Phase 3 work was conducted in two parts: Phase 3a, consisting of parametric tests, and Phase $3 b$, consisting of continuous tests. Phase 3a, was scheduled for the period from June 3, 1991 through November 29, 1991, but the start was delayed until early August. During Phase 3a, Bechtel carried out a parametric test program to optimize the performance of the CZD process. The test program was designed to develop operating conditions that would achieve high reliability and low cost operation. The initial program included a period of time from December 2, 1991 to July 1992 when no CZD testing was scheduled. With DOE's concurrence, this "no CZD testing" was modified by extending the CZD parametric testing until July 1992 for de-bugging and training the Penelec operating and maintenance personnel.

Based on the results of the parametric tests, Bechtel completed additional design, procurement, installation and facility construction as necessary to permit a 1-year continuous demonstration. The CZD system was fully 
instrumented and integrated with the operation of Penelec's Unit No. 5. The goal was to demonstrate the performance of the CZD process for $\mathrm{SO}_{2}$ removal without significantly affecting either the boiler operation or plant particulate emissions. Phase 3b started in August 1992 and continued until July 1993.

The cooperative agreement with DOE was terminated in July 1993.

\subsection{TEST PROGRAM}

\subsubsection{Parametric Testing}

The goal of parametric testing was to debug the system and to optimize its performance in readiness for continuous operation.

The following operating parameters were investigated:

- Lime concentration versus $\mathrm{SO}_{2}$ removal

- Lime injection rates versus $\mathrm{SO}_{2}$ removal

- Lime utilization versus $\mathrm{SO}_{2}$ removal

- Lime injection rate versus flue gas outlet temperature

- Effect of lime injection on stack gas opacity

- Effect of the sulfur content of coal on $\mathrm{SO}_{2}$ removal

The test findings are summarized in Section 4.

\subsubsection{Continuous Testing}

The goal of continuous testing was to demonstrate over a one-year period the commercial feasibility of the CZD system by removing up to $50 \%$ of the $\mathrm{SO}_{2}$ from treated flue gas on a continuous basis without creating operating problems such as stack discharges with excessive opacity or unmanagable duct deposits.

During the continuous testing, the CZD system was automated and its operation completely integrated with Seward Station Unit No. 5 so that it could be operated from the power plant control room as a normal part of Unit No. 5. Bechtel 
supervised the continuous testing and carried out various performance tests, data acquisition and chemical analysis. 


\section{Section 3}

\section{CZD SYSTEM DESCRIPTION}

This section describes the CZD system installed at the Penelec Seward Station for the project. Additional details can be found in the Confined Zone Dispersion Public Design Report.

\subsection{PROCESS DESCRIPTION}

The CZD process involves the injection of a lime slurry into the flue gas ductwork located between a boiler's air heater(s) and particulate removal equipment. In the presence of water, $\mathrm{SO}_{2}$ from the flue gas is absorbed as sulfurous acid; which, when exposed to lime, reacts to produce calcium and/or magnesium sulfites and sulfates, which are subsequently removed by the downstream particulate removal equipment. Some removal of oxides of nitrogen $\left(\mathrm{NO}_{\mathbf{x}}\right)$ occurs because of the presence of the magnesium hydroxide in the dolomitic lime. This magnesium hydroxide reacts with sulfurous acid to produce magnesium sulfite, which favors the removal of $\mathrm{NO}_{\mathbf{x}}$. The precise chemical mechanism for $\mathrm{NO}_{x}$ removal is not well understood at this time.

In the CZD process, the wet reaction particles and unreacted lime must dry before contacting the duct turning vanes, particulate removal equipment, etc., or they will adhere to these surfaces and cause unwanted deposit buildups which could plug the duct and thus affect operations. To prevent this from occurring, the prepared lime slurry is injected close to the center of the flue gas duct, parallel to the flow of gas. The use of narrow-angle sprays and carefully positioned atomizers makes it possible to obtain a wet zone in the middle of the duct for $\mathrm{SO}_{2}$ removal while maintaining an envelope of hot gas between the wet zone and the duct wall. This is the principle of the confined zone, as shown in Figure 3-1. As the cone of spray moves downstream and expands, the gas within the cone cools and the reacted lime slurry on the outside of the cone mixes with the hot gas and dries rapidly. If the proper slurry concentration and injection rate are employed, drying is complete before the droplets contact the walls of the duct. Approximately 90 to 95 feet downstream of the injection point, the free moisture in the spray completely evaporates, and the dry particles contact the duct and the 


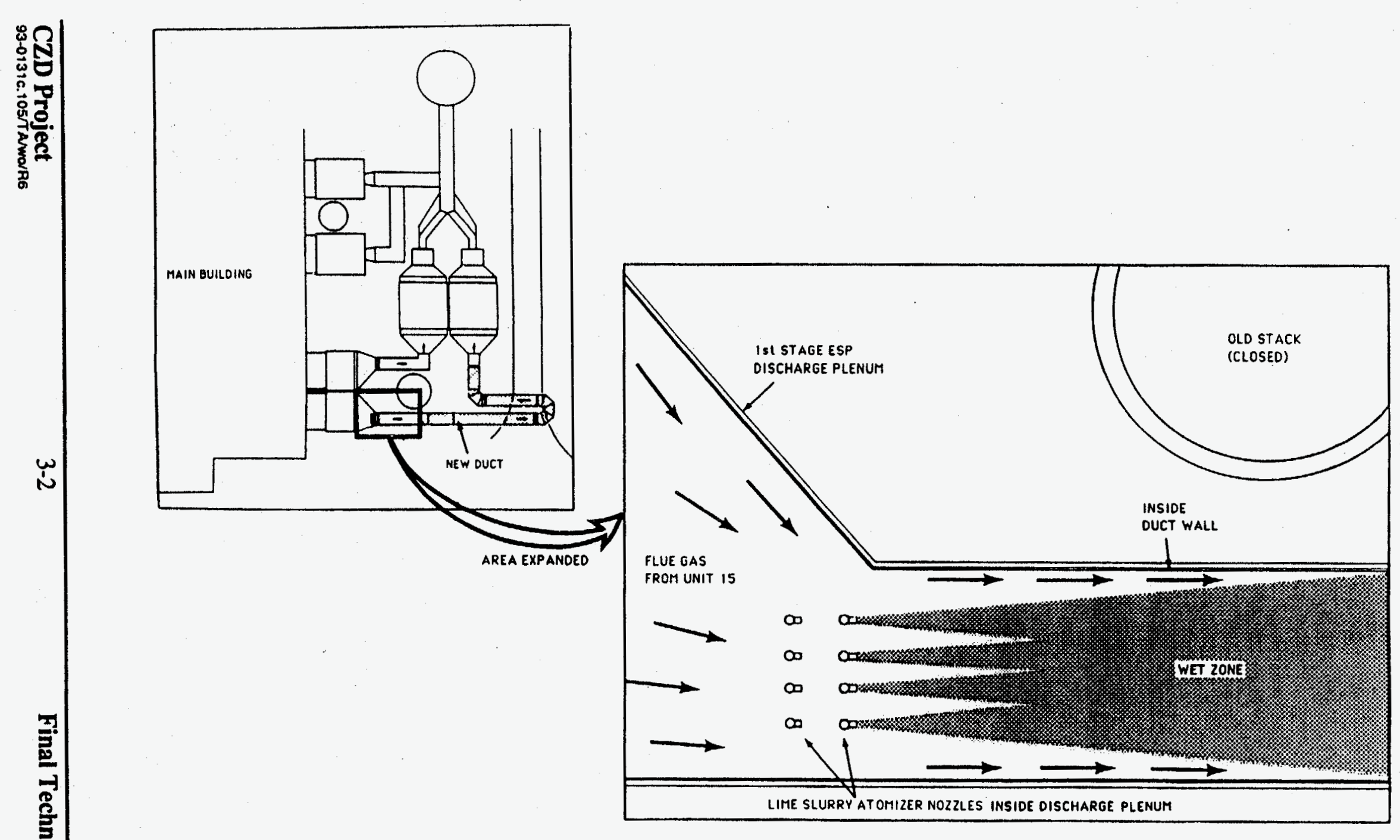

Figure 3-1 Confined Zone Dispersion Diagram 
turning vanes without adhering to them. The dry reaction particles and the unreacted lime are then removed by the ESP, along with the fly ash.

Sufficient residence time must also be provided to accomplish the $\mathrm{SO}_{2}$ reaction and to ensure that the droplets are completely dried. With only 40 to $50 \%$ total removal of $\mathrm{SO}_{2}$, a nominal 2-second residence time is sufficient. The injection of finely atomized sprays and the use of a reactive reagent combine to achieve this result. Longer residence times would be more favorable from a process standpoint, but would increase capital costs.

The CZD process was demonstrated on Seward Station's Unit 5. Unit 5 is a 147 MW utility unit, with two flue gas ducts, each serving a capacity equivalent to $73.5 \mathrm{MW}$. Each duct is connected to a chamber of the first-stage ESP and a chamber of the second-stage ESP. Both ESPs are located downstream of the air heaters. One of the two flue gas ducts leading from the unit was retrofitted with CZD equipment, as shown in Figure 3-2. The installation of the CZD equipment required that the B duct be replaced with a 211-foot-long duct, which includes a 120-foot-long straight section, to permit a lime slurry retention time of approximately 2 seconds and the addition of atomizers.

\subsection{PROCESS FLOW DIAGRAMS AND STREAM PROPERTIES}

Figure 3-3 contains a simplified process flow diagram of the CZD-FGD system installed at Seward Station. Figure 3-4 contains the stream property values and energy consumption for the process flow diagram for $50 \% \mathrm{SO}_{2}$ removal.

\subsection{PROCESS EQUIPMENT}

The process equipment represented by the process flow diagram of the CZD system shown in Figure 3-3 is divided into processing units called areas, as follows:

- Lime slurry preparation

- Lime slurry feed

- Lime slurry injection

- Flue gas desulfurization 


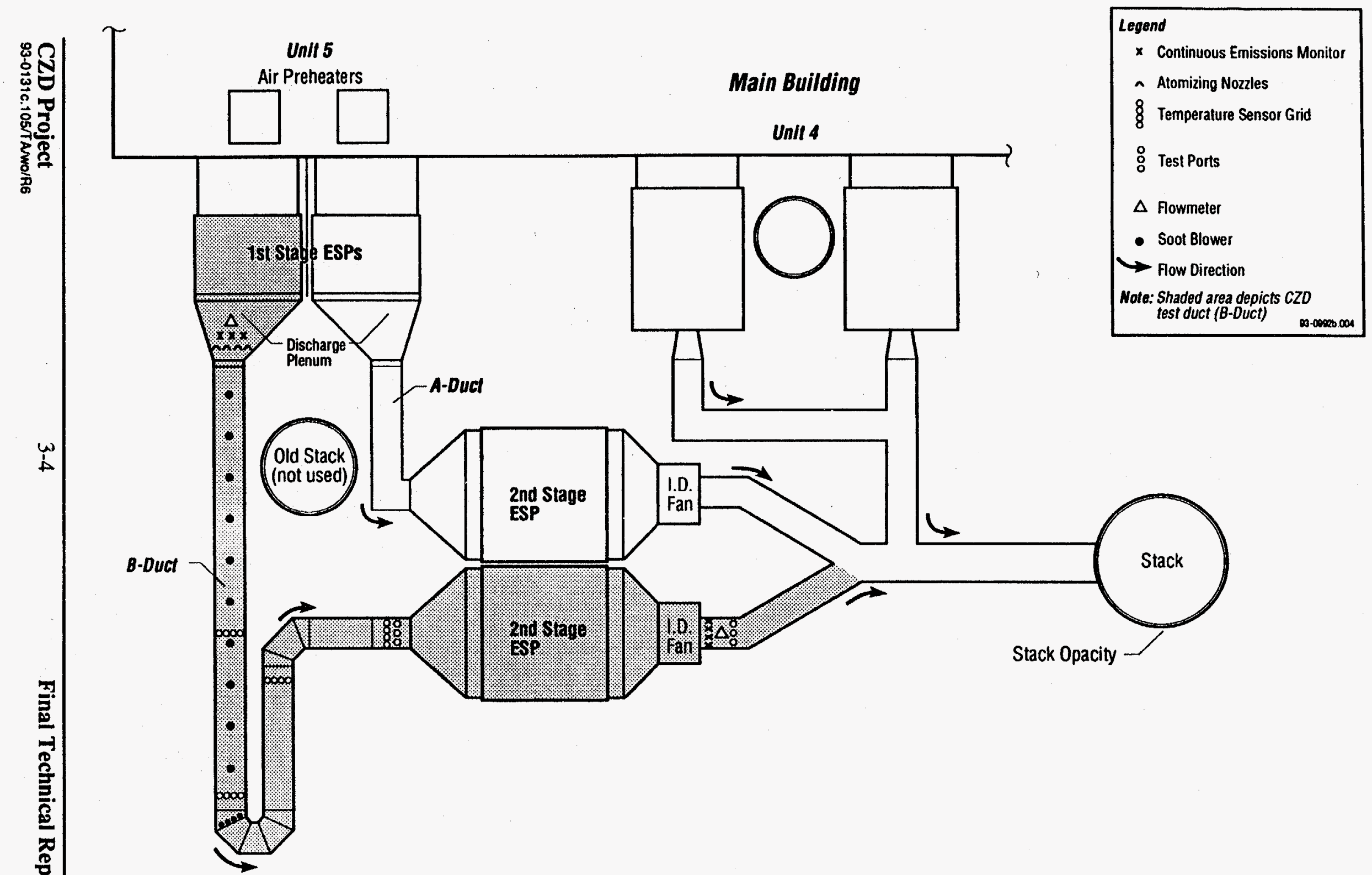

Figure 3-2 CZD Test Equipment Additions 


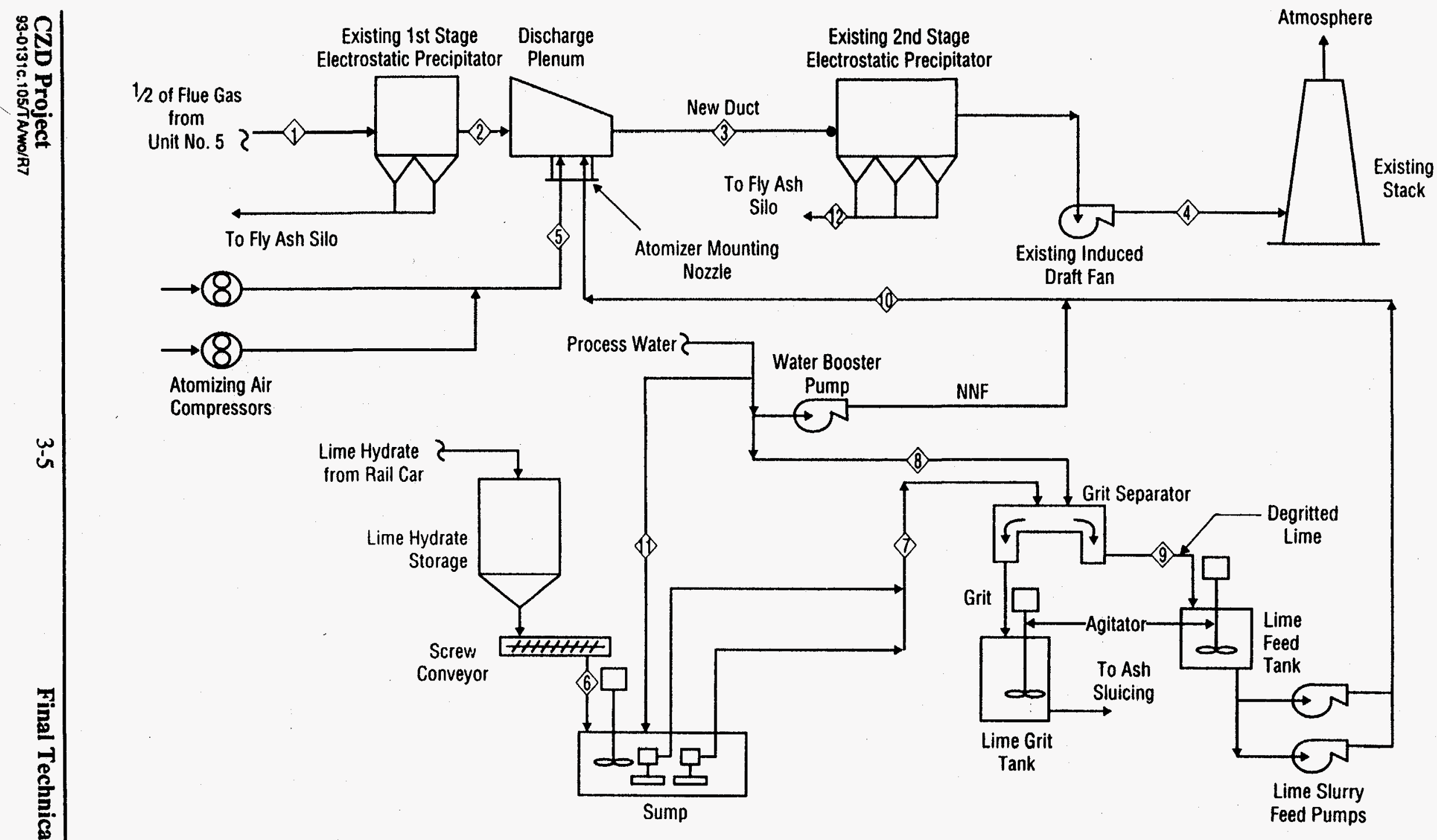

Note: NNF = Normally No Flow

Figure 3-3 Process Flow Diagram 


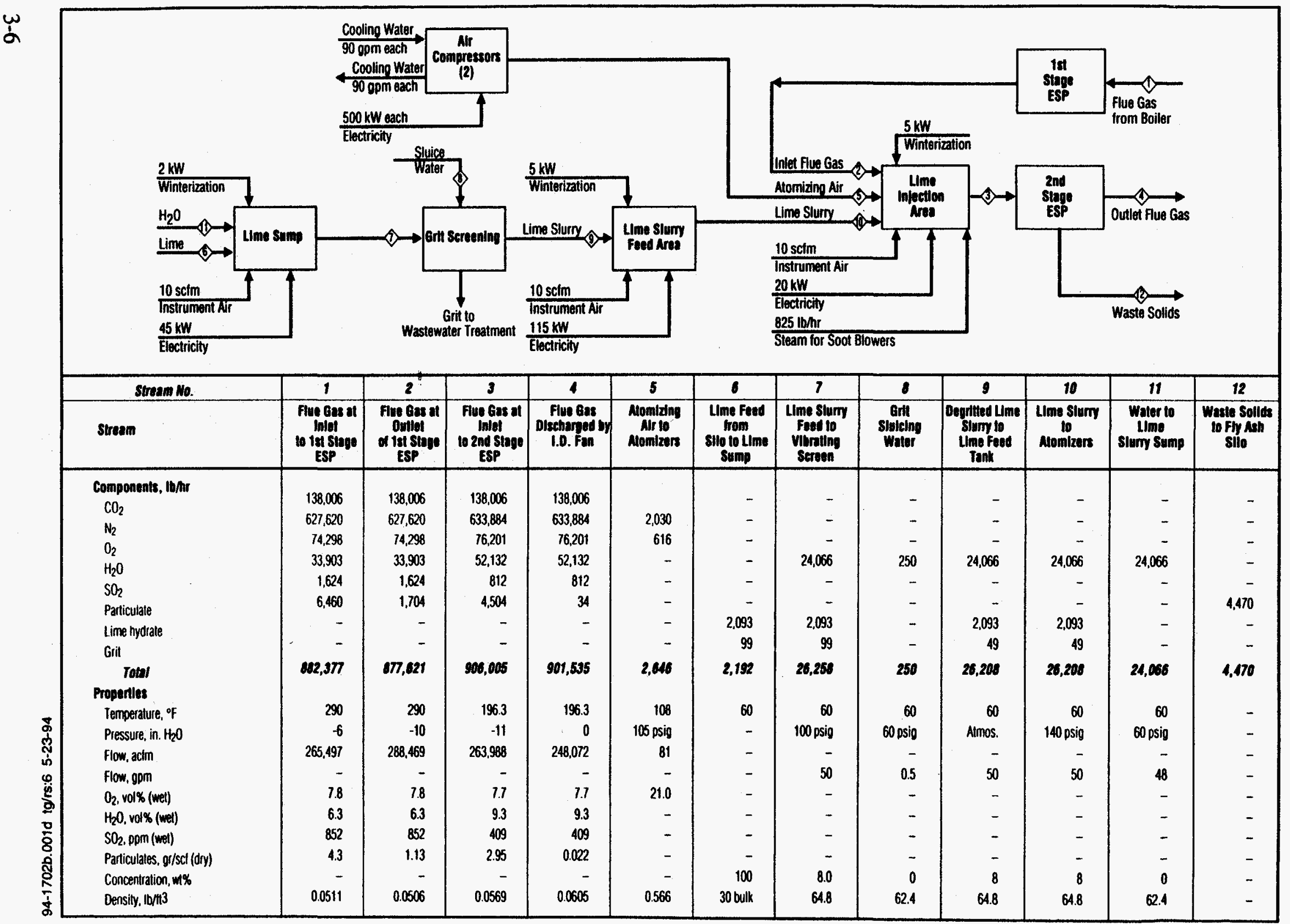

Figure 3-4 Material Balance and Energy Consumption 


\subsubsection{Lime Slurry Preparation}

This area, located in the water treatment building, is used for preparing lime slurry for transfer to the lime slurry feed area. It contains:

- A 50-ton lime silo for receiving and storing dry lime hydrate

- A vent baghouse filter on the top of the silo for preventing atmospheric emissions of hydrate

- An agitated lime hydrate slurrying sump

- Lime slurry sump pumps

- A variable-speed air lock for discharging the lime hydrate from the storage silo into the screw conveyor

- A screw conveyor feeding the hydrate into the sump

- Piping for transferring the lime slurry from the sump to the lime slurry feed area

- Control instrumentation for:

- Addition of water to the sump to maintain a constant slurry level in the sump

- Addition of lime hydrate to the sump to maintain a constant concentration/density of the sump slurry

The lime silo has about one day of gross storage capacity for hydrate, which is adequate for the operation of the CZD system with daily lime deliveries.

\subsubsection{Lime Slurry Feed}

The lime slurry feed area is located on the ground under the discharge plenum from the first-stage precipitator. It contains two agitated lime slurry feed tanks, two lime slurry feed pumps and the lime slurry feed loop main. Only one of the two lime slurry feed tanks is used during the continuous system operation; the second feed tank is used during parametric testing and is used as a spare during continuous operation. 
A vibrating screen, located on the second level, feeds the lime slurry feed tanks by gravity. The flow to the vibrating screen is controlled by the tank level controls, which modulate the flow control valve in the lime slurry transfer line.

Each lime feed tank is equipped with a level sensor. The controller is switched to the level sensor in the active lime tank. This sensor controls the transfer of the lime slurry from the lime slurrying sump to the vibrating screen from which the filtered slurry drains to the active feed tank. The tank is designed to operate full. It has $\mathbf{2}$ hours of storage capacity for emergency use in the event that normal operation of the lime slurrying system has to be interrupted for maintenance.

The feed loop piping contains the feed and return headers. The latter is fitted with a lime slurry back pressure controller to provide sufficient pressure in the lime slurry feed header that supplies the lime slurry to the atomizers.

The two lime feed pumps, one working and one spare, are single-stage, horizontal, high-head, high-speed centrifugal pumps. They are equipped with expellers for preventing lime slurry seal leakages.

\subsubsection{Lime Slurry Injection}

The lime slurry injection system is located on the top of the discharge plenum of the first-stage ESP at the inlet to the desulfurization duct. It contains atomizers, mounted on lances attached to plates, which are connected to the lime slurry and atomizing air supply headers.

The atomizers are connected to the atomizing air distribution header by individual feeders, each equipped with a flow indicator (glass rotameter), a pressure gauge, and an isolating valve. The atomizing air header is equipped with a pressure controller and with flow, pressure, and temperature indicators. The atomizers are also connected to the lime slurry distribution header by individual feeders, each equipped with a sealed pressure gauge and an isolating valve. The lime slurry supply header is equipped with a flow indicator and a pressure controller for controlling the lime slurry pressure in the distribution header. 
The water supply line is connected to the lime slurry supply header through a ready/standby valve and is fitted with a water flow controller. The flue gas handling system is cooled by injection of atomized water into the flue gas prior to lime slurry injection, and the atomizers are flushed whenever the lime slurry injection is interrupted.

The compressed air distribution header is supplied by the two oil-free screw-type air compressors located inside the power plant building. Each compressor has a capacity of $2000 \mathrm{cfm}$ and a discharge pressure of $125 \mathrm{psig}$; they discharge to a common air receiver with a 2-minute capacity. Each compressor uses about $90 \mathrm{gpm}$ of cooling water. One compressor is in operation; the other is on standby.

\subsubsection{Flue Gas Desulfurization}

A section of the original duct was removed and replaced with a 211-foot-long duct, which includes a 120-foot-long straight section. The purpose of this replacement is to increase the flue gas residence time in the duct. The new duct addition spans the access road with a truss-supporting structure.

Rotary soot blowers are provided in the bottom of the duct, spaced from the injection point to the turning vanes located at the first turn in the duct. There are 10 of these units. Retractable soot blowers are located on the turning vanes at the first corner in the duct. There are 4 of these units. The rotary soot blower reentrains any particulate matter that prematurely deposits on the floor of the duct. The retractable soot blowers remove deposits from the turning vanes and the thermocouples on these vanes. These thermocouples are used to control the injection flow rate of lime slurry into the duct.

The duct is equipped with various test ports for measuring gas flow, using Pitot tube traverses, and for measuring flue gas temperatures at various duct crosssections along the duct walls and along both sides of the duct central walkway. 


\subsection{PIPING AND INSTRUMENTATION DIAGRAM, INCLUDING OPERATING CONTROLS}

An overall piping and instrumentation diagram (P\&ID) of the CZD-FGD system is shown in Figure 3-5. For clarity, this overall diagram is subdivided, using dashed lines, into four sections entitled Lime Slurry Preparation, Lime Slurry Feed, Lime Injection, and Flue Gas Desulfurization, respectively. The instrumentation and controls for the CZD-FGD system installed at Seward Station parallel the plant operational divisions with respect to central control and monitoring. With the exception of the startup and shutdown of all pumps and the air compressors, the operation of the CZD-FGD system is controlled from the power plant control room.

\subsubsection{Lime Slurry Preparation}

The lime slurry preparation system is designed for fully automatic operation to be governed by the level controller in the lime feed tank.

One of the two sump pumps is designed to operate continuously, pumping the lime slurry to the water treatment plant and to the CZD lime feed system. A portion of the total lime pumped by the sump pump will be bypassed back to the sump through the back pressure controller. The slurry level in the lime feed tank will govern the demand for transfer of the lime slurry from the sump to the lime feed tank. The tank level controller will tend to maintain a nearly constant level in this tank by operating a lime flow control valve in the lime transfer line from the sump to the vibrating screen.

The lime sump is provided with a level controller, which is designed to maintain a constant level of slurry in the sump by controlling the sump's water inflow.

The lime sump pump feed line is equipped with a sump content density controller to maintain a constant concentration of lime slurry in the sump by controlling the discharge rate of lime hydrate from the silo (speed of rotation of the air lock discharge valve). A flow is maintained through the lime slurry density gauge, then the ready/standby valve bypass, back to the sump. 


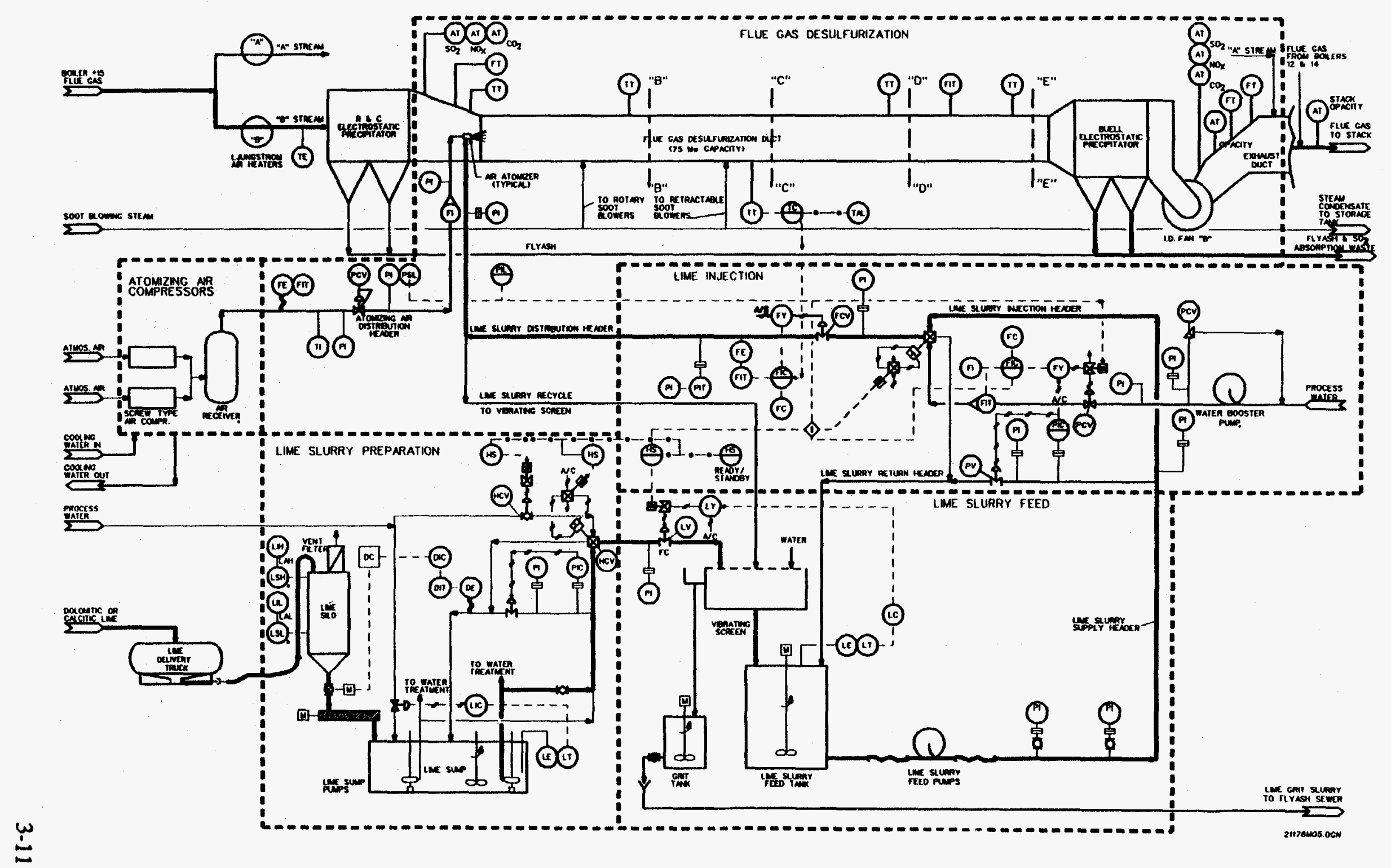

Figure 3-5 Simplified Overall P\&ID Diagram 
The silo has high- and low-level probes provided with low- and high-level alarms. The silo's rotary air lock discharge valve is equipped with a variable speed motor for controlling the discharge of the hydrate to the lime slurrying sump.

The lime hydrates will tend to arch in the silo's discharge hopper. This tendency can be successfully counteracted by aerating the hopper. The lime silo is equipped with air slides and an aeration air compressor for this purpose. The hopper is aerated constantly during lime withdrawal.

The lime hydrates also tend to cake in a screw conveyor exposed to humid air. To prevent or reduce lime caking in the screw conveyor, the unit is provided with an instrument air purge.

The lime sump level and lime slurry density will be controlled and information transmitted from this area to the control room regarding the sump level, lime density, status of the lime-high-level and lime-low-level alarms for the lime silo, lime pumps run status, agitator run status, lime silo blower run status, lock hopper run status, and lime feeder screw conveyor run status. The sump level, the lime density, and the position of the ready/standby valve may be adjusted/ controlled by the control room.

Duct instrumentation comprises skin thermocouples mounted below the nozzles, turning vane thermocouples mounted on the turning vanes, and two sets of 24 thermocouples mounted in the duct downstream of the first turning vanes to characterize the temperature profile in the duct. The signals from these thermocouples is sent to the weather enclosure for recording, display, and signal processing before being sent to the control room for integration into the operation database.

The individual atomizers are each equipped with direct-reading individual rotameters and pressure gauges to quantify the operation of each atomizer lance. Airflow, lime slurry flow and pressures, and water flow and pressures are transmitted to the control room duct. Inlet and outlet gas flows and temperatures are recorded in the weather enclosure and transmitted to the control room for inclusion in the operating database. 
Operation and position reporting of the ready/standby valve is accomplished either locally, or remotely from the control room.

\subsubsection{Lime Slurry Feed}

The lime slurry feed pumps supply lime from the feed tank to the lime slurry injection header. The slurry level in the tank is controlled by the tank level controller, which throttles the flow of the lime slurry from the lime slurry sump pump to the vibrating screen. The slurry flows from the screen to the feed tank by gravity.

The lime slurry feed pumps run status, vibrating screen run status, tank levels and agitator run status are recorded.

\subsubsection{Lime Slurry Injection}

Lime slurry is supplied to the injection lime header from the lime feed system via the loop main, which consists of the feed supply and the excess feed return headers. The operation of atomizers requires relatively high constant lime slurry injection pressure, which is maintained at a constant level at the inlet to the injection header by the back pressure controller in the lime slurry return header. The flow of lime slurry or water to the atomizers' distribution header is controlled by the flow controller, which is cascaded by a temperature controller in the duct downstream from the injection point.

The lime slurry injection header is connected to the lime slurry feed loop via a four-way valve, which also connects the lime injection header to the water supply piping from the water booster pump. The use of the four-way valve permits the lime injection header to be flushed with water whenever the lime injection is interrupted. The lime and water flow control valve is connected to the low-pressure switch on the atomizing air supply header so that the valve will shut in case of low atomizing air pressure.

This arrangement protects the flue gas-handling system from being flooded with unatomzied lime slurry or water. Such a flooding could require a boiler shutdown before it could be cleared. 
The power plant domestic water distribution system provides water for flushing the atomizers and their lime slurry supply piping and for injection of water into the flue gas stream. The domestic water system pressure varies, making it inadequate for high flow rate operation of the atomizers. Consequently, the CZD injection system is equipped with a water booster pump to maintain an adequate water supply pressure for the operation of atomizers during high-flow-rate water injection periods, when the water is used for cooling the flue gas treating system prior to the injection of lime, and for flushing the lime slurry piping and atomizers at the end of the lime injection period. The water booster pump must operate continuously to make water available for emergency use at all times.

The water booster pump has a pump bypass with a pressure controller for controlling the pump discharge pressure. A bleed line keeps the pump cool when it is operating without a net discharge of water.

\subsubsection{Flue Gas Desulfurization}

Figure 3-6 presents a plan view of the desulfurization duct, which has a 120-foot-long straight run for injection of the atomized lime slurry. The atomizing nozzles are located at the duct inlet. The duct is provided with four sets of thermocouples at four duct cross sections: B, C, D, and E. During normal operations, the B section thermocouples are used only briefly during injection testing.

Figure 3-7 illustrates the arrangement of thermocouples at one typical duct cross section. Single thermocouple probes can be inserted along the duct walls either 6 inches or 2 feet away from the duct walls. The near-wall thermocouples are used only for test purposes. The minimum temperature measured at Section C is used to control the lime slurry injection rate.

The flue gas flows and temperatures are measured at the inlet of the duct in the discharge plenum from the Research-Cottrell ( $R-C)$ precipitator, then at the $E$ section of the duct, and also at the outlet from the ID fan. $\mathrm{SO}_{2}, \mathrm{NO}_{\mathrm{x}}$, and $\mathrm{CO}_{2}$ concentrations and gas temperatures are measured at the discharge plenum from the R-C ESP and at the discharge from the ID fan. An opacity meter is installed in the discharge duct from the ID fan. 


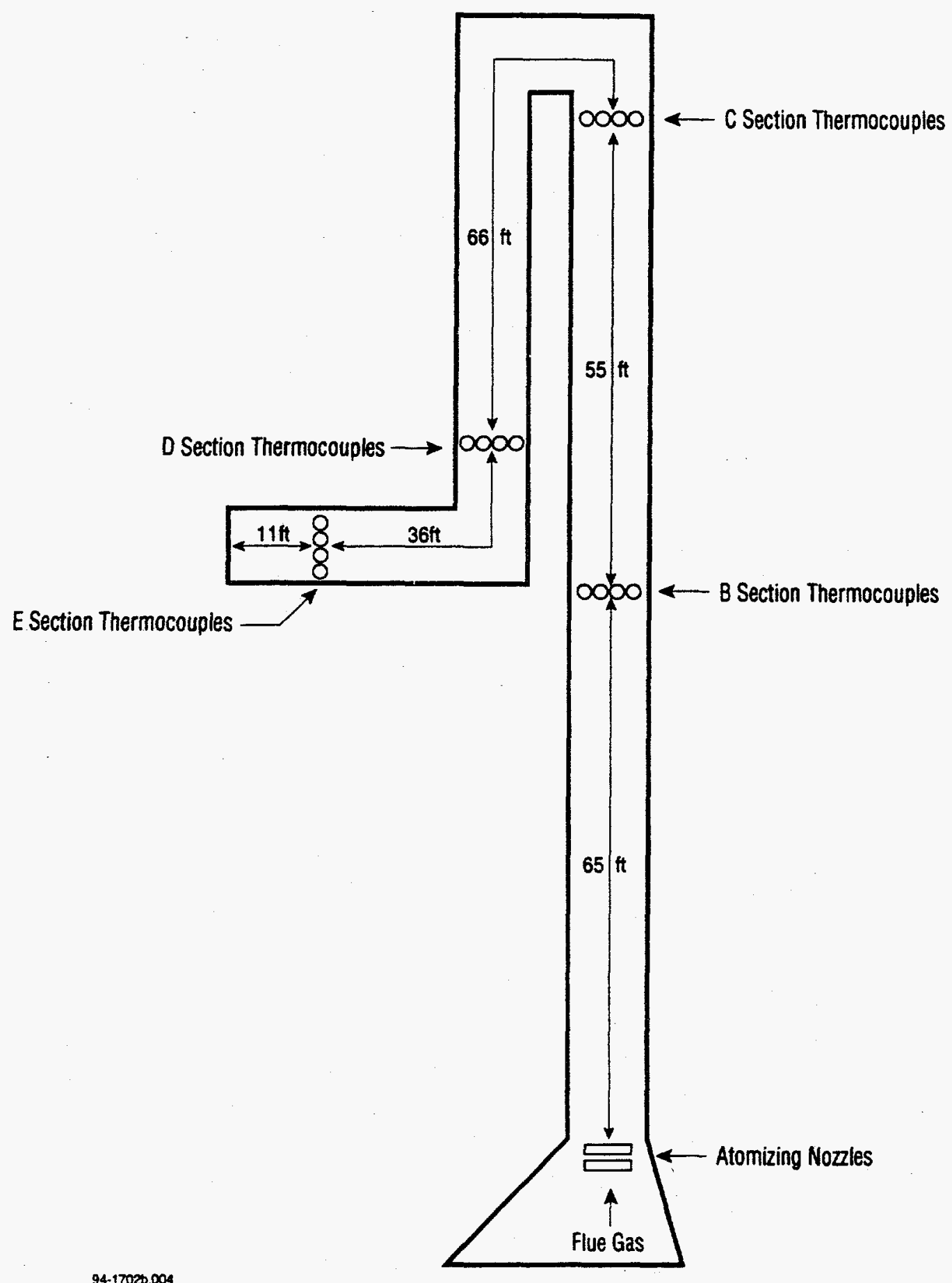

94-17020.004

Figure 3-6 Plan View of Duct with Thermocouple Locations 


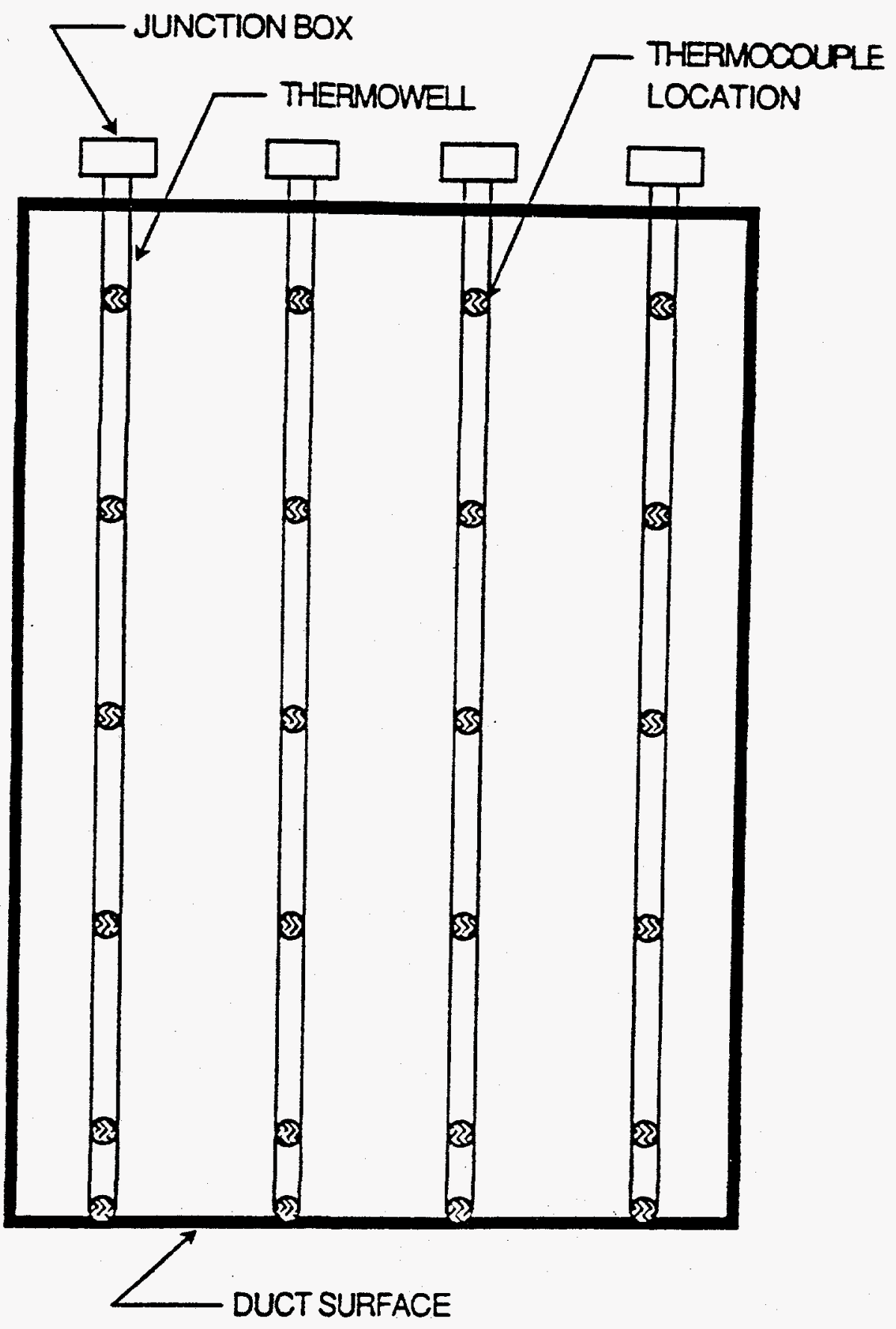

Figure 3-7 Typical Thermocouple Section

( 6 Thermocouples per Thermowell $=24$ per Section) 
Ten soot blowers are placed in the bottom of B duct to reentrain any particles of ash and/or reacted lime into the gas stream and allow them to be carried by the flue gas to the second ESP for removal. Four additional retractable soot blowers at the $C$ cross section clean the thermocouples on the turning vanes. The soot blower operation control is located in the main control room.

\subsection{SITE PLAN}

Figure 3-8 shows the site plan of Seward Station and the arrangement of the CZD system equipment in relation to the main power plant components. The new test duct $B$ is located between the two electrostatic precipitators referred to as the first stage ESP (Research-Cottrell ESP) and the second stage ESP (Buell ESP).

The lime slurry atomizers are upstream to the test duct. They are inserted in the flue gas discharge plenum from the first stage ESP. The lime slurry feed system is located on the ground below the first stage ESP discharge plenum.

The atomizing air compressors are inside the power plant building about 300 feet away from the test duct. The lime slurry preparation system is located close to the lime storage silo and the lime sump at the water treatment plant some 400 feet away from the test duct. 


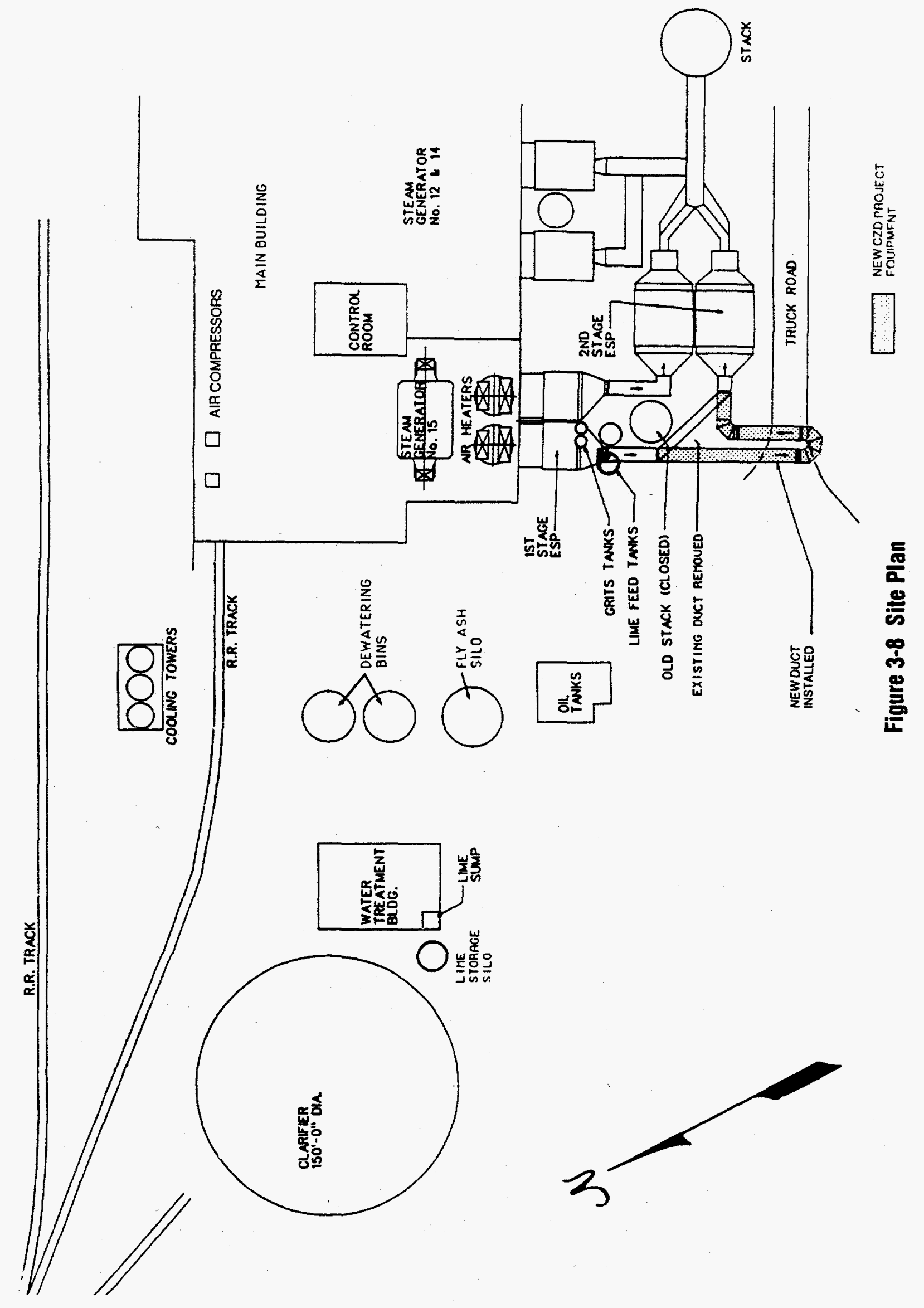




\section{Section 4}

ANALYSIS OF TEST PROGRAM RESULTS

This section provides an integrated discussion of all the results of the test program previously published in the Quarterly Reports. The Quarterly Reports should be referred to for additional details.

\subsection{OBJECTIVES}

The specific objectives of this project were to:

- Demonstrate the applicability of the CZD-FGD process for use in utility boiler flue gas operations which are derived from low- and high-sulfur coal combustion

- Evaluate/quantify the CZD-FGD process variable effects and determine the optimum operating requirements for long-term continuous testing

- Determine the operability and reliability of CZD-FGD during long-term testing and its impact on downstream operations - e.g., ESP and emissions (particulate, opacity, etc.)

- Demonstrate reduction of utility boiler flue gas $\mathrm{SO}_{2}$ emissions by 40 to $50 \%$

- Verify that the CZD-FGD process has no detrimental impact on waste streams

- Determine the cost of CZD-FGD, with the aim of achieving $\mathrm{SO}_{2}$ removal costs (capital and operating) in the range of $\$ 300 /$ ton or less

- Document this CZD-FGD test effort sufficiently to inform the public about the capability of the process and its applicability to the U.S. utility industry

\subsection{ATOMIZER TESTING}

\subsubsection{Selection and Calibration}

The atomizers selected for CZD testing were developed and calibrated at the University of California at Davis to determine their pressure/flow characteristics for very fine mist formation. It was determined that standard, off-the-shelf atomizers were not suitable. Standard nozzles were modified to provide the 
desired atomization characteristics. Then the atomizers, assembled in lances, were tested outside the duct to verify their pressure/flow characteristics at different water flow rates $(1-5 \mathrm{gpm})$ and the effect of the impact between the mists of adjacent atomizers.

Analysis of the atomizer test data showed:

- The arrangement of the atomizers in the first or second row, and the length of the lances (short, medium, or long) do not affect the flow rate of the atomized water if all other parameters remain the same

- By increasing the water pressure, the atomized water flow rate increases at the same compressed air pressure

- The higher the water pressure and the corresponding atomized water flow rate, the lower the compressed air consumption

- The particle size distribution of the atomized water - and, respectively, of the lime slurry - changes insignificantly at a liquid flow rate between 2 and $4 \mathrm{gpm}$

- The compressed air consumption for $2.5 \mathrm{gpm}$ atomized water (or lime slurry) is about $30 \mathrm{scfm}$ compressed air per gallon, equivalent to an air-towater ratio of about $0.275 \mathrm{lbair}$ per lbwater. For a 3 or $4 \mathrm{gpm}$ atomized water (or lime slurry), the air-to-water ratio is slightly less than $0.275 \mathrm{lb}$ air per lb water

\subsubsection{In-Duct Water Injection}

Water injection tests in the flue gas duct were performed to determine the atomizers' configuration to avoid wetting the duct and the turning vanes. The atomizers are attached to lances that are installed through nozzle ports on top of the ductwork. Each lance contains the compressed air and liquid feed pipes for the atomizers.

The dimensions of the plume resulting from injection are determined by thermocouple lances (with six thermocouples each) taking multipoint temperature traverses of the duct cross section at several locations downstream of the injection point. Figure 3-6 shows the position of the four cross sections of the thermocouple lances and their distances from the injection point. The cross 
section closest ( 65 feet) to the injection point is named Section B; the farthest (222 feet) is named Section E. In total, there are 96 thermocouples in the four cross sections that measure and record the flue gas temperature 65 feet, 120 feet, 186 feet, and 222 feet from the injection point. Figure 3-7 shows the typical thermocouple section with six thermocouples per thermowell, a total of 24 per section.

In addition to these thermocouples connected to the chart recorders, there are an additional 120 thermocouples incorporated in 20 portable lances. These can be distributed along both sides of the duct, with 10 lances (60 thermocouples) measuring the flue gas temperature 6 inches from the duct side walls, and 10 lances ( 60 thermocouples) installed 2 feet from the side walls. These portable lances are provided with hand readout instruments for flue gas temperature reading.

Another 20 thermocouples measure the temperature of the outside duct walls (bottom and sides). These temperatures are continuously recorded by the chart recorder. If by accident water or lime slurry drips to the bottom of the flue gas duct, these "skin" thermocouples will alarm at temperatures lower than $110^{\circ} \mathrm{F}$.

The thermocouple lances along the duct walls and those at the four duct cross sections at different distances from the injection point help determine the optimum position of the atomizer lances in the flue gas duct, and the maximum amount of atomized water that can be injected without cooling the duct walls. With so many thermocouples in the flue gas duct continuously showing the flue gas temperature in the duct with or without water injection, it is possible to determine the best orientation of atomizers for a maximum water rate without wetting the duct walls or the turning vanes.

The initial design of the nozzle lance assemblies was based on the results of previous testing at Seward Station. However, the atomizer nozzles selected for the current test program produce an extremely fine spray, finer than that produced by the nozzles used in the previous test program. As a result, the large allowances for gravity effects incorporated in the initial lance assembly design were not necessary. The nozzle assemblies did not extend deep enough into the duct. (Although the lances can be rotated to change the direction of spray, they cannot be raised or lowered.) 
In-duct water injection tests conducted early in the program with the initial lance design showed that the spray/gas mixing was not acceptable. Therefore, the arrangement of atomizers was redesigned and a new lance configuration was fabricated and used for all testing performed after March 1992.

Figures 4-1 and 4-2 contain typical temperature profiles of the flue gas stream without water injection at Sections B and C. The location of Sections B and C is shown in Figure 3-6. The flue gas temperature varies within the stream crosssection by up to $20^{\circ} \mathrm{F}$.

Figure 4-3 illustrates how the temperature profile of Section B changes when water is injected at a rate of $50 \mathrm{gpm}$. This test was conducted on May 5, 1992, with the new lance configuration. At $50 \mathrm{gpm}$, cross-section B contains wet spots inside the confined zone of the treated flue gas. However, they are separated from the duct wall by warmer, drier flue gas.

Figure 4-4 contains Section $C$ temperature profile during the water injection test. At $50 \mathrm{gpm}$, the lowest Section $C$ temperature is $150^{\circ} \mathrm{F}$ within the confined zone and is separated from the duct walls by warmer gas.

The $150^{\circ} \mathrm{F}$ temperature is considered high enough for the lime slurry to dry sufficiently to avoid sticking to the duct surfaces. Hence, the 120-foot length of the test duct between the atomizers and the Section $C$ turning vanes should be adequate to allow the evaporation of $50 \mathrm{gpm}$ of water from the injected lime slurry without the formation of deposits on the turning vanes.

Figures 4-5 and 4-6 contain diagrams illustrating how the average and minimum temperatures at Sections B, C, D, and E are affected by the water injection rates. At Sections $D$ and $E$, the average and low temperatures are almost the same, which means that the gas is well mixed. At Sections $B$ and $C$, the average and low temperatures are significantly different, indicating that the flue gas flow is stratified. The low Section B temperature becomes the same as the adiabatic saturation temperature at a water injection rate of $38 \mathrm{gpm}$, indicating that the first 65 feet of the duct length can evaporate up to $38 \mathrm{gpm}$ of injected water and that at least $45 \mathrm{gpm}$ of water can be evaporated upstream to Section C. 


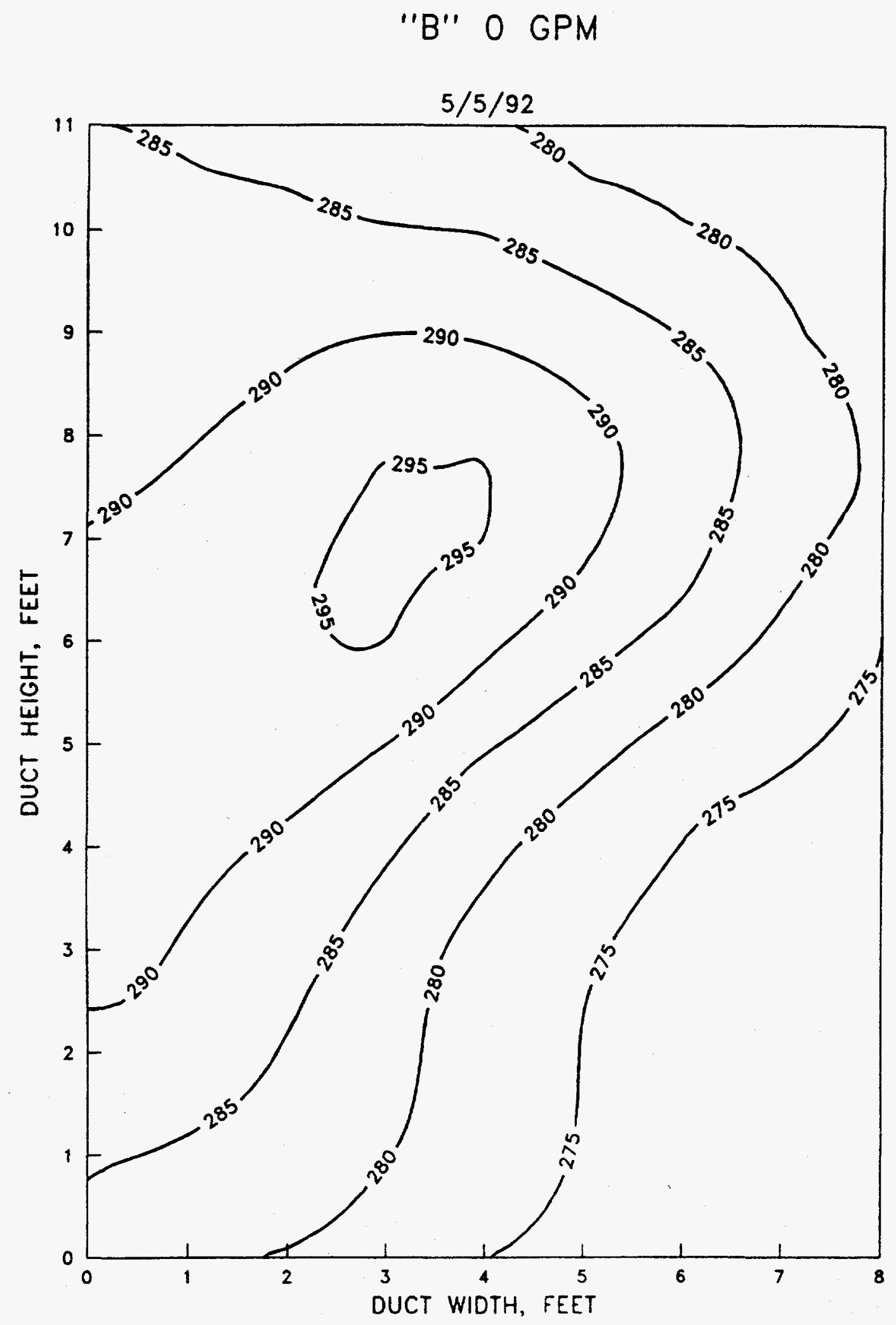

Figure 4-1 Temperature Profile Before Water Injection at the B Cross Section 


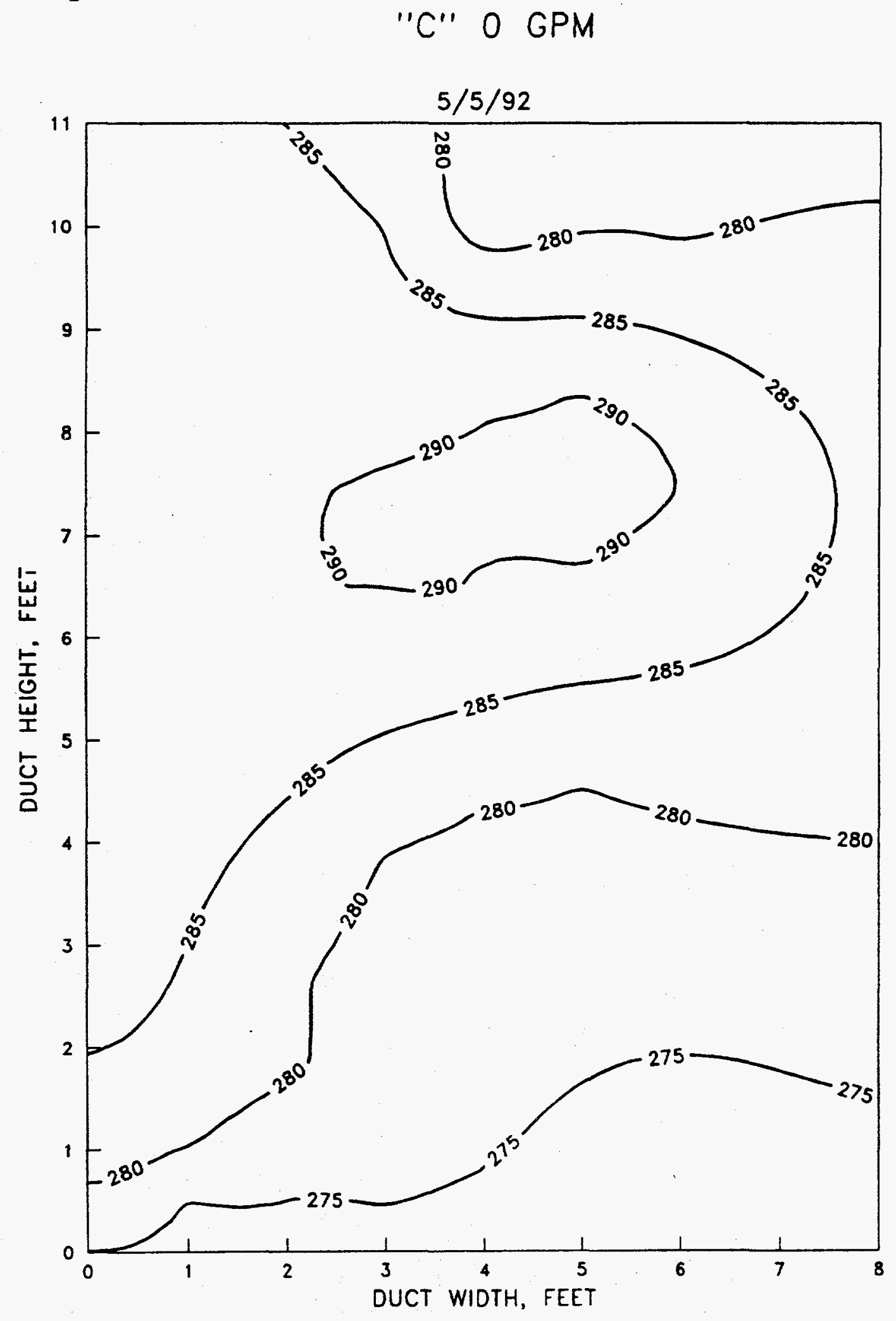

Figure 4-2 Temperature Profile Before Water Injection at the C Cross Section 


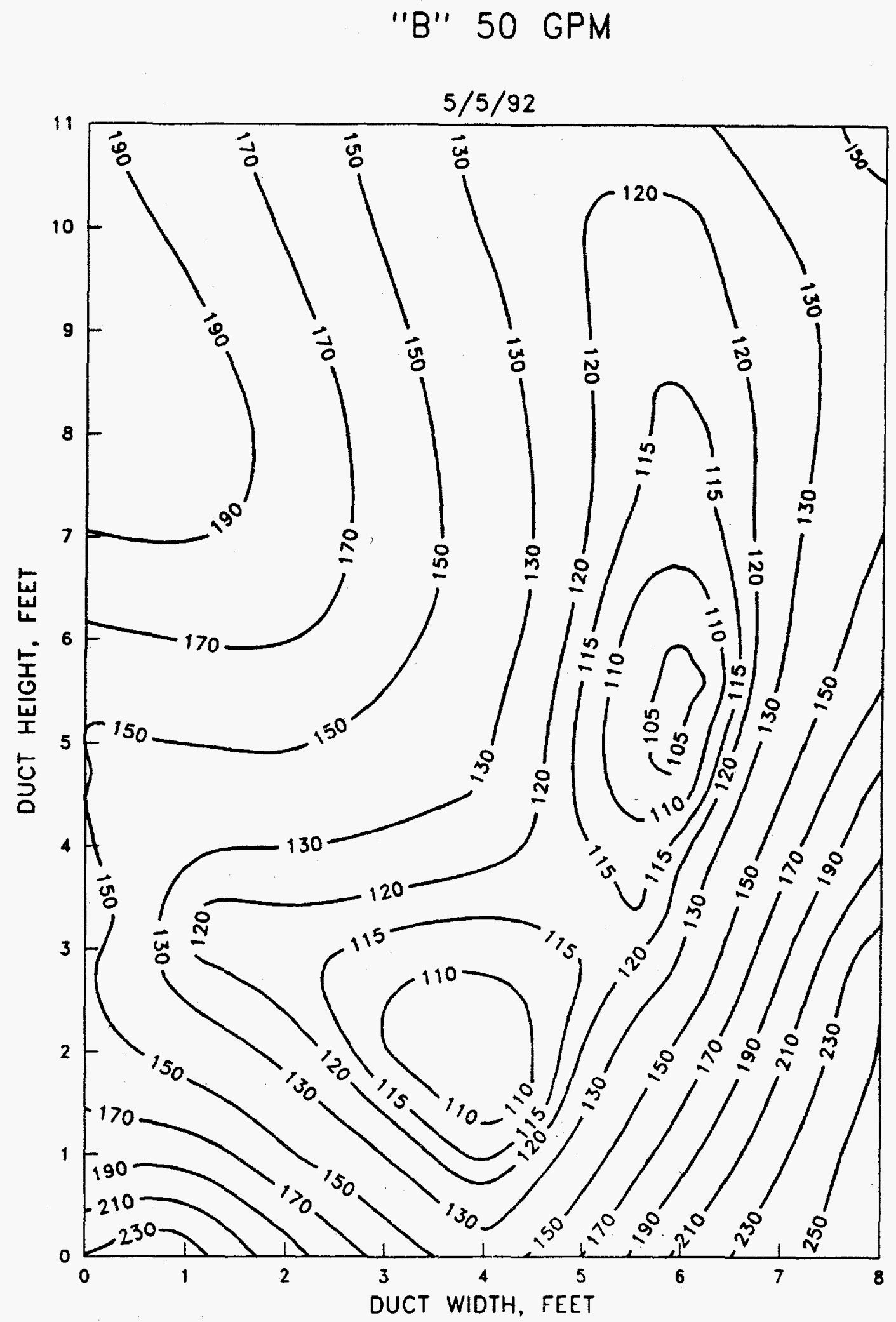

Figure 4-3 Temperature Profile with $50 \mathrm{gpm}$ Water Injection at the B Cross Section 
"C" 50 GPM

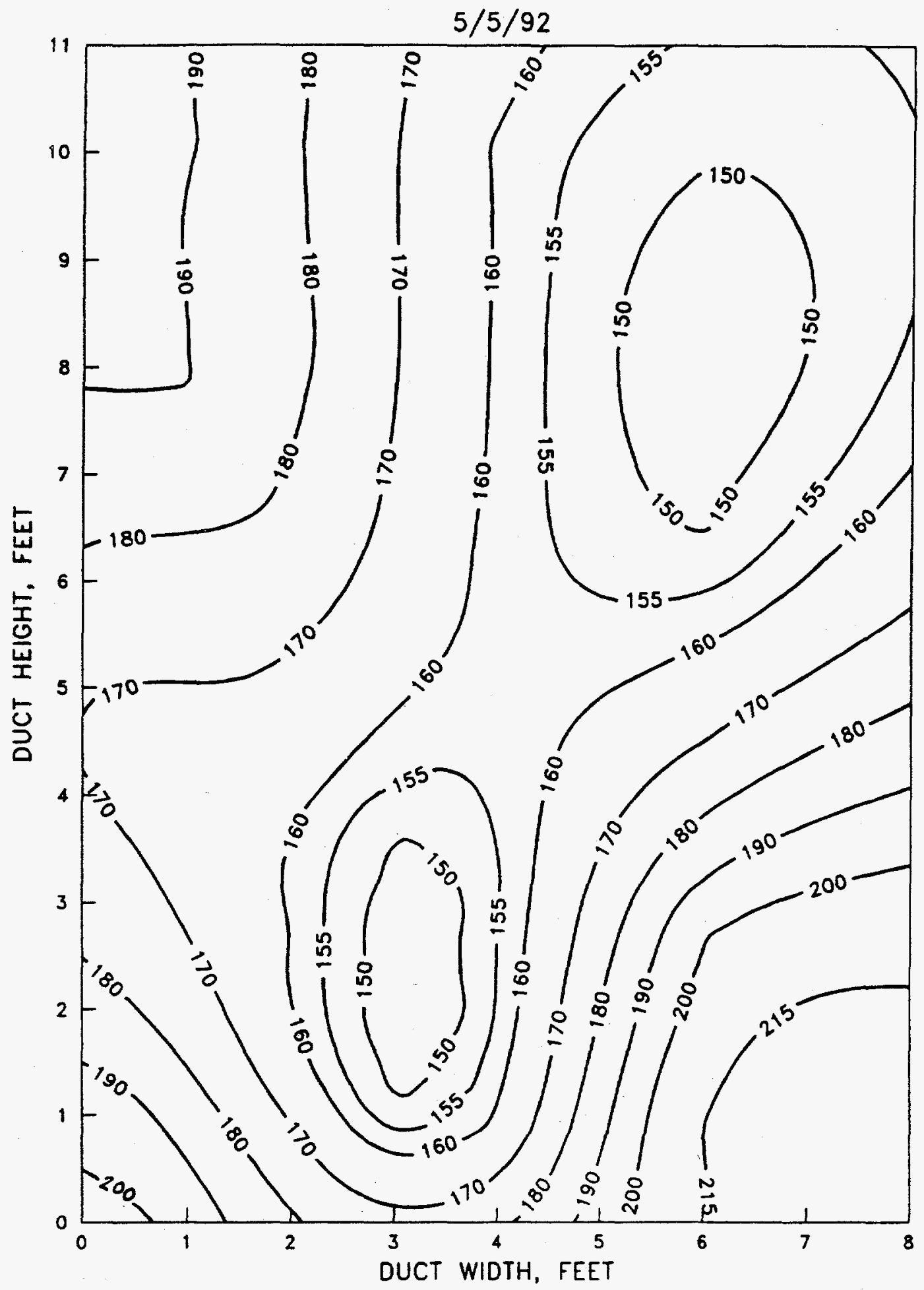

Figure 4-4 Temperature Profile with $50 \mathrm{gpm}$ Water Injection at the C Cross Section 

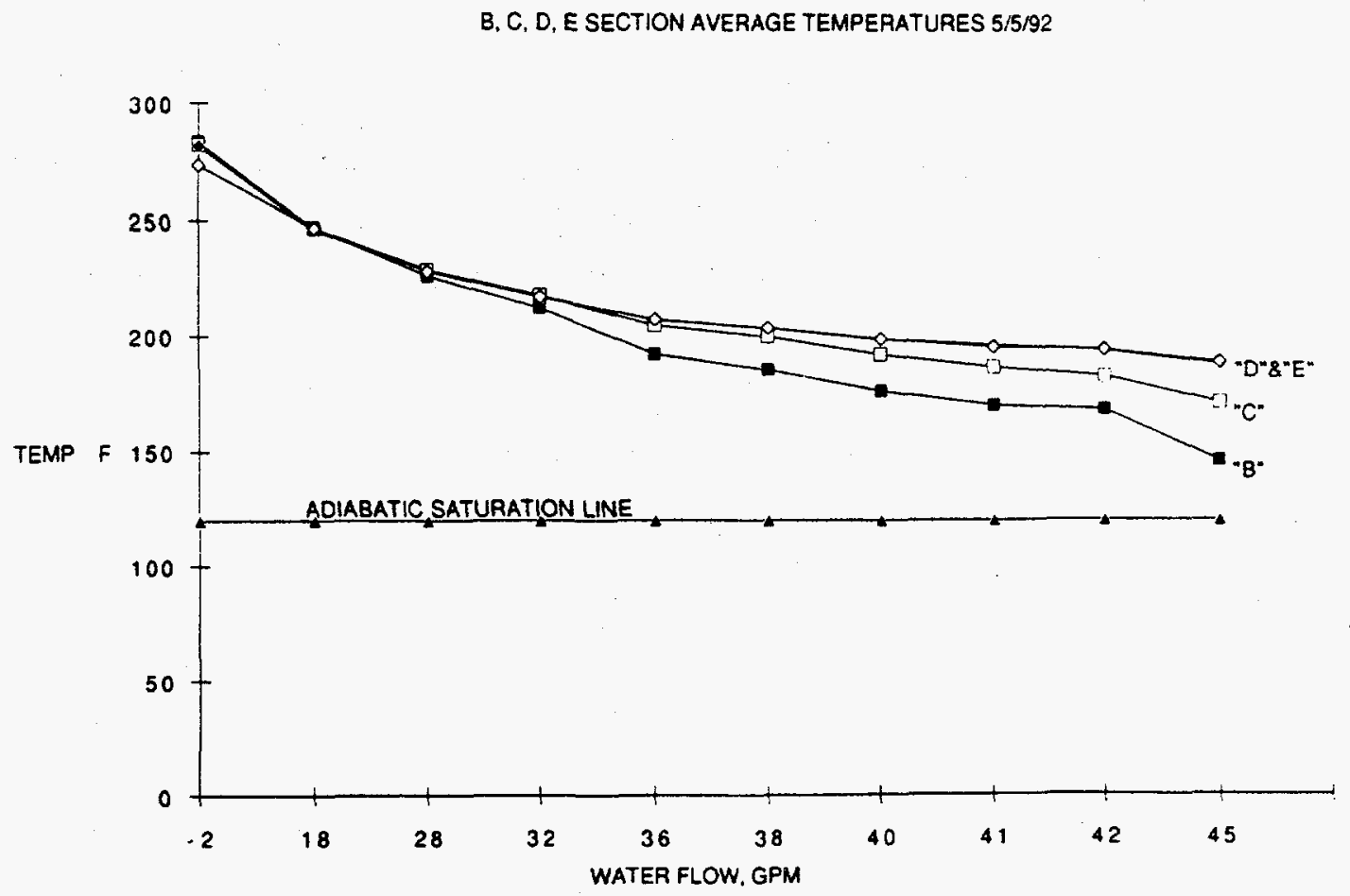

Figure 4-5 Average Temperatures During Water Injection of 18 to $45 \mathrm{gpm}$ at B, C, D, and E Cross Sections

B. C. D. E SECTION LOW TEMPERATURES 5/5/92

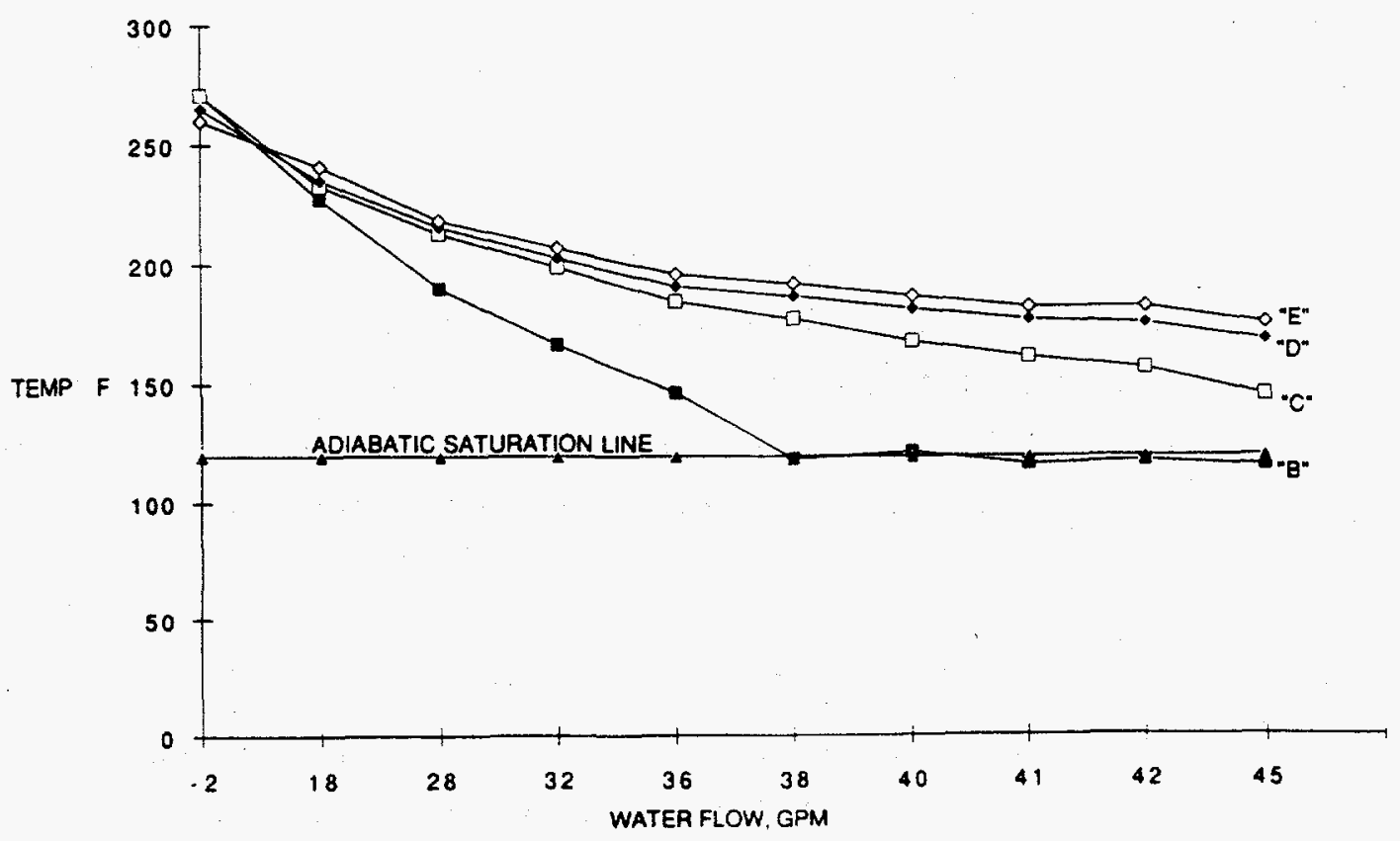

Figure 4-6 Low Temperatures During Water Injection of 18 to $45 \mathrm{gpm}$ at B, C, D, and E Cross Sections 


\section{3 $\mathrm{SO}_{2}$ REMOVAL TESTING}

Testing was conducted with three different types of lime: pressure hydrated dolomitic (PHDL), hydrated calcitic, and freshly slaked calcitic (prepared from quicklime). A summary of the typical chemical analysis for each type is included in Appendix A-1.

The parameter testing examined many of the variables that affect the CZD process. The following parameters could be controlled:

- Lime slurry concentration

- Lime slurry injection rate

- Lime type

- Lime feed ratio, the moles of lime fed divided by the moles $\mathrm{SO}_{2}$ entering the CZD system

- The flue gas temperature at $C$ section

The following parameters could not be controlled but were varied by the boiler operation:

- Inlet flue gas temperature

- Inlet flue gas flow rate

- Inlet $\mathrm{SO}_{2}$ concentration

The parametric tests normally lasted for several hours with conditions kept as constant as possible during that time. However, because the temperature and flow rate of the inlet gas and the concentration of $\mathrm{SO}_{2}$ were affected by the boiler operation and could not be controlled, test conditions often varied to some extent.

After the completion of the parametric tests, the CZD system was operated continuously to verify the operation on automatic control and to determine the long-term effects of lime injection on system performance. 


\subsubsection{Dolomitic Lime}

The major portion of the $\mathrm{SO}_{2}$ removal testing was performed using PHDL as the reagent. PHDL was chosen because it is:

- A commercially available product made from plentiful, naturally occurring dolomite

- A highly reactive lime due to its ultrafine particle size and high surface area

- Supplied in bulk as a dry powder that can be easily mixed with water to the desired slurry concentration

- Capable of forming more stable and less viscous slurries than normally hydrated limes

\subsubsection{Parametric Testing}

Extensive short-term parametric testing of the PHDL was conducted from November 1991 through February 1992. A 2-day, 24-hour-per-day test was conducted in February to collect stabilized performance data and to evaluate longer term effects. There is considerable variability (noise) in the data that could not be explained, and which hampered analysis. Some of the variability was caused by wet deposits that affected $\mathrm{SO}_{2}$ removal. The evaluation of the PHDL parametric testing data shows the following:

- The $\mathrm{SO}_{2}$ removal is directly proportional to the lime slurry feed rate.

- By maintaining the lime slurry feed rate to the flue gas duct constant, and increasing the lime slurry concentration, the percent of $\mathrm{SO}_{2}$ removed increases until it reaches a peak, after which any increase in lime slurry concentration does not increase the percent of $\mathrm{SO}_{2}$ removed.

- The maximum amount of lime slurry feed rate is a function of the following parameters:

- The geometry and size of the flue gas duct at Seward Station is 8 feet $x$ 11 feet.

- The straight length of the duct between the injection point and turning vanes at Seward Station is 120 feet. 
- Flue gas velocity in the duct, which determines the residence time for reaction and drying at Seward Station, is $50-60 \mathrm{ft} / \mathrm{sec}$, about 2 seconds residence time.

- The flue gas inlet temperature at Seward Station is about $300^{\circ} \mathrm{F}$.

- Fine atomization of the lime slurry at Seward Station has a Sauter mean diameter of the droplets of $60 \mu$.

A summary of the test results from November 1991 through February 1992 is presented in Table 4-1. Results are reported for the time period during which the test conditions were stable and are the average values for that period.

Figure 4-7 is a plot of $\mathrm{SO}_{2}$ removal versus the slurry injection rate using the data in Table 4-1 with a least squares straight line fit to the data. The graph shows that the percent of $\mathrm{SO}_{2}$ removed is directly proportional to the lime slurry feed rate. An inspection of the lime slurry feed concentration values shows that increasing feed concentration above a certain value does not improve $\mathrm{SO}_{2}$ removal. For instance, a $40 \mathrm{gpm}$ lime slurry feed rate of $7-8 \%$ lime concentration removed about $40 \%$ of the $\mathrm{SO}_{2}$ in the inlet flue gas; an increase in the lime slurry concentration to $10 \%$ and $11 \%$ did not obtain a higher percentage of $\mathrm{SO}_{2}$ removal at a constant lime slurry feed rate.

\subsubsection{Continuous Testing}

Continuous operation of the CZD system with PHDL injection was demonstrated for four months from August 17 to December 16, 1992. During August, the temperature of the flue gas to the CZD system was in the design range of 300 to $310^{\circ} \mathrm{F}$, which allowed adequate slurry injection to achieve $\mathrm{SO}_{2}$ removals approaching 50\%. After August, the inlet flue gas temperatures were lower than $300^{\circ} \mathrm{F}$, which limited $\mathrm{SO}_{2}$ removal, as described later.

Table 4-2 presents the daily average of the test results for the period August 17, 1992, through September 3, 1992, when the flue gas inlet temperature was above $295^{\circ} \mathrm{F}$. Figure $4-8$ is a plot of $\mathrm{SO}_{2}$ removal versus the slurry injection rate with a least squares straight line fit to the data. 
Table 4-1

Summary of the CZD Parametric Test Program Using Pressure Hydrated Dolomitic Lime

\begin{tabular}{|c|c|c|c|c|c|c|c|c|c|c|c|c|c|}
\hline \multirow{3}{*}{ 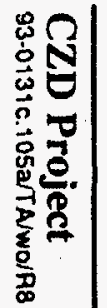 } & \multicolumn{13}{|c|}{ Using Pressure Hydrated Dolomitic Lime } \\
\hline & Date & $\begin{array}{c}\text { Test } \\
\text { Duration } \\
\text { (hours) }\end{array}$ & $\begin{array}{c}\text { Flue Gas } \\
\text { In } \\
\text { (kscfm) }\end{array}$ & $\begin{array}{c}\mathrm{SO}_{2} \\
\text { Conc. } \\
\text { In } \\
\text { (ppmv) }\end{array}$ & $\begin{array}{c}\mathrm{SO}_{2} \\
\text { Rate } \\
\text { In } \\
\text { (lb/hr) }\end{array}$ & $\begin{array}{c}\mathrm{SO}_{2} \\
\text { Removal } \\
(\%)\end{array}$ & $\begin{array}{c}\text { Lime } \\
\text { Slurry } \\
\text { Feed Rate } \\
\text { (gpm) }\end{array}$ & $\begin{array}{l}\text { Lime } \\
\text { Slurry } \\
\text { Conc. } \\
\text { (wt. \%) }\end{array}$ & $\begin{array}{c}\text { Llme } \\
\text { Feed } \\
\text { Rate } \\
\text { (lb/hr) }\end{array}$ & $\begin{array}{c}\text { Inlet Flue } \\
\text { Gas } \\
\text { Temp } \\
\text { ('F) }\end{array}$ & $\begin{array}{l}\text { Lime } \\
\text { Feed } \\
\text { Ratio }\end{array}$ & \begin{tabular}{|c|} 
Lime \\
Utilization \\
$(\%)$
\end{tabular} & $\begin{array}{c}\text { Average } \\
\text { C-Section } \\
\text { Temp } \\
\text { ('F) }\end{array}$ \\
\hline & $11 / 19 / 91$ & 1.9 & 194 & 945 & 1,856 & 41.0 & 50.0 & 12.5 & 3,401 & 301 & 1.52 & 27.0 & 173 \\
\hline \multirow{14}{*}{$\frac{t}{\omega}$} & $11 / 20 / 91$ & 2.5 & 195 & 955 & 1,881 & 35.2 & 48.0 & 9.9 & 2,573 & 301 & 1.14 & 31.0 & 180 \\
\hline & $12 / 11 / 91$ & 1.0 & 205 & 849 & 1,767 & 49.7 & 52.9 & 8.4 & 2,395 & 304 & 1.13 & 44.2 & 152 \\
\hline & $12 / 16 / 91$ & 2.0 & 192 & 884 & 1,719 & 42.3 & 36.5 & 8.4 & 1,652 & 256 & 0.80 & 53.0 & 165 \\
\hline & $12 / 18 / 91$ & 1.3 & 195 & 896 & 1,769 & 44.0 & 42.3 & 7.5 & 1,704 & 284 & 0.80 & 55.1 & 155 \\
\hline & $12 / 19 / 91$ & 2.3 & 195 & 896 & 1,773 & 36.4 & 37.5 & 8.0 & 1,614 & 291 & 0.76 & 48.1 & 169 \\
\hline & $12 / 20 / 91$ & 1.3 & 196 & 926 & 1,837 & 35.4 & 34.4 & 9.4 & 1,748 & 263 & 0.79 & 44.8 & 177 \\
\hline & $12 / 31 / 91$ & 2.2 & 200 & 953 & 1,932 & 41.6 & 45.5 & 10.9 & 2,691 & 299 & 1.16 & 36.0 & 152 \\
\hline & $01 / 06 / 92$ & 3.1 & 190 & 909 & 1,745 & 33.8 & 34.4 & 9.0 & 1,672 & 282 & 0.80 & 42.6 & 177 \\
\hline & $01 / 07 / 92$ & 3.8 & 197 & 951 & 1,898 & 33.8 & 39.5 & 7.0 & 1,481 & 287 & 0.65 & 52.2 & 158 \\
\hline & $01 / 08 / 92$ & 2.1 & 181 & 873 & 1,599 & 42.1 & 41.0 & 7.0 & 1,538 & 296 & 0.80 & 52.8 & 159 \\
\hline & $01 / 09 / 92$ & 1.8 & 192 & 823 & 1,601 & 42.6 & 44.7 & 9.7 & 2,346 & 297 & 1.22 & 35.0 & 165 \\
\hline & $01 / 10 / 92$ & 1.1 & 187 & 842 & 1,597 & 44.0 & 44.1 & 10.2 & 2,437 & 292 & 1.27 & 34.8 & 160 \\
\hline & $01 / 13 / 92$ & 2.2 & 194 & 907 & 1,785 & 38.3 & 42.3 & 8.4 & 1,915 & 288 & 0.89 & 43.0 & 162 \\
\hline & $01 / 14 / 92$ & 4.0 & 193 & 938 & 1,833 & 39.2 & 42.2 & 8.0 & 1,817 & 283 & 0.82 & 47.6 & 157 \\
\hline \multirow{7}{*}{ 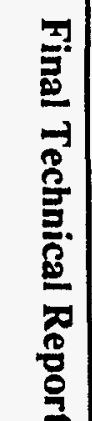 } & $01 / 30 / 92$ & 2.0 & 199 & 970 & 1,957 & 28.8 & 38.4 & 8.2 & 1,696 & 264 & 0.72 & 40.1 & 166 \\
\hline & $02 / 03 / 92$ & 2.0 & 193 & 844 & 1,652 & 15.0 & 27.6 & 8.0 & 1,188 & 250 & 0.60 & 25.1 & 178 \\
\hline & $02 / 05 / 92$ & 2.0 & 196 & 811 & 1,614 & 17.4 & 32.1 & 8.3 & 1,435 & 251 & 0.74 & 23.6 & 168 \\
\hline & $02 / 06 / 92$ & 2.0 & 196 & 845 & 1,673 & 20.7 & 34.9 & 10.2 & 1,929 & 260 & 0.96 & 21.6 & 169 \\
\hline & $02 / 07 / 92$ & 2.0 & 195 & 844 & 1,669 & 27.6 & 36.5 & 11.8 & 2,341 & 256 & 1.16 & 23.7 & 165 \\
\hline & $02 / 11 / 92$ & 24.0 & 202 & 950 & 1,939 & 25.0 & 34.0 & 11.0 & 2,030 & 250 & 0.87 & 28.8 & 165 \\
\hline & $02 / 12 / 92$ & 24.0 & 208 & 920 & 1,939 & 28.4 & 35.0 & 10.0 & 1,895 & 250 & 0.81 & 35.0 & 162 \\
\hline
\end{tabular}




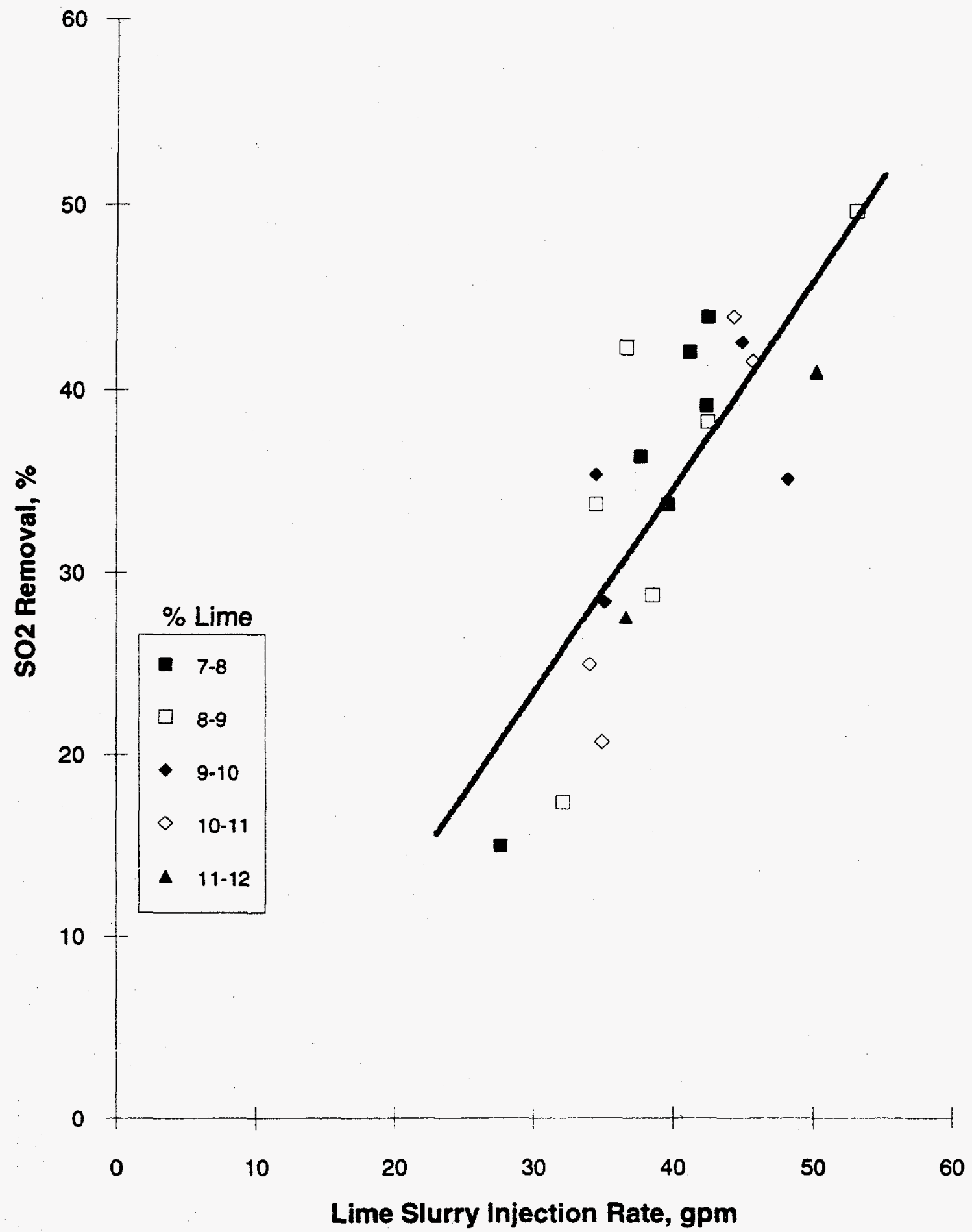

Figure 4-7 $\mathrm{SO}_{2}$ Removal versus PHDL Lime Slurry Injection Rate Based on

Parametric Test Data Taken from November 1991 Through February 1992 


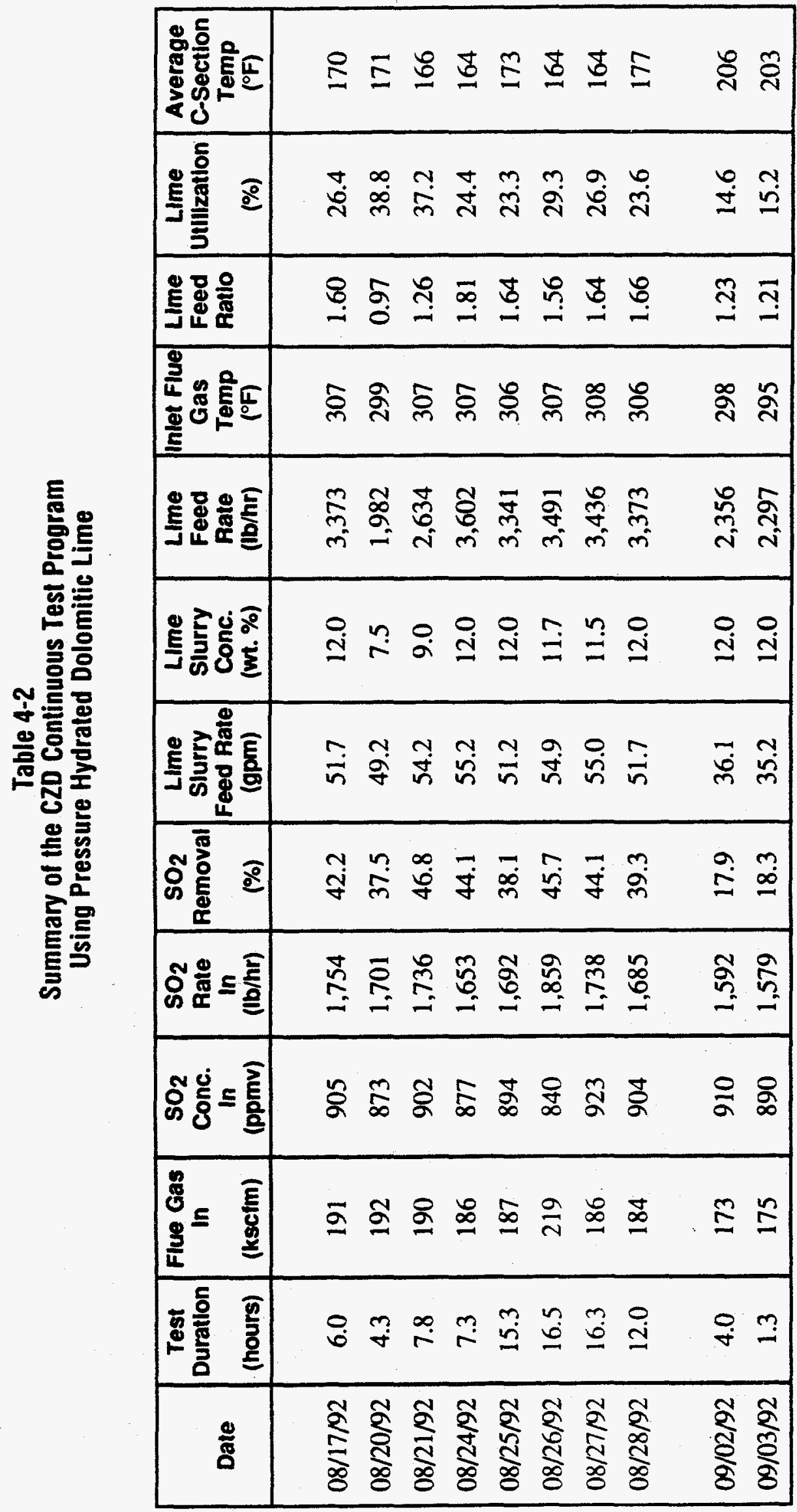




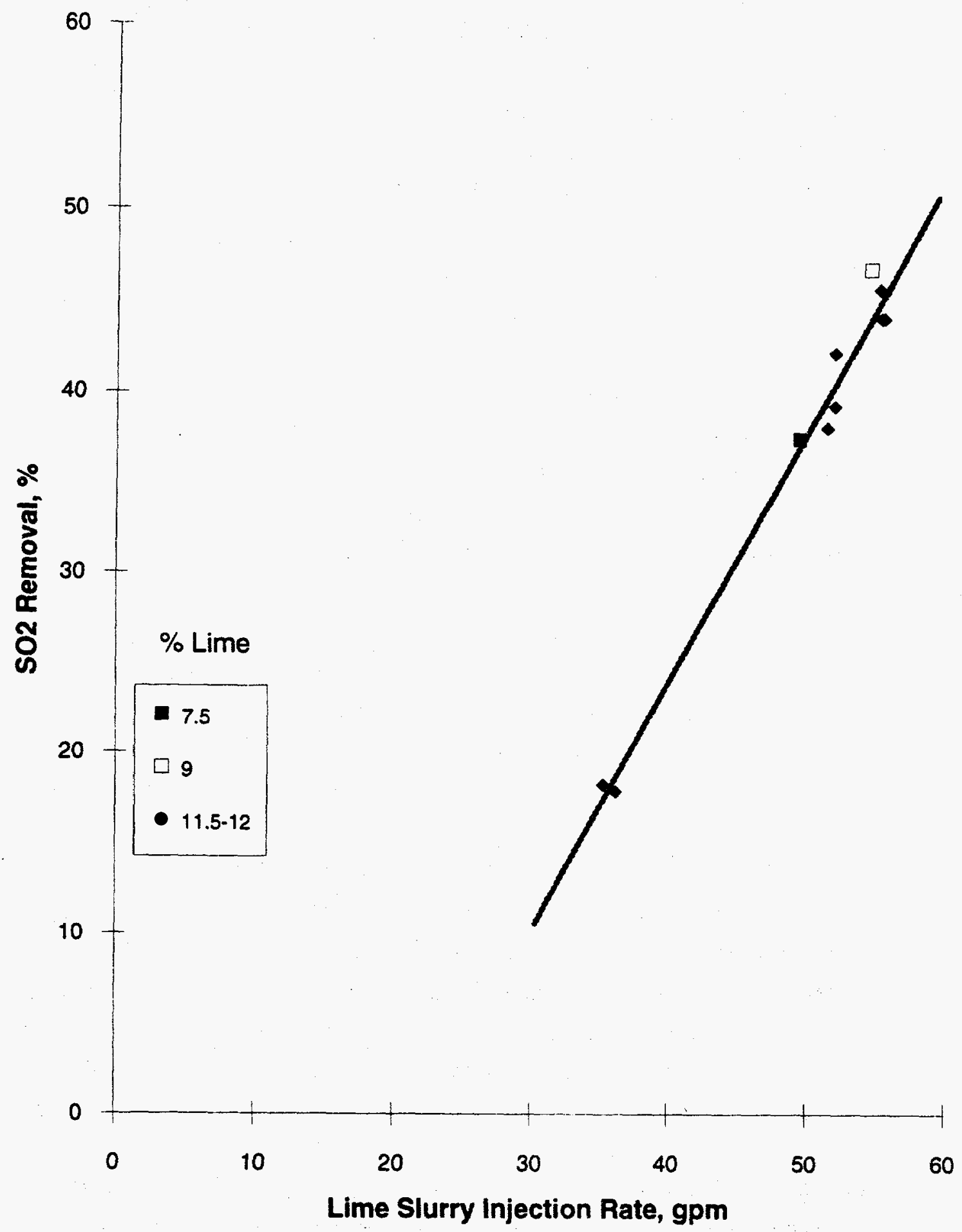

Figure 4-8 $\mathrm{SO}_{2}$ Removal versus PHDL Lime Slurry Injection Rate Based on Continuous Test Data Taken Between August 17, 1992 and September 3, 1992 
Figure 4-9 shows a comparison of the least squares fit for PHDL parametric and continuous testing. The continuous test results have shifted to the right, apparently indicating that a higher injection rate is required to achieve a given percentage of $\mathrm{SO}_{2}$ removal. While the total explanation for this shift is unknown, at least part of the reason is that the average $C$ section temperature was increased for the continuous tests to minimize buildup. This raised the approach to saturation temperature and reduced $\mathrm{SO}_{2}$ removal performance.

During CZD operation after August, the inlet flue gas temperatures were lower than $300^{\circ} \mathrm{F}$, which limited both injection rates and $\mathrm{SO}_{2}$ removal. In addition, deterioration of the radial and circumferential seals around the boiler's preheater allowed air to leak into the flue gas, resulting in temperature stratifications. These stratifications further limited the slurry injection capability because the injection rate is controlled by the lowest temperature in the duct vertical cross section. This low temperature area is reached at a lower slurry injection rate in flue gas with a stratified temperature distribution than in one with a uniform temperature distribution.

Figure 4-10 shows the relationship between the duct inlet flue gas temperature and the lime slurry injection rate, which directly affects $\mathrm{SO}_{2}$ removal. The graph shows how the lowering of the inlet flue gas temperature required the lime slurry injection rates to be decreased from over $50 \mathrm{gpm}$ to less than $30 \mathrm{gpm}$.

Figure 4-11 shows $\mathrm{SO}_{2}$ reduction, lime slurry injection rate, and lime slurry concentration for the four months of continuous CZD operation from August 17 to December 16, 1992. During this period there were times of no injection when the boiler was down and times when water was injected. However, the graph shows only those times when lime was being injected into the duct. Lime injection during September lasted only a few days, hence September does not show on the time axis.

Figure 4-12 is a cross plot showing $\mathrm{SO}_{2}$ removal versus lime slurry concentration for this period. This graph shows that increasing the lime slurry concentration to $25 \%$ does not increase the percentage of $\mathrm{SO}_{2}$ removal above that achieved with about $7-8 \%$ concentration. 


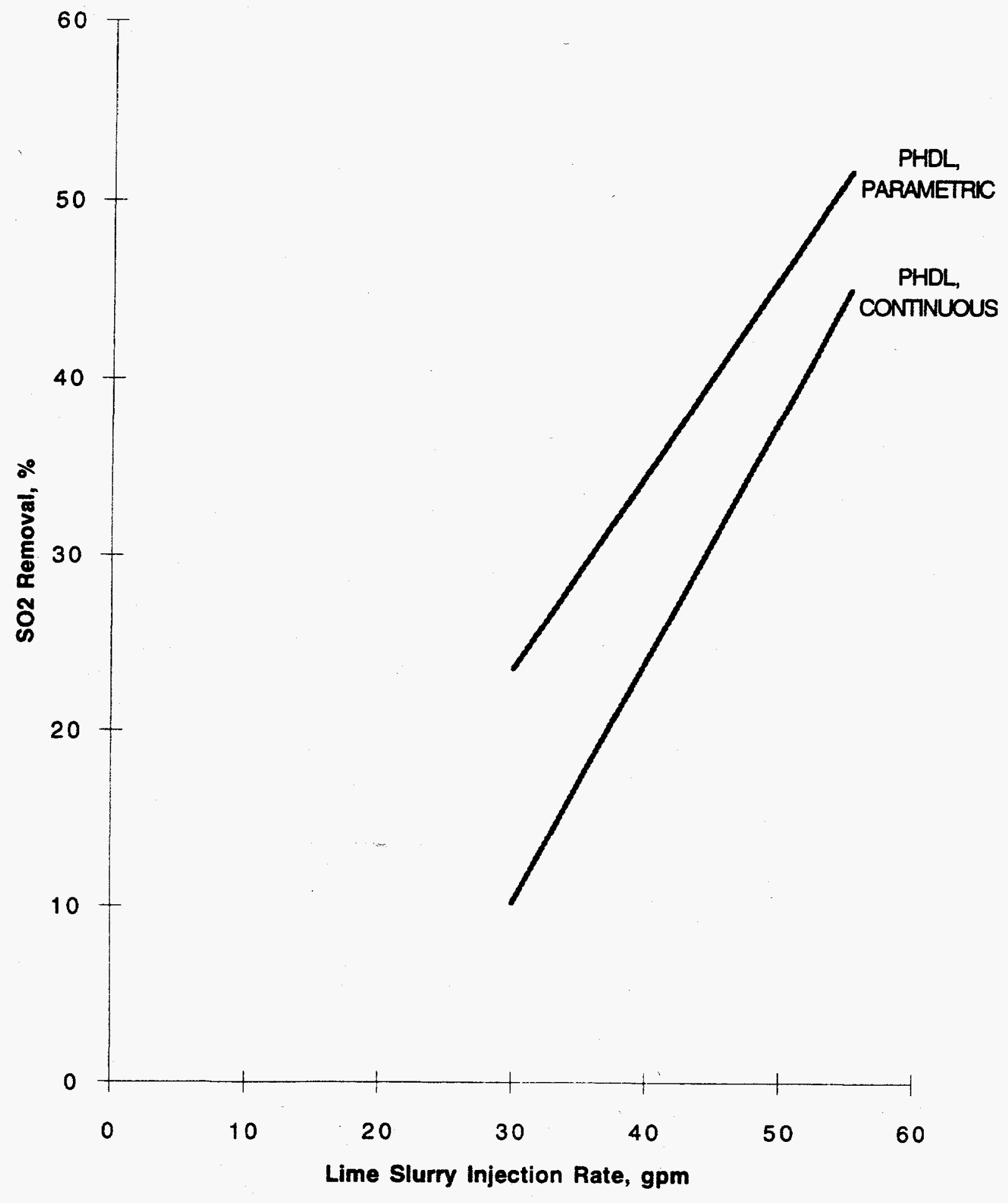

Figure 4-9 $\mathrm{SO}_{2}$ Removal versus PHDL Lime Slurry Injection Rate for Parametric and Continuous Test Data 


\section{Lime Flow, GPM}

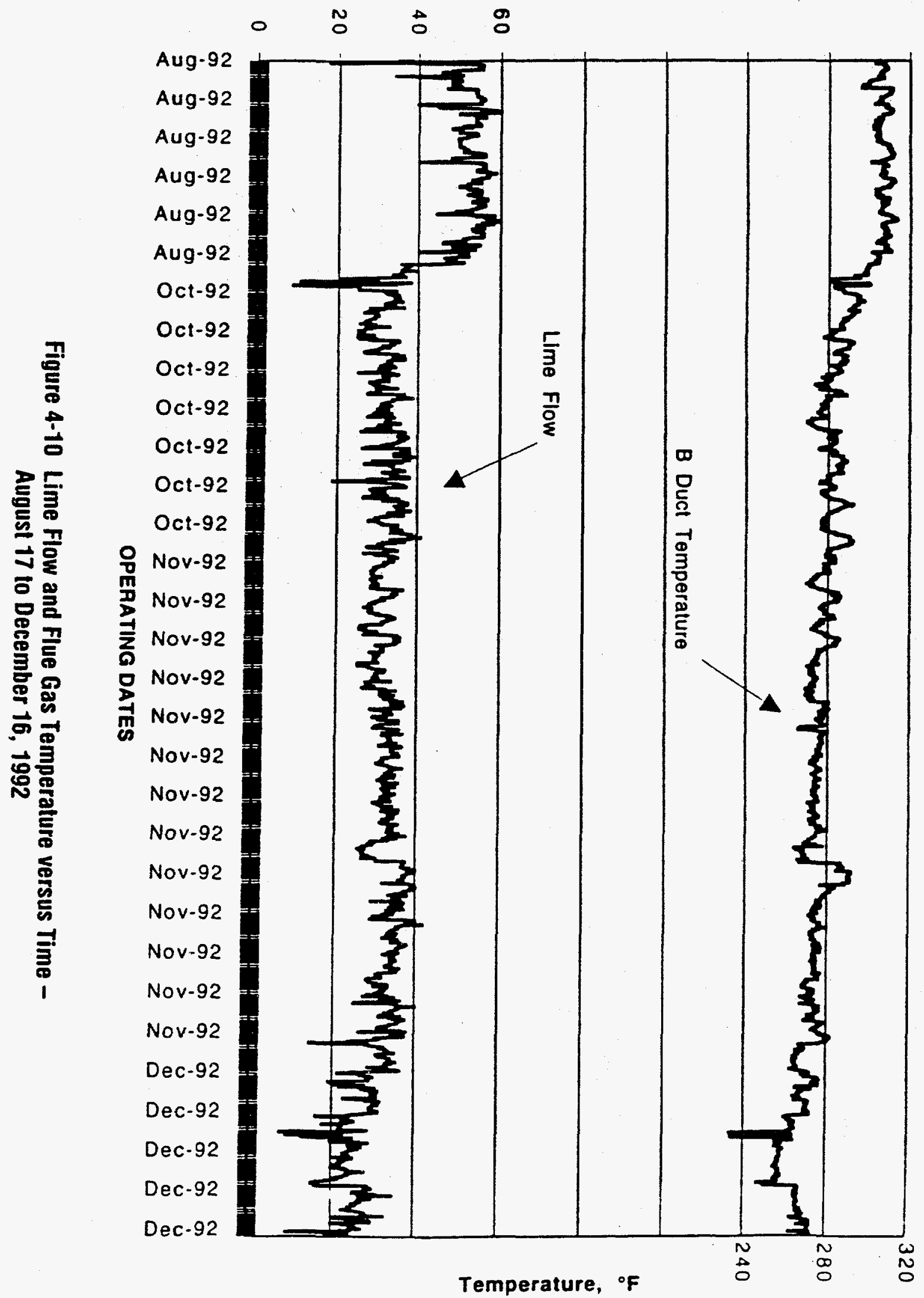




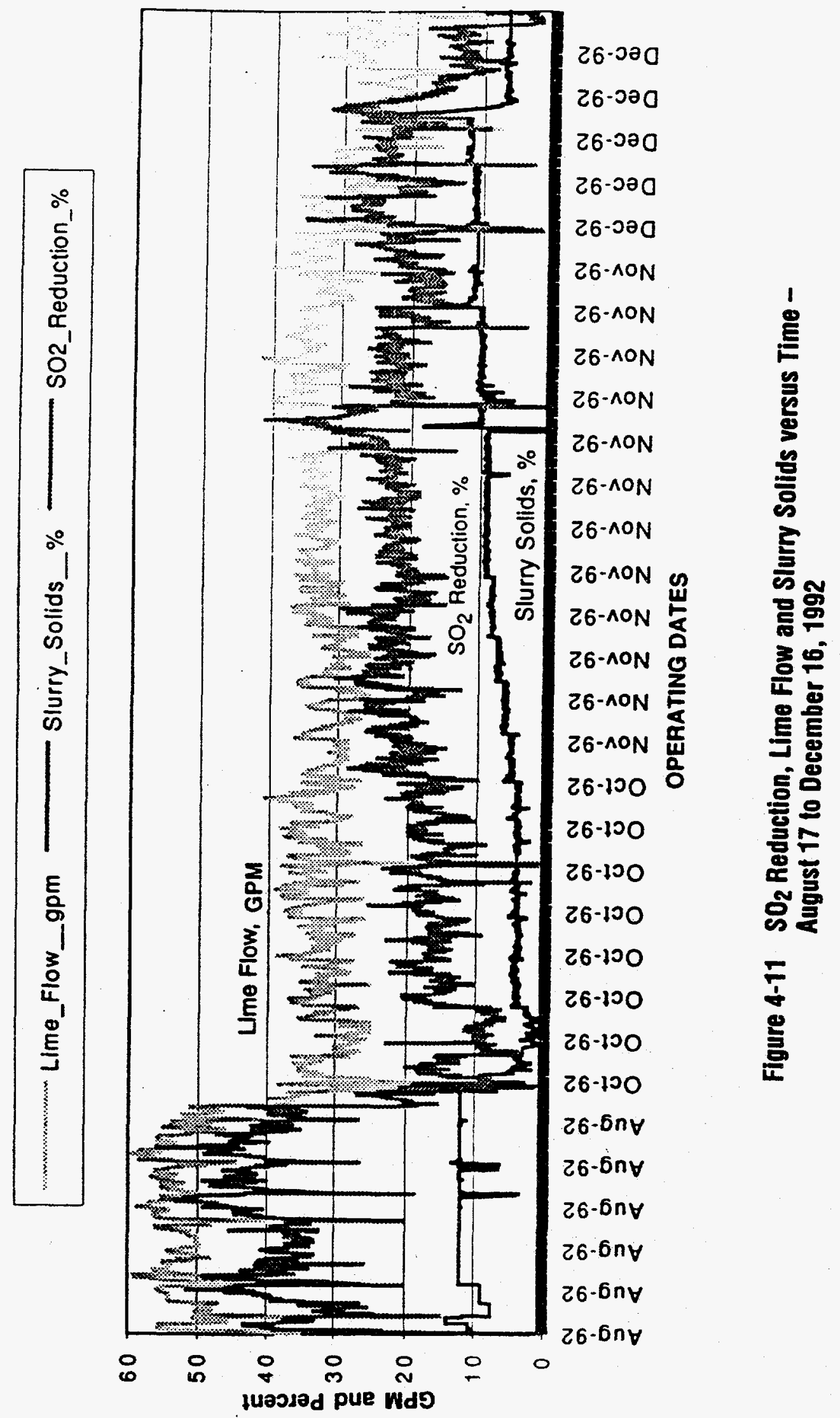




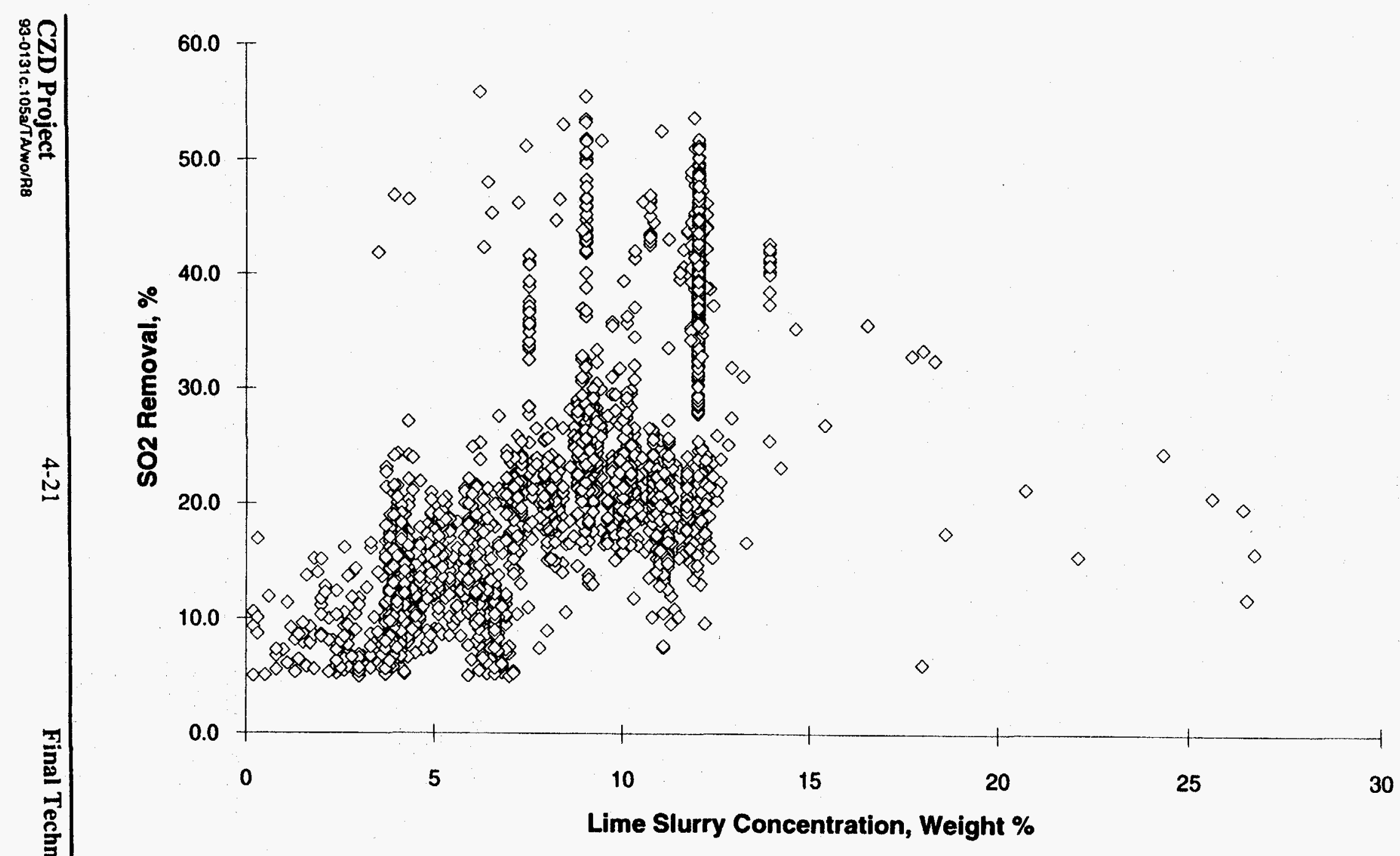

Figure 4-12 $\mathrm{SO}_{2}$ Removal versus Lime Slurry Concentration August 17 to December 16, 1992 
Lime utilization is defined as the percent of lime fed that reacts with $\mathrm{SO}_{2}$. It can be obtained by dividing the percent $\mathrm{SO}_{2}$ removal by the lime feed ratio. Lime feed ratio is defined as the moles of lime fed divided by the moles of $\mathrm{SO}_{2}$ entering the CZD system.

Figure 4-13 shows the lime utilization and lime slurry concentration versus time for the four months of continuous lime injection from August 17 to December 16, 1992. Similarly to Figure 4-11, this graph shows only those times when lime was injected. The graph shows that, consistently, the percentage of lime utilization decreases with an increase in lime slurry concentration above a certain level. At Seward Station when operating with normal sulfur coal and above $300^{\circ} \mathrm{F}$ inlet flue gas temperature, this level is $7-8 \%$. In August when the lime slurry concentration was $12 \%$ and the flue gas temperature was above $300^{\circ} \mathrm{F}$, the lime utilization was about $25 \%$. In October, when the lime slurry concentration was $4-5 \%$, the lime utilization was $40-55 \%$. In November and December when the lime concentration was above $10 \%$, the lime utilization came down to $15-25 \%$. Later in December, when the lime slurry concentration was reduced to about $7 \%$, the lime utilization went back to $20-25 \%$. The low values for lime utilization during the period November 17 to December 16 are caused by low flue gas temperature at the duct inlet, which reduced lime slurry injection and $\mathrm{SO}_{2}$ removal rates. The design of the CZD system at Seward Station was based on a $300^{\circ} \mathrm{F}$ flue gas temperature at the B duct inlet, because this was (in the past) the flue gas temperature at the B duct inlet. For a lower flue gas temperature, the design of the CZD treatment duct would be different to obtain higher utilization levels.

Figure 4-14 is a cross plot of lime utilization versus lime slurry concentration for this period. The graph shows that the lime utilization decreases with the increase in lime slurry concentration above a level of $7-8 \%$ (when burning coal with about $1.6 \%$ sulfur).

\subsubsection{Calcitic Lime}

Parametric testing was conducted with two types of calcitic lime, hydrated and freshly slaked. 


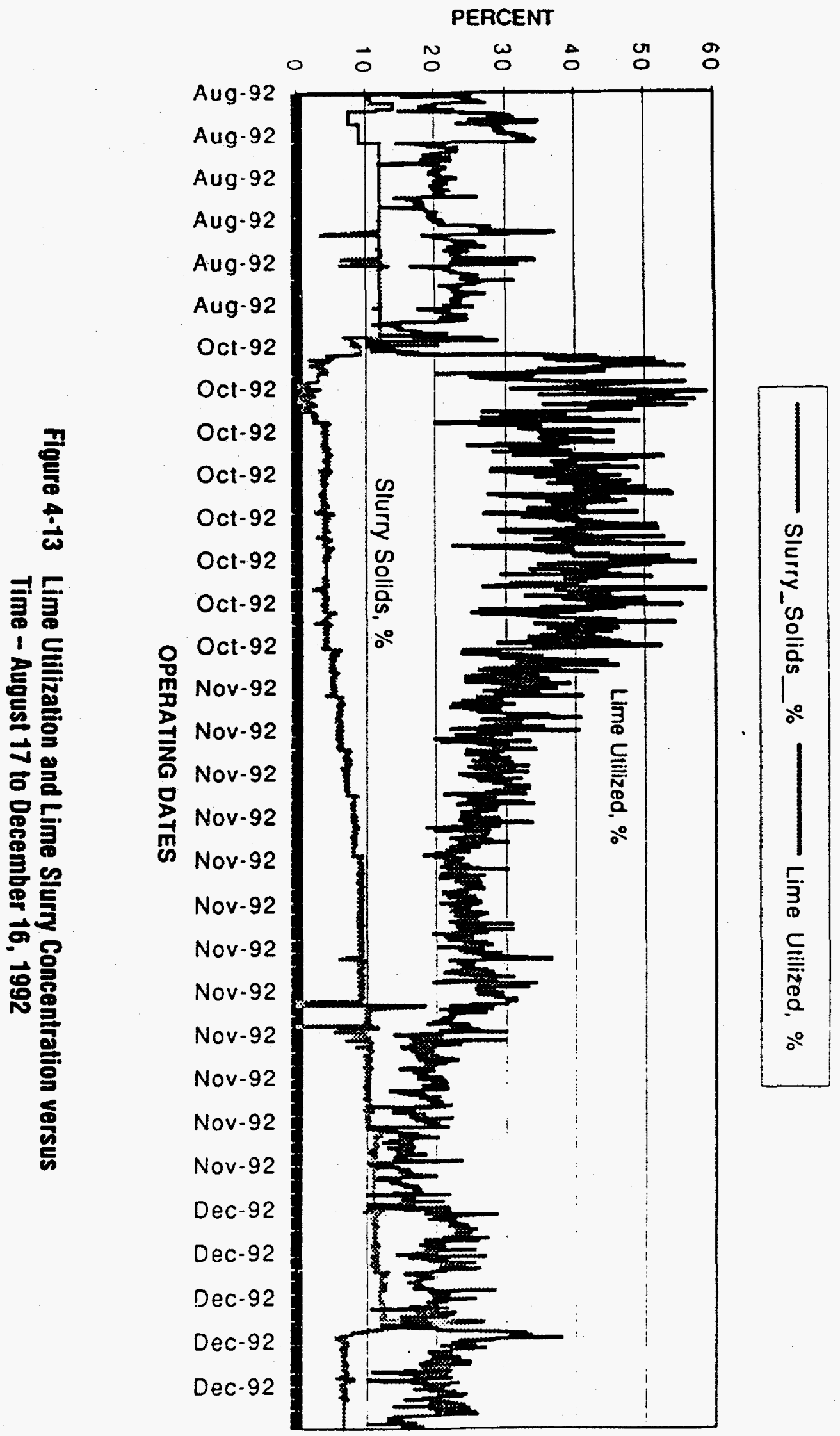




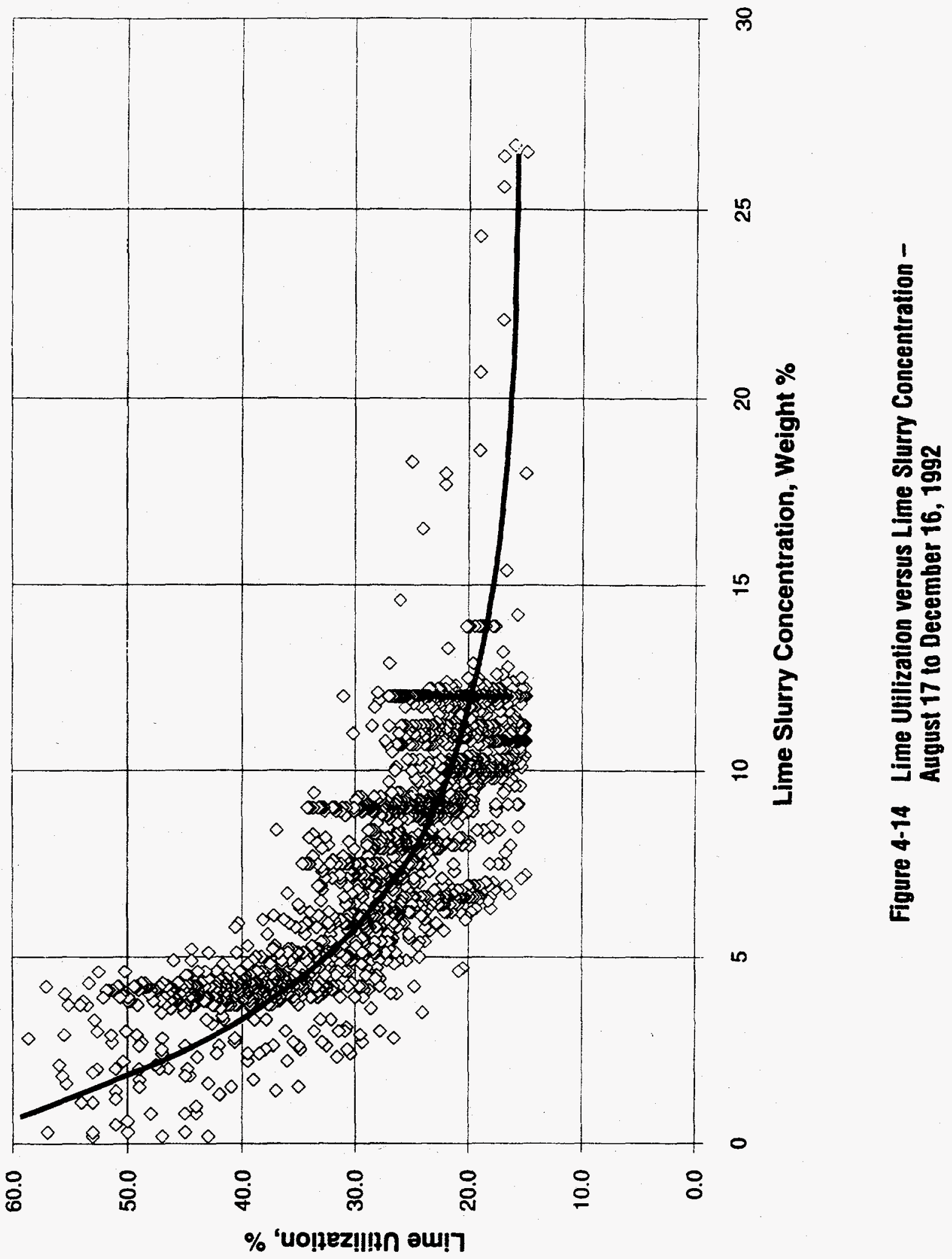




\subsubsection{Hydrated Calcitic Lime}

The initial slurry duct injection testing of the CZD system was performed with hydrated calcitic lime during October and November 1991. The source of the lime was the available Seward stock that was stored in the lime silo. The reactivity of this lime may have deteriorated due to aging or recarbonation. However, no analytical testing was performed to measure the reactivity or quality of the lime. The dry hydrated lime was slurried with water in the lime sump, pumped to a vibrating screen to remove impurities, and discharged by gravity to one of the two lime slurry feed tanks.

The results of the hydrated calcitic lime tests are presented in Table 4-3. A plot of $\mathrm{SO}_{2}$ removal versus lime slurry injection rate is shown in Figure 4-15. A least squares straight line has been fit to the data.

\subsubsection{Freshly Slaked Calcitic Lime}

Testing with the freshly-slaked calcitic lime started on July 10, 1992 and continued for approximately one month. The freshly slaked lime was trucked daily from the Conemaugh Station a few miles away. The lime slurry had a large amount of fine inert solids that passed through the 60-mesh vibrating screen. These solids tended to settle out in the slurry feed lines and the atomizers, which frequently resulted in several of the atomizers plugging during the tests.

The results of the freshly-slaked calcitic lime tests are presented in Table 4-4. A plot of $\mathrm{SO}_{2}$ removal versus the lime slurry injection rate is shown in Figure 4-16 with a least squares straight line fitted to the data.

\subsubsection{Comparison with PHDL Results}

The least squares fit for the PHDL parametric data (from Section 4.3.1.1), the PHDL continuous data (from Section 4.3.1.2), and the hydrated calcitic lime and freshly slaked calcitic lime data are presented on one graph in Figure 4-17. The PHDL parametric data and the freshly slaked calcitic data show the best performance because they were run at a lower approach to saturation temperature than the PHDL continuous data and the hydrated calcitic data. The hydrated calcitic lime shows the poorest performance. While the aging of 


\begin{tabular}{|c|c|c|c|}
\hline \multirow{13}{*}{ 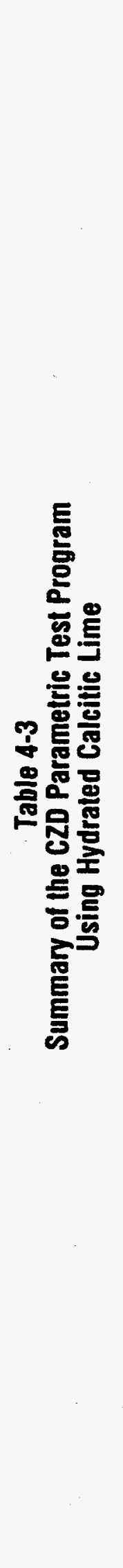 } & 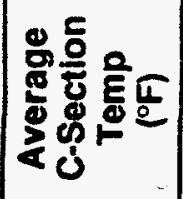 & 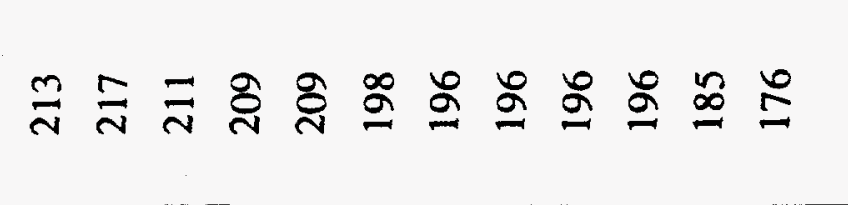 & $\stackrel{\infty}{\cong}$ \\
\hline & 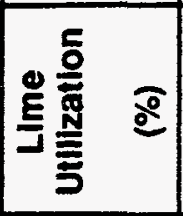 & 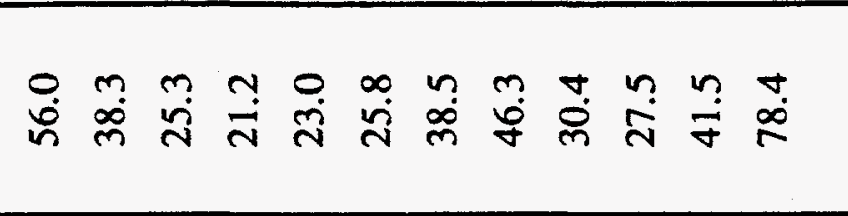 & $\ddot{q} \overrightarrow{\dot{q}}$ \\
\hline & 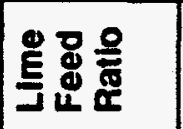 & đิ̃ & $\stackrel{8}{0} \stackrel{\infty}{\leftrightarrows}$ \\
\hline & 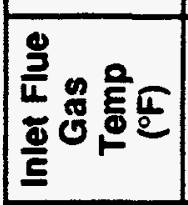 & 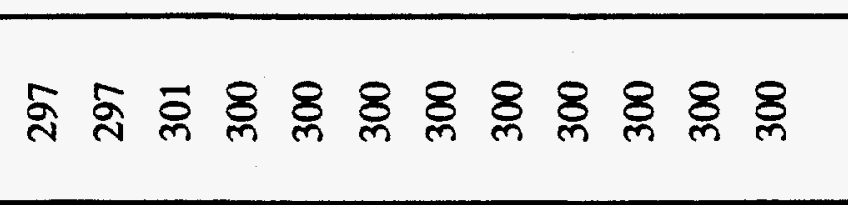 & \&్ల \& \\
\hline & 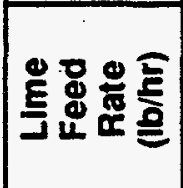 & 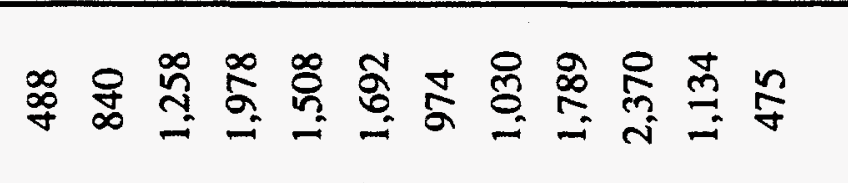 & 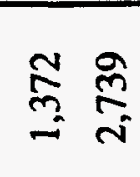 \\
\hline & 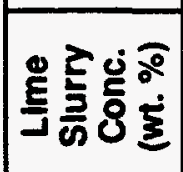 & 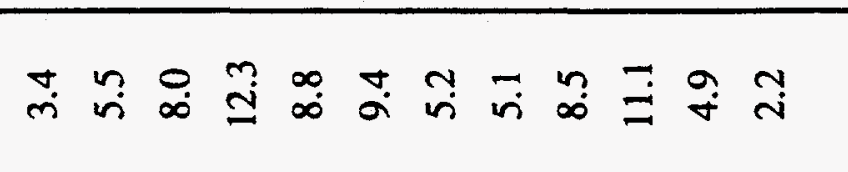 & $\approx \stackrel{n}{0}$ \\
\hline & 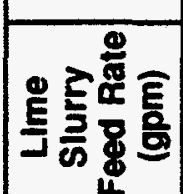 & 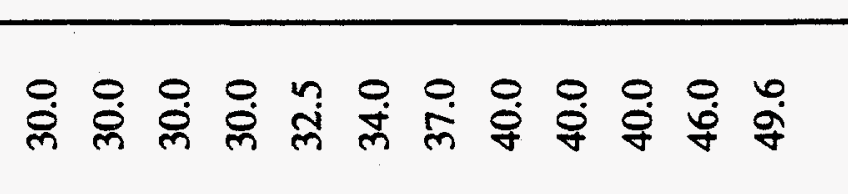 & $\stackrel{\circ}{\circ} \stackrel{\circ}{\ddot{q}}$ \\
\hline & 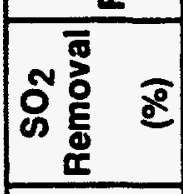 & 島 & $\stackrel{\circ}{\circ} \bar{d}$ \\
\hline & 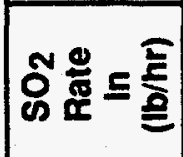 & 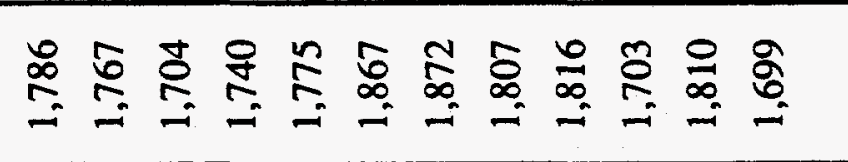 & 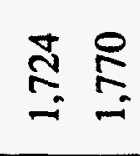 \\
\hline & 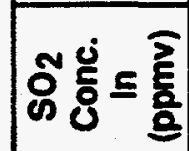 & ఫू : & $\approx$ \\
\hline & 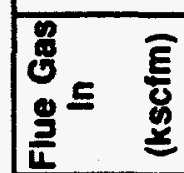 & 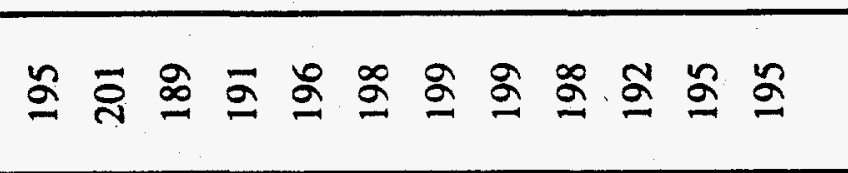 & $\cong$ \\
\hline & 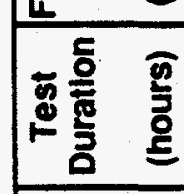 & 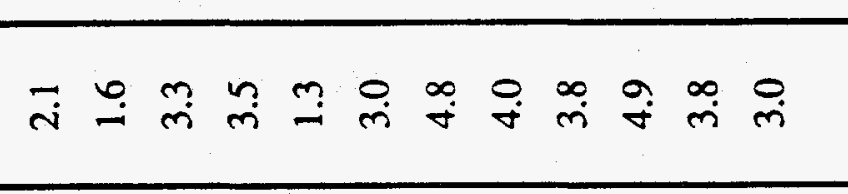 & $\stackrel{\sim}{i} \stackrel{\infty}{n}$ \\
\hline & 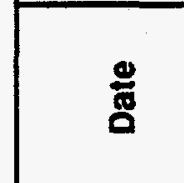 & 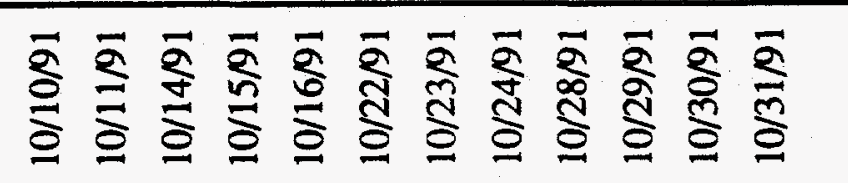 & $\stackrel{\overline{2}}{\stackrel{\overline{2}}{\mathrm{~S}}}$ \\
\hline
\end{tabular}




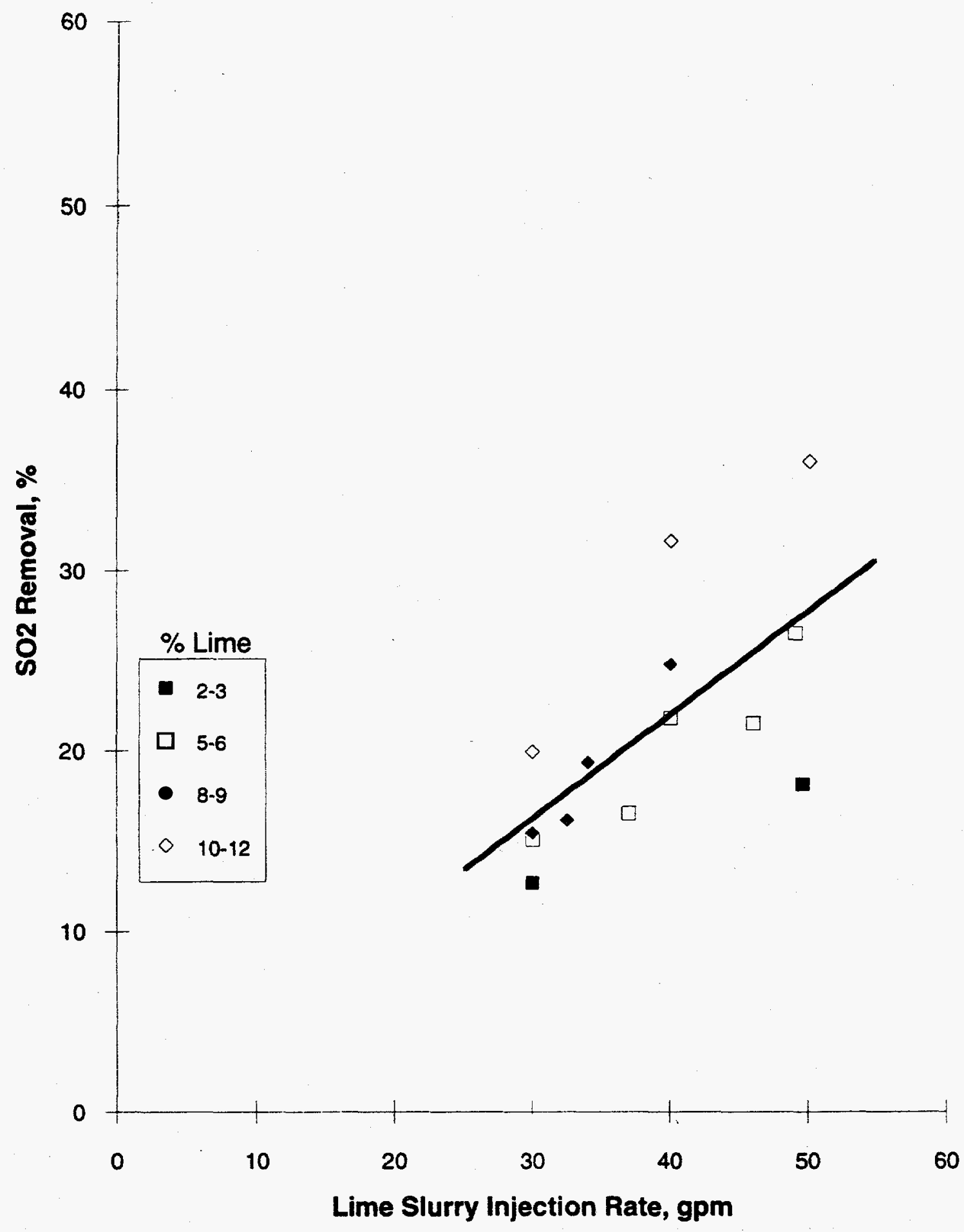

Figure 4-15 $\mathrm{SO}_{2}$ Removal versus Hydrated Calcitic Lime Slurry Injection Rate 
Table 4-4

Summary of the CZD Parametric Test Program Using Freshly Slaked Calcitic Lime

\begin{tabular}{|c|c|c|c|c|c|c|c|c|c|c|c|c|}
\hline Date & \begin{tabular}{|c|} 
Test \\
Duration \\
(hours) \\
\end{tabular} & $\begin{array}{c}\text { Flue Gas } \\
\text { in } \\
\text { (kscim) }\end{array}$ & $\begin{array}{c}\mathrm{SO}_{2} \\
\text { Conc. } \\
\text { In } \\
\text { (ppmv) }\end{array}$ & $\begin{array}{c}\mathrm{SO}_{2} \\
\text { Rate } \\
\text { In } \\
(\mathrm{lb} / \mathrm{hr}) \\
\end{array}$ & $\begin{array}{c}\mathrm{SO}_{2} \\
\text { Removal } \\
(\%) \\
\end{array}$ & $\begin{array}{c}\text { Llme } \\
\text { Slurry } \\
\text { Feed Rate } \\
\text { (gpm) }\end{array}$ & $\begin{array}{l}\text { Lime } \\
\text { Slurry } \\
\text { Conc. } \\
\text { (wt. \%) } \\
\end{array}$ & $\begin{array}{c}\text { Lime } \\
\text { Feed } \\
\text { Rate } \\
\text { (lb/hr) } \\
\end{array}$ & $\begin{array}{c}\text { Inlet Flue } \\
\text { Gas } \\
\text { Temp } \\
\left({ }^{\circ} \mathrm{F}\right)\end{array}$ & $\begin{array}{l}\text { LIme } \\
\text { Feed } \\
\text { Ratlo }\end{array}$ & \begin{tabular}{|c|} 
Lime \\
Utilization \\
$(\%)$
\end{tabular} & $\begin{array}{c}\text { Average } \\
\text { C-Section } \\
\text { Temp } \\
\left.\text { ( }{ }^{\circ} \mathrm{F}\right)\end{array}$ \\
\hline $07 / 10 / 92$ & 0.8 & 188 & 905 & 1,721 & 43.3 & 50.0 & 10.0 & 2,655 & 300 & 1.28 & 33.8 & 158 \\
\hline $07 / 13 / 92$ & 2.5 & 185 & 908 & 1,703 & 43.3 & 51.5 & 10.0 & 2,735 & 312 & 1.33 & 32.5 & 172 \\
\hline $07 / 15 / 92$ & 1.0 & 191 & 853 & 1,651 & 41.4 & 46.5 & 10.5 & 2,599 & 283 & 1.31 & 31.7 & 162 \\
\hline $07 / 15 / 92$ & 1.5 & 190 & 867 & 1,668 & 45.1 & 50.0 & 15.0 & 4,050 & 283 & 2.01 & 22.4 & 160 \\
\hline $07 / 15 / 92$ & 1.2 & 190 & 864 & 1,663 & 39.1 & 45.0 & 12.0 & 2,892 & 283 & 1.44 & 27.1 & 160 \\
\hline $07 / 16 / 92$ & 1.0 & 193 & 896 & 1,747 & 36.6 & 43.0 & 8.5 & 1,923 & 290 & 0.91 & 40.1 & 178 \\
\hline $07 / 16 / 92$ & 0.8 & 188 & 885 & 1,683 & 37.1 & 42.5 & 11.5 & 2,612 & 290 & 1.29 & 28.8 & 168 \\
\hline $07 / 17 / 92$ & 1.1 & 188 & 866 & 1,650 & 48.8 & 52.6 & 10.5 & 2,940 & 300 & 1.48 & 33.0 & 154 \\
\hline $07 / 17 / 92$ & 1.8 & 188 & 868 & 1,653 & 35.1 & 41.0 & 8.5 & 1,834 & 300 & 0.92 & 38.1 & 178 \\
\hline $07 / 27 / 92$ & 2.0 & 187 & 873 & 1,653 & 39.4 & 45.0 & 9.7 & 2,314 & 280 & 1.16 & 33.9 & 160 \\
\hline $08 / 05 / 92$ & 1.0 & 187 & 848 & 1,609 & 37.0 & 42.5 & 10.3 & 2,328 & 290 & 1.20 & 30.8 & 169 \\
\hline 08/05/92 & 0.7 & 186 & 849 & 1,601 & 40.7 & 45.0 & 9.5 & 2,264 & 290 & 1.17 & 34.7 & 162 \\
\hline 08/06/92 & 3.7 & 183 & 870 & 1,612 & 39.7 & 45.0 & 10.3 & 2,465 & 305 & 1.27 & 31.3 & 162 \\
\hline 08/07/92 & 1.9 & 165 & 885 & 1,479 & 43.5 & 50.0 & 10.0 & 2,655 & 305 & 1.49 & 29.2 & 160 \\
\hline $08 / 10 / 92$ & 0.6 & 189 & 928 & 1,774 & 47.1 & 54.0 & 16.5 & 4,826 & 300 & 2.26 & 20.9 & 165 \\
\hline $08 / 10 / 92$ & 1.5 & 190 & 925 & 1,779 & 46.4 & 51.5 & 15.7 & 4,373 & 300 & 2.04 & 22.7 & 160 \\
\hline
\end{tabular}




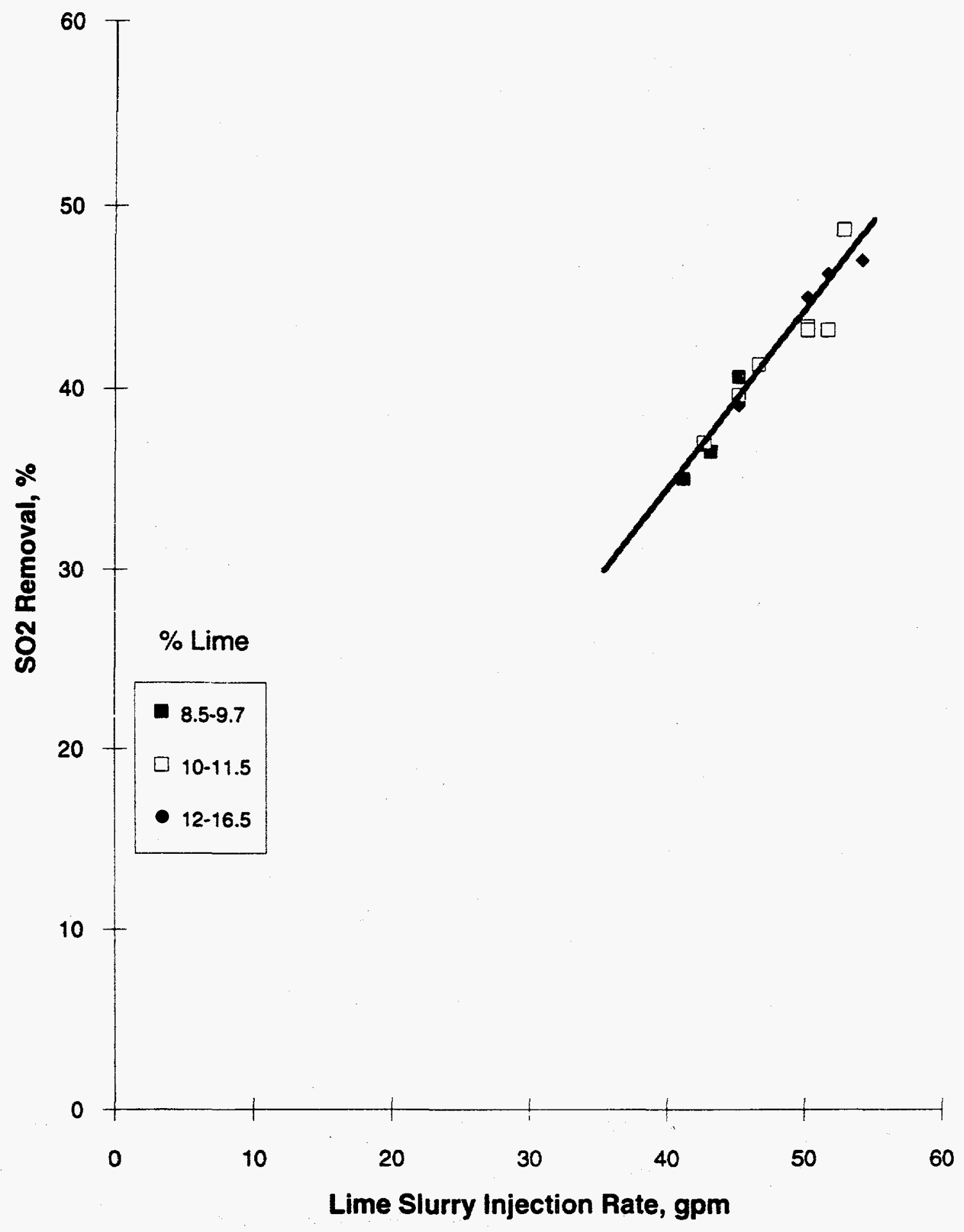

Figure 4-16 $\mathrm{SO}_{2}$ Removal versus Freshly Slaked Calcitic Lime Slurry Injection Rate 


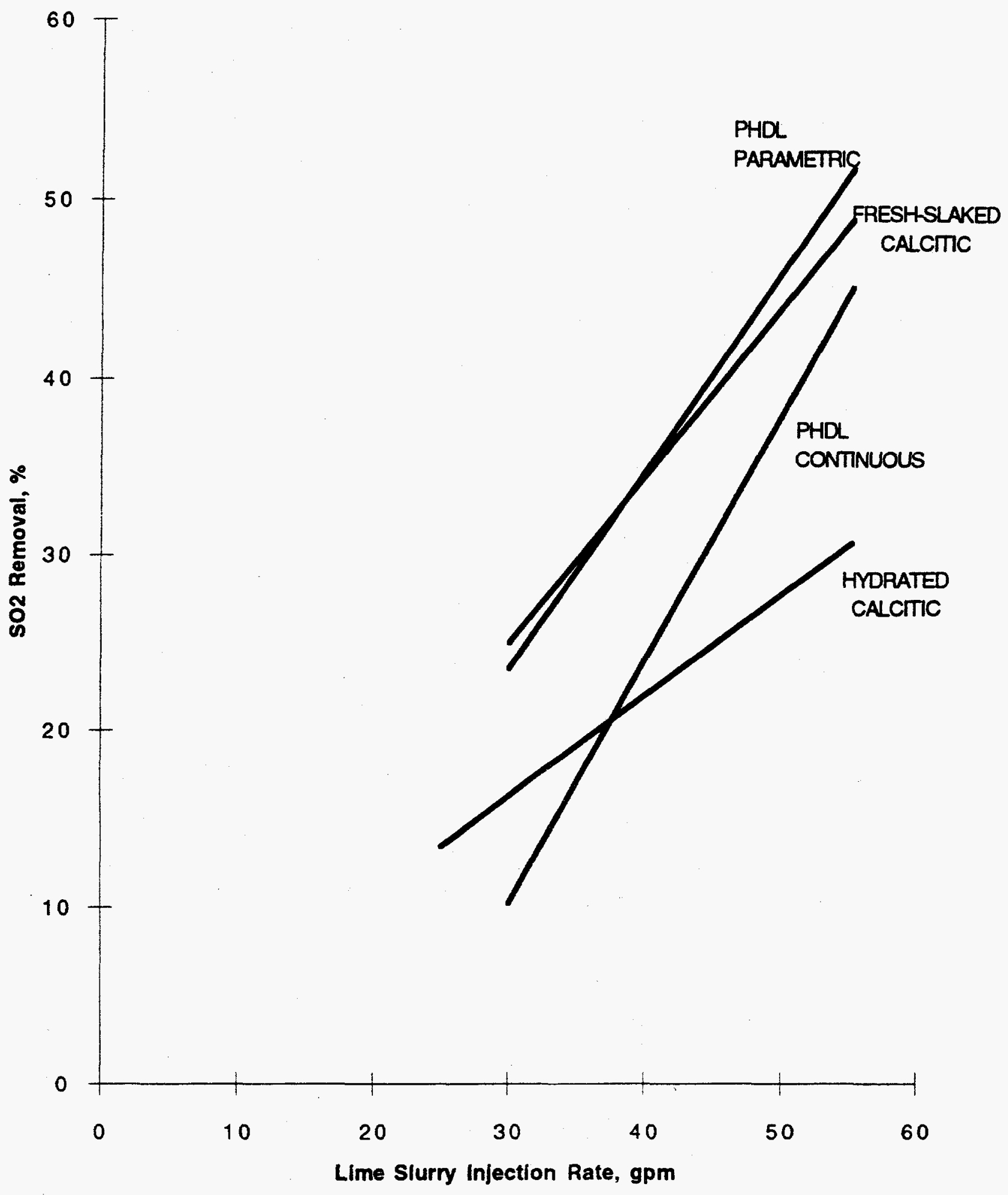

Figure 4-17 Effect of Lime Type on $\mathrm{SO}_{2}$ Removal 
this lime may have contributed to its poorer performance, the major reason for the poorer performance was that these tests were run at a significantly higher approach to saturation temperature compared with the other tests.

\subsubsection{High-Sulfur Coal}

To determine how a higher $\mathrm{SO}_{2}$ concentration in the flue gas resulting from burning higher sulfur coal affects the CZD system performance, Penelec and Bechtel requested PaDER approval to conduct tests at Seward Station with higher sulfur coal ( 2.1 to $2.4 \%$ sulfur content) for a 15 -day period. The regular coal burned has a nominal sulfur content of $1.6 \%$. The composition for each coal type is given in Appendix A-2.

Table 4-5 shows a comparison between the daily CZD summaries of operating data when higher sulfur coal and regular sulfur coal were burned. The table shows that the average $\mathrm{SO}_{2}$ removal and maximum $\mathrm{SO}_{2}$ removal were slightly higher during the period when higher sulfur coal was burned. The percentage of lime utilization was also slightly higher. These results could be expected because the higher $\mathrm{SO}_{2}$ concentration creates a higher partial pressure of $\mathrm{SO}_{2}$, leading to the faster reaction with water and $\mathrm{SO}_{2}$ absorbent.

\subsubsection{Approach to Adiabatic Saturation Temperature}

The use of the approach to adiabatic saturation temperature as a parameter for correlating data from the CZD system is not as straightforward as it is for spray dry FGD systems. Spray dry systems uniformly cool the total inlet flue gas stream to some lower outlet temperature. The approach to adiabatic saturation temperature of the bulk gas stream can be readily determined by subtracting the adiabatic saturation temperature of the flue gas from this outlet gas temperature.

In contrast, the CZD system cools that portion of the inlet flue gas in the confined zone (50\% to $70 \%$ of the total inlet flue gas) completely to the saturation temperature. The remainder of the inlet flue gas initially stays as a hot layer along the duct surfaces but eventually mixes with and reheats the cooled portion of the flue gas. This mixing is not yet complete at $\mathrm{C}$ section (the turning vanes), 120 feet downstream from the atomizers. As described earlier, the flue gas 


\section{Table 4-5}

Comparison of Daily CZD Summaries of Operating Data with Regular Sulfur Coal Versus Higher Sulfur Coal

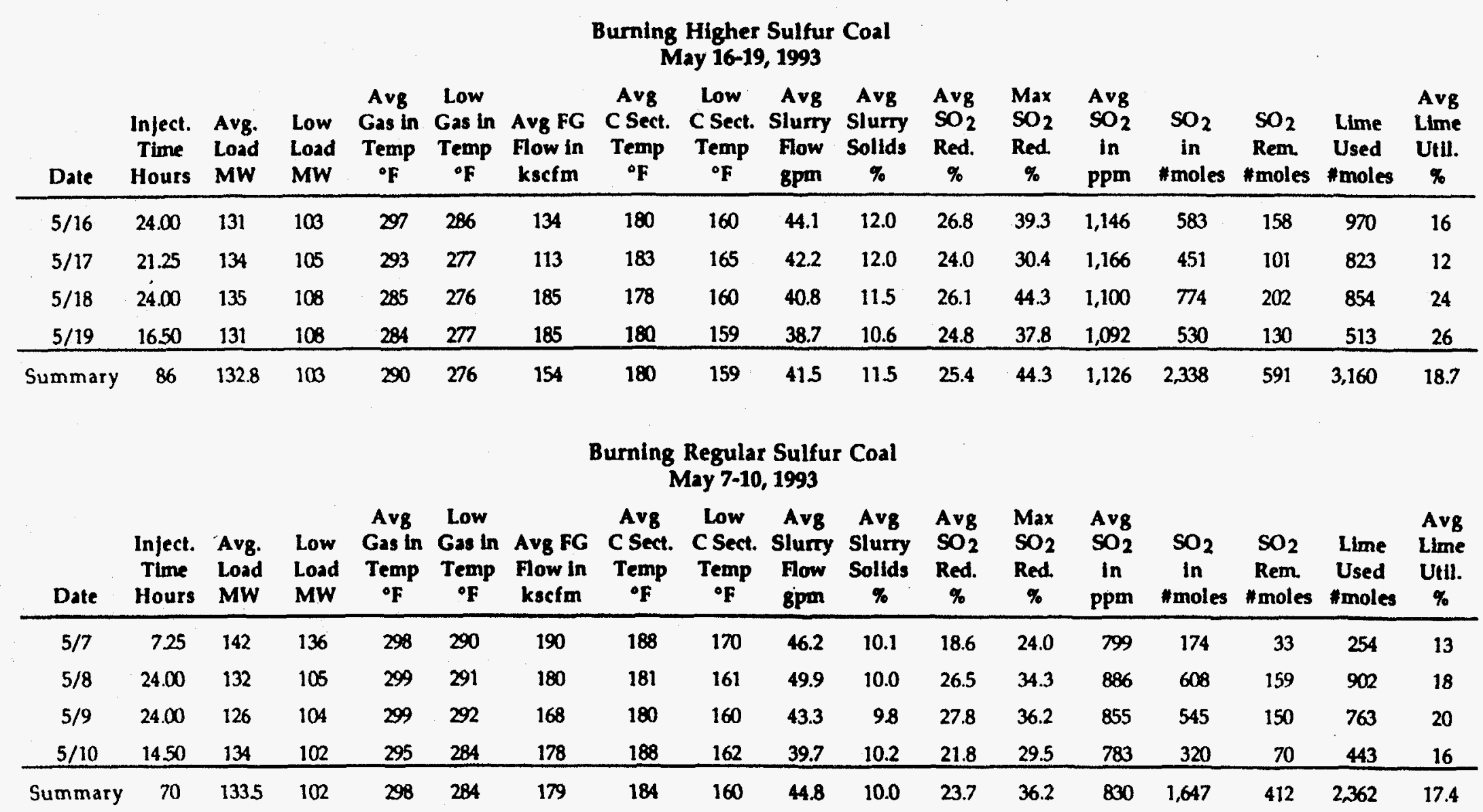


temperature at this point is measured by an array of thermocouples distributed over the duct vertical cross section. These measurements are averaged to get the average flue gas temperature.

This average temperature at $C$ section is used to calculate an approach to saturation temperature for the CZD system. However, it is recognized that this is only an approximation and does not have the same meaning as it does for the spray dry systems.

Furthermore, because the cooled flue gas in the confined zone has to be heated with the surrounding hot gas to a temperature of approximately $160^{\circ} \mathrm{F}$ to $165^{\circ} \mathrm{F}$ to sufficiently dry the wet particles to avoid deposition on the turning vanes, the calculated approach to saturation temperature for the CZD system is always much higher than it is for spray dry systems.

If the average flue gas temperature at $\mathrm{C}$ section is $160^{\circ} \mathrm{F}$ and the adiabatic saturation temperature is $120^{\circ} \mathrm{F}$, the approach to adiabatic saturation temperature is $160^{\circ} \mathrm{F}-120^{\circ} \mathrm{F}=40^{\circ} \mathrm{F}$. For the CZD system at Seward station, an approach to adiabatic saturation temperature of $35^{\circ} \mathrm{F}$ is considered a low approach; an approach to adiabatic saturation temperature above $70^{\circ} \mathrm{F}$ is considered a high approach. A high approach is caused by a low lime slurry flow rate that does not cool the flue gas sufficiently and consequently causes a low $\mathrm{SO}_{2}$ removal.

For spray dry systems, all the flue gas is treated and no hot flue gas is required to reheat the treated cold gas. A very low approach to saturation can be obtained because no envelope of hot untreated flue gas is necessary to avoid deposition. Therefore, the approach to adiabatic saturation temperature in the spray dry systems can be as low as $20^{\circ} \mathrm{F}$.

Figure 4-18 shows the approach to adiabatic saturation temperature at the $C$ cross section, lime slurry injection rate, and $\mathrm{SO}_{2}$ removal during the period November 17 to December 16, 1992. The graph shows that at a high approach to adiabatic saturation $\left(70-80^{\circ} \mathrm{F}\right)$, the $\mathrm{SO}_{2}$ removal is lower than at a lower approach of $60^{\circ} \mathrm{F}$. The high approach to adiabatic saturation is caused by low lime slurry injection rates. For example, at a $20 \mathrm{gpm}$ lime slurry injection rate, 


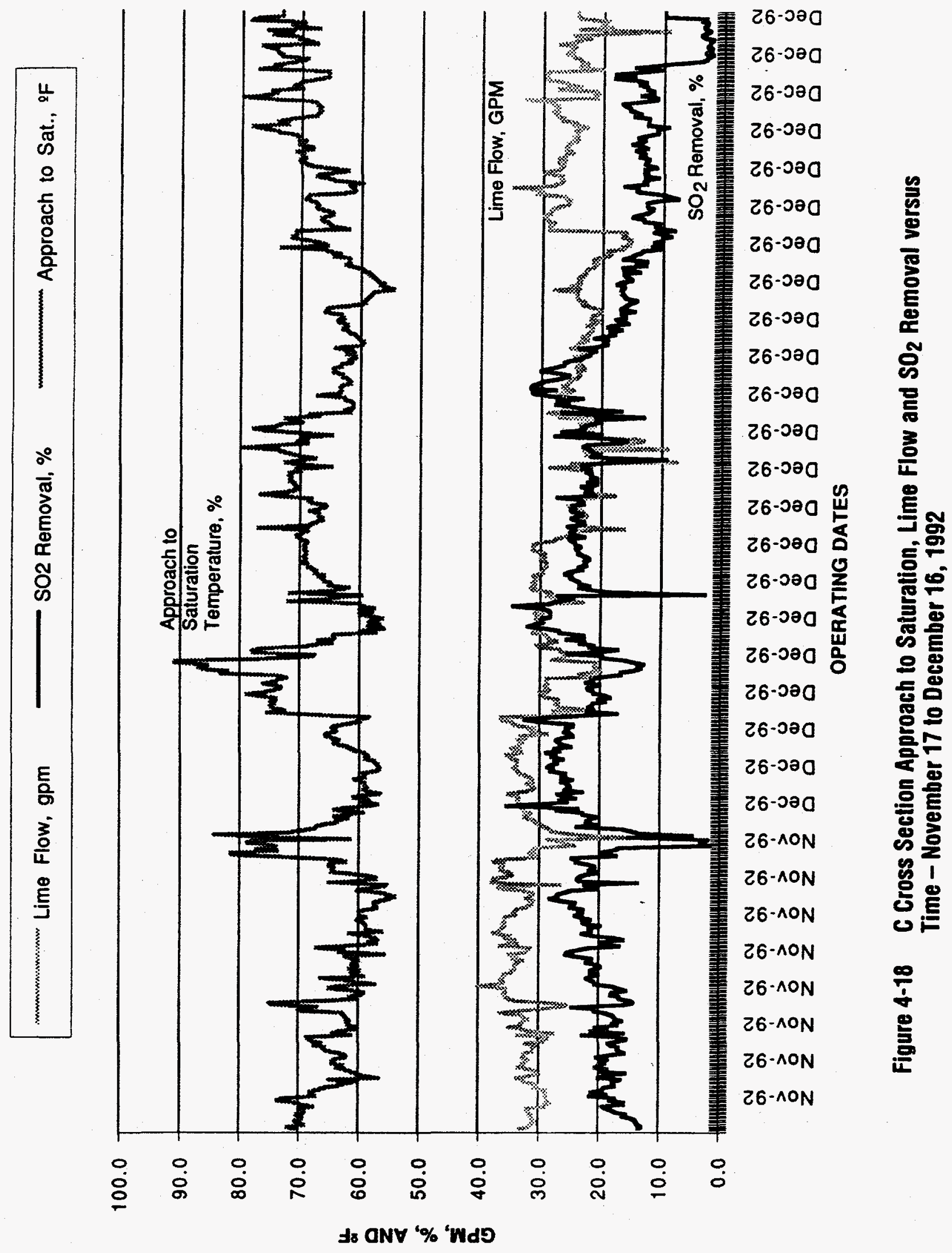


the approach to adiabatic saturation reached $90^{\circ} \mathrm{F}$ and, as a consequence, the percentage of $\mathrm{SO}_{2}$ removed came down to $15 \%$ from $30 \%$ at a $60^{\circ} \mathrm{F}$ approach to adiabatic saturation temperature.

As can be seen, the approach to adiabatic saturation temperature is a very important factor in determining $\mathrm{SO}_{2}$ removal. The highest $\mathrm{SO}_{2}$ removal can be obtained at the lowest possible approach to adiabatic saturation. The lowest approach to adiabatic saturation obtainable during the demonstration was $40^{\circ} \mathrm{F}$ at the turning vanes because at a lower temperature than that, the fly ash and reaction products can be moist and may stick to the turning vanes, creating a deposit of solids. To keep a low approach to adiabatic saturation of $35-40^{\circ} \mathrm{F}$ (that is, $155-160^{\circ} \mathrm{F}$ flue gas temperature) requires an inlet flue gas temperature above $300^{\circ} \mathrm{F}$ and a lime slurry injection rate of $54-56 \mathrm{gpm}$. Because of the excessive air leakage in the boiler, the flue gas inlet temperature in the duct was $270^{\circ} \mathrm{F}$ or less. The lime slurry injection rate had to be limited to less than $35 \mathrm{gpm}$; therefore, a low $\mathrm{SO}_{2}$ removal (about $25-28 \%$ ) resulted.

Figure 4-19 is a cross plot of $\mathrm{SO}_{2}$ removal versus the $\mathrm{C}$ cross section approach to saturation temperature. As shown in the figure, the $\mathrm{SO}_{2}$ removal increases at a lower approach to saturation temperature.

\subsubsection{Waste Product Analysis}

A chemical analysis of the solid waste resulting from the CZD operation was performed to determine the chemical species present and to compare the sulfur pickup in the waste with the $\mathrm{SO}_{2}$ removed from the flue gas. The results are summarized here; detailed calculations and analyses are presented in Quarterly Report No. 10, Appendix F.

Samples of the solid waste products were taken from A duct ESP hoppers (without CZD) and B duct ESP hoppers (with CZD) on May 19 and 20, 1993, and were chemically analyzed by Geochemical Testing Co. The results of the chemical analysis and the material balance calculations are listed in Table 4-6. 
Table 4-6

Solid Waste Product Analyses

Samples Collected from B Duct ESP Hopper

\begin{tabular}{|l|c|c|}
\hline & $\begin{array}{c}\text { Solid Waste } \\
\text { of } \\
5 / 19 / 93\end{array}$ & $\begin{array}{c}\text { Solid Waste } \\
\text { of } \\
5 / 20 / 93\end{array}$ \\
\hline CZD reaction products and unreacted reagents, wt\% & 25 & 37 \\
Fly Ash, wt\% & 75 & 63 \\
$\quad$ Total & $100 \%$ & $100 \%$ \\
PHDL utilization, on a molar basis & $30 \%$ & $30 \%$ \\
In Leachate: & & \\
pH & 12 & 12 \\
CaSO $3, \mathrm{mg} / 1$ & 22 & 22 \\
$\mathrm{MgSO}_{3}+\mathrm{MgSO}$, mg/1 & 0.17 & 0.17 \\
Nitrite, $\mathrm{mg} / 1$ & $<0.05$ & $<0.05$ \\
Nitrate, $\mathrm{mg} / \mathrm{l}$ expressed as $\mathrm{N}_{2}$ & 0.40 & 1.30 \\
Equivalent nitrate in solid waste, ppm (by wt) as $\mathrm{N}_{2}$ & 26 & 114 \\
Equivalent nitrate in (reacted and unreacted) & 104 & 308 \\
products, ppm (by wt) & & \\
\hline
\end{tabular}




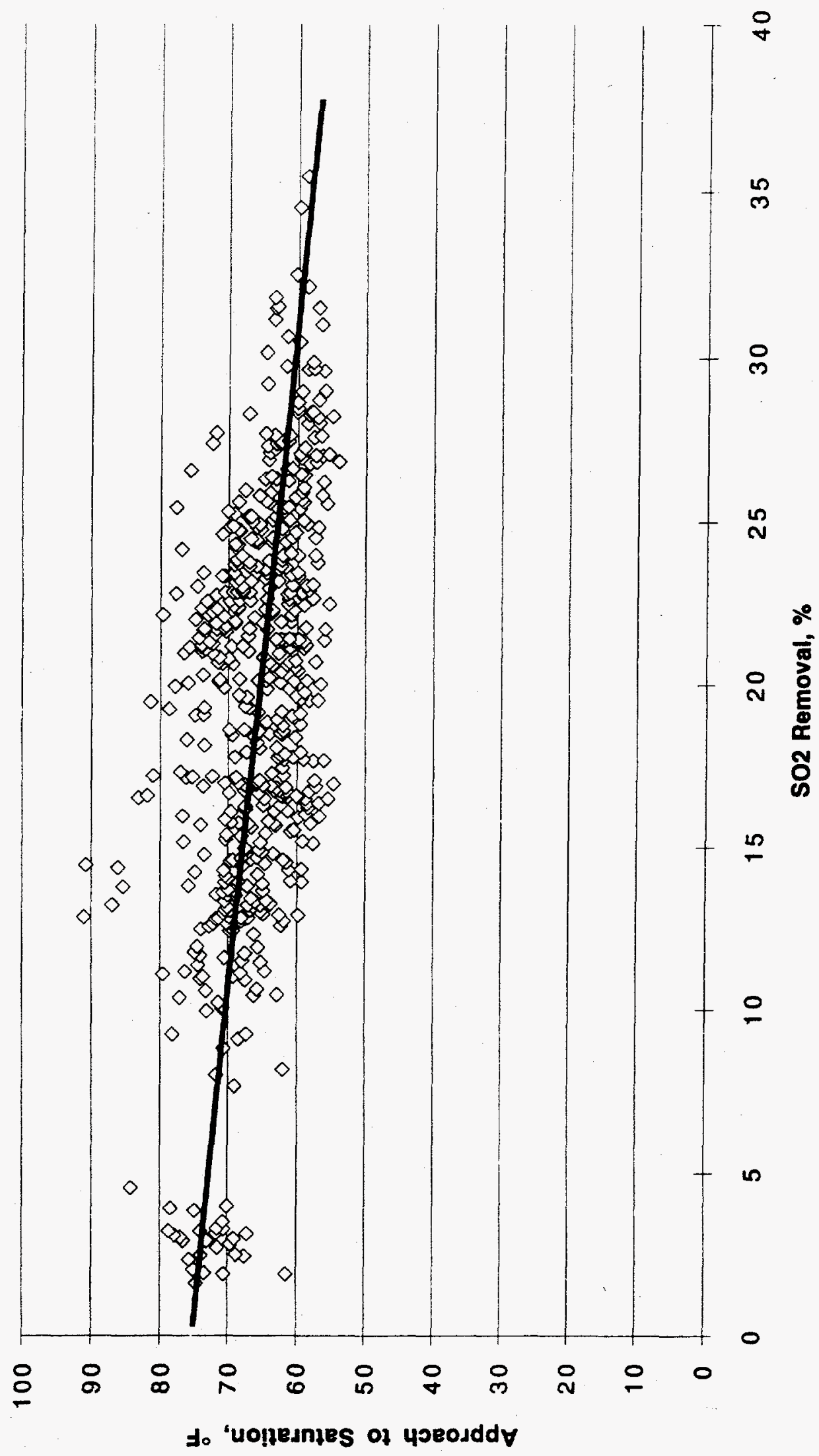

Figure 4-19 $\mathrm{SO}_{2}$ Removal versus C Cross Section Approach to Saturation November 17 to December 16, 1992 
The items in Table 4-6 are described as follows:

- The percentage of PHDL utilized was determined by material balance calculations to be $30 \%$ - that is, on a molar basis, $30 \%$ of the PHDL injected into the $\mathrm{B}$ duct reacted with $\mathrm{SO}_{2}$. This compares with the calculated daily average lime utilization for $\mathrm{SO}_{2}$ removal during May 19 and 20, 1993 of 26\%. (See Daily CZD Summaries, April 21 - May 25, 1993, Section 3.3 .2 of Quarterly Report No. 10). The solid waste collected in the ESP hoppers was pneumatically removed from the hoppers every few hours; therefore, the samples for analysis taken from the hoppers did not represent the average per day, but the results of only a few hours of operation. On this basis the comparison is a close one.

- Of the total solid waste collected in the ESP hoppers during the CZD operation, Sample \#1 of May 19, 1993, contains $25 \%$ by weight of reaction products, plus unreacted lime; Sample \#2 of May 20, 1993 contains about $37 \%$ of reaction products and unreacted lime, with the difference being fly ash.

- The unreacted lime and magnesium hydroxide maintain a high alkalinity of solid waste with a pH of 12 .

- The sulfite concentration in the leachate of solid waste of Samples \#1 and \#2 is extremely low - about $22 \mathrm{mg} / 1$ - indicating that the reaction products are mostly sulfate.

- The magnesium concentration in the leachate of solid waste of Samples \#1 and \#2 is extremely low - about $0.17 \mathrm{mg} / \mathrm{l}$ - indicating that magnesium is in the form of $\mathrm{Mg}(\mathrm{OH})_{2}$, not magnesium sulfite or sulfate.

- The amount of nitrite in the leachate of fly ash from the A duct (without CZD) and the B duct (with CZD) of Samples \#1 and \#2, is very small - less than $0.05 \mathrm{mg} / \mathrm{l}$ nitrogen.

- Nitrate in the leachate of the fly ash sample from the A duct (without CZD) is very low - less than $0.05 \mathrm{mg} / 1$ nitrogen.

- Nitrate in the leachate of Samples \#1 and \#2 from the B duct (with CZD) are $0.40 \mathrm{mg} / 1$ nitrogen and $1.30 \mathrm{mg} / \mathrm{l}$, respectively. The leachate contains 100 grams of solid waste in 2 liters of deionized water. This is equivalent to $26 \mathrm{ppm}$ (by weight) of nitrate, expressed as nitrogen, of the solid waste of 
Sample \#2, or about 114 ppm (by weight) of nitrate of the solid waste. It is also equivalent to about $342 \mathrm{ppm}$ (by weight) of nitrate in the reaction products, plus unreacted lime.

The nitrate found in the solid waste proved that some $\mathrm{NO}_{\mathbf{x}}$ was removed from the flue gas. The $\mathrm{NO}_{x}$ analyzers were unreliable so it was not possible to compare $\mathrm{NO}_{\mathrm{x}}$ removed from the flue gas with nitrogen picked up in the solid waste. More tests are required to determine the conditions that could improve the percentage of $\mathrm{NO}_{x}$ removal.

\subsubsection{Duct Deposits}

During most of the CZD system testing, duct deposits were not significant, as confirmed by duct inspections performed during outages. However, on two occasions, during August 1992 and May 1993, significant duct deposition occurred. This section describes the events leading up the duct deposit formation and the measures taken to monitor the duct condition and prevent hard duct deposits from forming.

The first significant duct deposition occurred during the startup phase of lime injection automation, when there were some maloperations. At the end of August 1992, after 10 days of continuous (24-hour/day) operations, it was determined that the steam pressure at which the duct sootblowers were operating was set too low (150 psi) to prevent deposits from forming on the bottom of the duct. A few times when moving from standby mode to ready condition, the injection flow control valve - being not fully tuned - remained fully open and the lime injection rate reached over $80 \mathrm{gpm}$ for 1-2 minutes. At that point the flow control valve closed to limit the lime slurry flow rate to the level to maintain a temperature of about $160^{\circ} \mathrm{F}$ at Section $C$ (at the turning vanes). During these excursions, wet deposits were formed because there was not enough heat in the duct to evaporate the very large amount of lime slurry. Some small quantities of atomized lime slurry reached the ESP, coating the collecting plates and the discharge wires of Fields \#3 and \#4. This lime coating caused some opacity problems.

The steam supply pressure to the sootblowers was increased to the maximum (300 psi) and the frequency of operation was increased. However, it was not 
possible to remove all of the deposits that had already formed. In a few areas, the deposits in the duct were significant, and measurements confirmed that further lime injection operations would cause accelerated growth of these deposits. Consequently, it was decided to stop lime injection and remove the deposits manually at the next boiler outage.

After the deposits were removed and the boiler was brought to full load, lime injection was resumed from October 9 to October 26. Following this, an inspection of the duct showed that the changed sootblower operation was effective in controlling deposits.

The second significant duct deposition occurred when continuous lime injection operations resumed on April 21, 1993, following a long period of nonoperation. During startup, the lime injection was hampered by frequent plugging of the nozzles due to aged lime in the silo and in the lime slurry preparation pit. A stable injection was finally achieved on May 3, 1993, but other mechanical problems prevented attainment of the injection rates necessary for optimum $\mathrm{SO}_{2}$ removal. Frequent removal and cleaning to unplug the atomizers resulted in several atomizers leaking around the flanges and spray tips. Incorrect gasket selection prevented proper sealing of some of the atomizers, causing leakage and deposits on the atomizer tips.

The above problems were initially noted when the lowest skin temperature decreased from its normal $210^{\circ} \mathrm{F}$ down to $127^{\circ} \mathrm{F}$ (alarm). These problems resulted in wetting of the duct floor with deposits that the rotary sootblowers were not able to break up. In addition, the thermal drain valve on the sootblower system was set too low. This allowed condensate to accumulate and discharge from the retractable sootblowers at the turning vanes each time they were operated. This discharged condensate wet the turning vanes and the particles suspended in the flue gas stream causing wet deposits on the turning vanes. The net result was the formation of duct deposits that were too heavy to be removed by the sootblowers. By the time the operations were smoothed out, the deposits had progressed into the confined zone. To avoid further accelerated growth of these deposits, the lime injection was stopped on May 25, 1993, when it was decided to manually remove the deposits during the next boiler maintenance outage. 
The first step in avoiding problems with duct deposits begins with the timely detection of abnormal operating conditions which lead to deposit formation. At the time operation began on April 21, 1993, after-the-fact 'mapping' of the duct was relied upon as the only means of deposit formation detection. During the first two weeks of operation beginning April 21, through numerous opportunities, engineers and operators learned how to use available information to detect abnormal operating conditions, so that appropriate preventative measures could be applied to control duct deposits. This information includes the inlet slurry or water pressure to each atomizer, the inlet air pressure and air flow rate to each atomizer, and the temperature differential between the low $\mathrm{C}$ section temperature and the average $C$ section temperature.

For example, if the inlet slurry or water feed pressure of one atomizer is higher than that of the rest of the atomizers, it could indicate a plugged nozzle. If the feed pressure to one atomizer is lower than that to the rest of the atomizers, it could indicate a broken spray tip or a decrease in atomizing air pressure. Lower air pressure or air flow rate to one atomizer and not the rest would probably indicate poor slurry atomization from that particular nozzle. In all of the above cases, that particular atomizer would be shut off and inspected.

Finally, when the system is put into service and all atomizers are operating properly, there is a fairly constant temperature differential between the lowest $C$ section temperature and the average $C$ section temperature. If during the course of operation this temperature differential increases (assuming no change in the operation of the boiler), this would indicate a problem with one or more atomizers. The troubleshooting guidelines described above would be used to investigate which nozzle(s) is causing the problem.

In the immediate future, CZD will use the lessons learned from operations just concluded to install and test a redesigned spray tip. This modification is expected to reduce duct deposit formation and improve the $\mathrm{SO}_{2}$ removal efficiency. System operation will also benefit from improved detection techniques, combined with increased skill of the operators at maintaining proper nozzle atomization. In addition, during an accident or upset conditions, lime injection should be suspended if duct deposits build up into the confined zone. 
Future CZD installations will include automated duct deposit detection and nozzle monitoring systems which will allow operators to maintain duct cleanliness. Commercially available, noncontact type level gauges using electromagnetic waves will be adapted to measure duct deposits. Other commercially available devices that measure vibrations will be adapted to provide performance indications of the operating spray nozzles. The level gauges and the vibration devices will be set up as automated monitoring systems to continuously track duct cleanliness and atomizer performance, and notify the operator of any irregularities. In the event that deposits begin to form due to upset conditions, these automated systems will allow for the early detection and control of the deposits.

\subsection{ESP PERFORMANCE}

In general, CZD system operation had a beneficial effect on ESP performance. This was first observed during parametric testing during the period November 1 , 1991 to January 31, 1992 when it was discovered that during the lime slurry in-duct injection, the ESP removal efficiency increased because the stack opacity was lower during injection than it was before and after injection. The explanation for the increase in ESP removal efficiency during the water and lime slurry injection in the flue gas duct is as follows:

- The cooling of the flue gas during the lime slurry injection (from about $300^{\circ} \mathrm{F}$ to $180^{\circ} \mathrm{F}$ ) decreases the flue gas volume and the gas velocity, thereby increasing the flue gas residence time inside the ESP.

- The ash resistivity and that of reacted products (calcium sulfite and sulfate) varies with the temperature. For some ashes, the lower temperature reduces resistivity, allowing a higher electric current that improves ESP performance.

- It is known that the water vapor is a conditioning agent for improving ESP performance.

- It was demonstrated that during lime slurry injection, an agglomeration of fly ash particles with lime and reacted products occurred, creating larger particles that can be more easily removed by the ESP. 
Details on the ESP performance during CZD system operation in November, 1991 are reported below. These results are typical for the entire demonstration program when the ESP was in good working order. The CZD system is in operation in the B duct that is connected with D ESP; the A duct is connected with the C ESP and its data are recorded only for comparison. Operating data for the C ESP and D ESP fields recorded on November 15, 16, and 19, 1991, show much higher electric currents (milliamps) in the D ESP fields than in the C ESP fields. This increase of electric current milliamps in the D ESP fields contributes to the increase of the ESP particulate removal efficiency. Data from these tests are shown in Tables 4-5 through 4-8. Figures 4-20 and 4-21 show the recordings of opacity in B duct for November 15 and 19, respectively.

To confirm that the injected fine atomized lime slurry particles will intercept and impact the fly ash particles, agglomerating both lime and fly ash into larger particles more easily removed by the ESP, samples of solid wastes containing fly ash, CZD reaction products, and unreacted lime were collected during the CZD continuous operation and analyzed by scanning electron micrographs (SEM).

The SEMs show how the fine particles of reaction products and spent lime agglomerate on the larger fly ash spheres, creating even larger particles that are more easily removed by the ESP.

The higher the fly ash concentration in the flue gas, the better the chances are for agglomeration and formation of larger particles that are more easily removed by the ESP. This was demonstrated on May 21, 1993, when the first ESP was deenergized and the concentration of particulates in the flue gas treated by the second ESP increased by over $100 \%$. ESP removal efficiency increased substantially because the opacity increased only slightly, although the total amount of particulates had more than doubled. This theory of impaction and agglomeration also helps explain why the injection of atomized lime slurry into the duct was more effective in decreasing the stack opacity than the injection of atomized water. 
Table 4-7

Lime Slurry Injection in the B Duct on November 15

Followed by Water Injection on November 16

Date and Time

Lime Slurry Injection Rate

Lime Content of Slurry

Boiler Load

Stack Opacity*

Duct Opacity

Inlet Flue Gas Temperature

Date and Time

Water Injection Rate

Boiler Load

Stack Opacity

Duct Opacity

Inlet Flue Gas Temperature
12:50 p.m. on November 15, 1991

$47 \mathrm{gpm}$

$12 \%$

146 MW

$10 \%$

$10.6 \%$

$303^{\circ} \mathrm{F}$

9:30 a.m. on November 16, 1991

$11 \mathrm{gpm}$

$146 \mathrm{MW}$

$14.9 \%$

$18.8 \%$

$303^{\circ} \mathrm{F}$

* Figure 4-20 shows the recording of opacity in B duct for November 15, 1991.

\begin{tabular}{|c|c|c|c|c|c|c|c|c|}
\hline \multicolumn{3}{|c|}{$11 / 16 / 91$} & & & & & & \\
\hline Field & $\mathbf{D}_{1}$ & & \multicolumn{2}{|c|}{$\mathbf{D}_{2}$} & \multicolumn{2}{|c|}{$\mathbf{D}_{3}$} & \multicolumn{2}{|c|}{$\mathbf{D}_{4}$} \\
\hline \multicolumn{2}{|c|}{$\begin{array}{l}\text { Water Injection } \\
11 \mathrm{gpm}\end{array}$} & $\begin{array}{l}\text { Lime Slurry } \\
\text { Injection } \\
12 \% \text { Lime } \\
\text { Concen. } \\
47 \mathrm{gpm}\end{array}$ & $\begin{array}{c}\text { Water } \\
\text { Injection } \\
11 \mathrm{gPm}\end{array}$ & \multirow{3}{*}{ 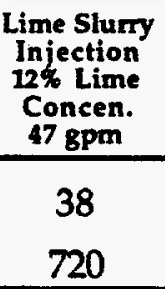 } & \multirow{3}{*}{$\begin{array}{c}\begin{array}{c}\text { Water } \\
\text { Injection } \\
\text { 11 } \mathrm{gPm}\end{array} \\
40 \\
700\end{array}$} & \multirow{3}{*}{$\begin{array}{c}\text { Lime Slurry } \\
\text { Injection } \\
\text { 12\% Lime } \\
\text { Concen. } \\
\text { 47 gpm } \\
36 \\
800\end{array}$} & \multirow{3}{*}{$\begin{array}{c}\begin{array}{c}\text { Water } \\
\text { Injection } \\
11 \text { gpm }\end{array} \\
37 \\
900\end{array}$} & \multirow{3}{*}{$\begin{array}{c}\begin{array}{c}\text { Lime Slumy } \\
\text { Injection } \\
\text { 120 Lime } \\
\text { Concen. } \\
\text { 47 gpm }\end{array} \\
31 \\
850\end{array}$} \\
\hline$v_{D C}$ & 33 & 36 & 37 & & & & & \\
\hline$A_{D C}$ & 820 & 830 & 400 & & & & & \\
\hline $\mathbf{v}_{\mathrm{AC}}$ & 300 & 330 & 340 & 350 & 350 & 330 & 380 & 320 \\
\hline $\mathbf{A}_{\mathbf{A C}}$ & 115 & 115 & 80 & 115 & 90 & 120 & 125 & 125 \\
\hline$v_{D C} \times A_{D C}$ & 27,060 & 29,880 & 14,800 & 27,360 & 28,000 & 28,800 & 33,300 & 26,350 \\
\hline$v_{A C} \times A_{A C}$ & 34,500 & 37,950 & 27,200 & 40,250 & 31,500 & 39,600 & 47,500 & 40,000 \\
\hline Field & $C_{1}$ & & \multicolumn{2}{|c|}{$\mathbf{C}_{2}$} & \multicolumn{2}{|c|}{$C_{3}$} & \multicolumn{2}{|c|}{$\mathrm{C}_{4}$} \\
\hline$v_{D C}$ & - & - & 38 & 38 & 38 & 40 & 47 & 47 \\
\hline$A_{D C}$ & 500 & 500 & 500 & 660 & 500 & 600 & 800 & 850 \\
\hline $\mathbf{v}_{\text {AC }}$ & 330 & 330 & 330 & 340 & 320 & 300 & 340 & 350 \\
\hline $\mathbf{A}_{A C}$ & 70 & 72 & 70 & 85 & 75 & 90 & 125 & 125 \\
\hline$V_{D C} \times A_{D C}$ & & & 19,000 & 25,080 & 19,000 & 24,000 & 37,600 & 39,950 \\
\hline$v_{A C} \times A_{A C}$ & 23,100 & 23,760 & 23,100 & 28,900 & 24,000 & 27,000 & 42,500 & 43,750 \\
\hline
\end{tabular}

$V_{D C}=$ Direct current voltage

$A D C=$ Direct current amperage

$\mathrm{V}_{\mathrm{AC}}=$ Alternating current voltage

$\mathrm{A}_{\mathrm{AC}}=$ Alternating current amperage 
Table 4-8

Data Recorded With No Injection in the B Duct at 7:30 a.m. and 9:30 a.m. on November 19

Date and Time

Boiler Load

Stack Opacity

Duct Opacity

Inlet Flue Gas Temperature

Date and Time

Boiler Load

Stack Opacity

Duct Opacity

Inlet Flue Gas Temperature
7:30 a.m. on November 19, 1991

$145 \mathrm{MW}$

$10 \%$

$17.4 \%$

$301^{\circ} \mathrm{F}$

9:30 a.m. on November 20, 1991

$147 \mathrm{MW}$

$10 \%$

$9.6 \%$

$301^{\circ} \mathrm{F}$

\begin{tabular}{|c|c|c|c|c|c|c|c|}
\hline \multicolumn{2}{|c|}{ Field $\quad D_{1}$} & \multicolumn{2}{|c|}{$D_{2}$} & \multicolumn{2}{|c|}{$D_{3}$} & \multicolumn{2}{|c|}{$\mathbf{D}_{4}$} \\
\hline $\begin{array}{c}\text { No } \\
\text { Injection } \\
7: 30 \text { a.m. }\end{array}$ & $\begin{array}{c}\text { No } \\
\text { Injection } \\
9: 30 \text { a.m. }\end{array}$ & $\begin{array}{c}\text { No } \\
\text { Injection } \\
\text { 7:30 a.m. }\end{array}$ & $\begin{array}{c}\text { No } \\
\text { Injection } \\
\text { 9:30 a.m. }\end{array}$ & $\begin{array}{c}\text { No } \\
\text { Injection } \\
7: 30 \text { a.m. }\end{array}$ & $\begin{array}{c}\text { No } \\
\text { Injection } \\
\text { 9:30 a.m. }\end{array}$ & $\begin{array}{c}\text { No } \\
\text { Injection } \\
\text { 7:30 a.m. }\end{array}$ & $\begin{array}{c}\text { No } \\
\text { Injection } \\
9: 30 \text { a.m. }\end{array}$ \\
\hline $\begin{array}{lr}v_{D C} & 34 \\
A_{D C} & 820 \\
\end{array}$ & $\begin{array}{r}36 \\
820 \\
\end{array}$ & $\begin{array}{l}37 \\
400 \\
\end{array}$ & $\begin{array}{r}36 \\
400 \\
\end{array}$ & $\begin{array}{l}38 \\
600 \\
\end{array}$ & $\begin{array}{r}38 \\
500 \\
\end{array}$ & $\begin{array}{l}36 \\
850 \\
\end{array}$ & $\begin{array}{r}35 \\
800 \\
\end{array}$ \\
\hline $\begin{array}{ll}\mathrm{v}_{\mathrm{AC}} & 350 \\
\mathrm{~A}_{\mathrm{AC}} & 115 \\
\end{array}$ & $\begin{array}{l}320 \\
115 \\
\end{array}$ & $\begin{array}{l}330 \\
80 \\
\end{array}$ & $\begin{array}{r}320 \\
75 \\
\end{array}$ & $\begin{array}{l}340 \\
90 \\
\end{array}$ & $\begin{array}{r}330 \\
85 \\
\end{array}$ & $\begin{array}{l}360 \\
115 \\
\end{array}$ & $\begin{array}{l}360 \\
115 \\
\end{array}$ \\
\hline $\begin{array}{l}v_{A C} \times A_{A C} \\
v_{D C} \times A_{D C}\end{array}$ & $\begin{array}{l}36,800 \\
29,520 \\
\end{array}$ & $\begin{array}{l}26,400 \\
14,800 \\
\end{array}$ & $\begin{array}{l}24,000 \\
14,400 \\
\end{array}$ & $\begin{array}{l}30,600 \\
22,800 \\
\end{array}$ & $\begin{array}{l}28,050 \\
12,000 \\
\end{array}$ & $\begin{array}{l}41,400 \\
30,600\end{array}$ & $\begin{array}{l}41,400 \\
28,000 \\
\end{array}$ \\
\hline Field & $C_{1}$ & \multicolumn{2}{|c|}{$\mathrm{C}_{2}$} & \multicolumn{2}{|c|}{$C_{3}$} & \multicolumn{2}{|c|}{$C_{4}$} \\
\hline $\begin{array}{c}\text { No } \\
\text { Injection } \\
\text { 7:30 a.m. }\end{array}$ & $\begin{array}{c}\text { No } \\
\text { Injection } \\
9: 30 \text { a.m. }\end{array}$ & $\begin{array}{c}\text { No } \\
\text { Injection } \\
7: 30 \text { a.m. }\end{array}$ & $\begin{array}{c}\text { No } \\
\text { Injection } \\
9: 30 \text { a.m. }\end{array}$ & $\begin{array}{c}\text { No } \\
\text { Injection } \\
7: 30 \text { a.m. }\end{array}$ & $\begin{array}{c}\text { No } \\
\text { Injection } \\
9: 30 \text { a.m. }\end{array}$ & $\begin{array}{c}\text { No } \\
\text { Injection } \\
\text { 7:30 a.m. }\end{array}$ & $\begin{array}{c}\text { No } \\
\text { Injection } \\
9: 30 \text { a.m. }\end{array}$ \\
\hline $\begin{array}{ll}v_{D C} & - \\
A_{D C} & 400 \\
\end{array}$ & 500 & $\begin{array}{l}37 \\
500 \\
\end{array}$ & $\begin{array}{r}36 \\
500 \\
\end{array}$ & $\begin{array}{r}40 \\
500 \\
\end{array}$ & $\begin{array}{r}38 \\
600 \\
\end{array}$ & $\begin{array}{r}48 \\
850 \\
\end{array}$ & $\begin{array}{r}48 \\
850 \\
\end{array}$ \\
\hline $\begin{array}{rr}v_{A_{A C}} & 290 \\
A_{A C} & 60 \\
\end{array}$ & $\begin{array}{r}340 \\
60 \\
\end{array}$ & $\begin{array}{l}350 \\
80 \\
\end{array}$ & $\begin{array}{r}330 \\
80 \\
\end{array}$ & $\begin{array}{l}300 \\
75 \\
\end{array}$ & $\begin{array}{r}300 \\
75 \\
\end{array}$ & $\begin{array}{l}350 \\
130 \\
\end{array}$ & $\begin{array}{l}350 \\
125 \\
\end{array}$ \\
\hline $\begin{array}{r}\mathrm{V}_{\mathrm{A} C} \times \mathrm{A}_{\mathrm{A}} \mathrm{C} \\
17,400\end{array}$ & 20,400 & 28,000 & 26,400 & 22,500 & 22,500 & 45,500 & 43,750 \\
\hline$V_{D C} \times A_{D C}$ & - & 18,500 & 18,000 & 20,000 & 22,800 & 40,800 & 40,800 \\
\hline
\end{tabular}

$V_{D C}=$ Direct current voltage

$A D C=$ Direct current amperage

$V_{A C}=$ Alternating current voltage

$A_{A C}=$ Alternating current amperage 
Table 4-9

Lime Slurry Injection in the B Duct on November 19

Date and Time

Lime Slurry Injection Rate

Lime Content of Slurry

Boiler Load

Stack Opacity

Duct Opacity
10:05 a.m. - 4:00 p.m. on November 19, 1991

$32.5 \mathrm{gpm}$

$12.5 \%$

145 MW

$10.1 \%$

$15.3 \%$

\begin{tabular}{|c|c|c|c|c|}
\hline Field & & $D_{2}$ & $D_{3}$ & $\mathrm{D}_{4}$ \\
\hline $\begin{array}{l}V_{D C} \\
\text { ADC } \\
\text { Sparking } \\
\text { Rates/min }\end{array}$ & $\begin{array}{r}37.17 \\
851 \\
23.41 \\
\end{array}$ & $\begin{array}{r}39.21 \\
449 \\
\\
14.94 \\
\end{array}$ & $\begin{array}{r}38.4 \\
523 \\
17.12 \\
\end{array}$ & $\begin{array}{r}36.29 \\
770 \\
\\
11.62 \\
\end{array}$ \\
\hline Field & & $C_{2}$ & $C_{3}$ & $\mathrm{C}_{4}$ \\
\hline $\begin{array}{l}\mathrm{V}_{D C} \\
\text { ADC } \\
\text { Sparking } \\
\text { Rates/min }\end{array}$ & $\begin{array}{r}39.23 \\
392 \\
18.66 \\
\end{array}$ & $\begin{array}{r}36.46 \\
449 \\
12.65 \\
\end{array}$ & $\begin{array}{r}42 \\
493 \\
15.85 \\
\end{array}$ & $\begin{array}{r}43.52 \\
863 \\
2.889 \\
\end{array}$ \\
\hline
\end{tabular}

$V_{D C}=$ Direct current voltage

$A D C=$ Direct current amperage

$\mathrm{V}_{\mathrm{AC}}=$ Alternating current voltage

$\mathrm{A}_{\mathrm{AC}}=$ Alternating current amperage 
Water Injection in the B Duct on November 19

After Completion of Lime Injection

Date and Time

Water Injection Rate

Boiler Load

Stack Opacity

Duct Opacity
4:45 p.m. on November 19, 1991

$15 \mathrm{gpm}$

$145 \mathrm{MW}$

$8.8 \%$

$11 \%$

\begin{tabular}{|c|c|c|c|c|}
\hline \multirow{2}{*}{\multicolumn{2}{|c|}{$\begin{array}{c}\text { Field } \quad \mathrm{D}_{\mathbf{1}} \\
\begin{array}{c}\text { Water Injection } \\
\text { 4:45 p.m. }\end{array} \\
\end{array}$}} & \multirow{3}{*}{$\begin{array}{c}\mathrm{D}_{2} \\
\begin{array}{c}\text { Water Injection } \\
4: 45 \text { p.m. }\end{array} \\
39 \\
610 \\
\end{array}$} & \multirow{3}{*}{$\begin{array}{c}\mathrm{D}_{\mathbf{3}} \\
\begin{array}{c}\text { Water Injection } \\
4: 45 \text { p.m. }\end{array} \\
42 \\
850 \\
\end{array}$} & \multirow{3}{*}{$\begin{array}{c}\mathrm{D}_{\mathbf{4}} \\
\begin{array}{c}\text { Water Injection } \\
\text { 4:45 p.m. }\end{array} \\
39 \\
1,000 \\
\end{array}$} \\
\hline & & & & \\
\hline $\begin{array}{l}V_{D C} \\
A_{D C}\end{array}$ & $\begin{array}{r}34 \\
820\end{array}$ & & & \\
\hline $\begin{array}{l}V_{A C} \\
A_{A C}\end{array}$ & $\begin{array}{r}37.17 \\
851\end{array}$ & $\begin{array}{l}350 \\
100\end{array}$ & $\begin{array}{l}370 \\
120\end{array}$ & $\begin{array}{l}375 \\
135\end{array}$ \\
\hline $\begin{array}{l}V_{A C} \times A \\
V_{D C} \times A\end{array}$ & $\begin{array}{l}36,225 \\
\text { X } \\
\text { C }\end{array}$ & $\begin{array}{l}35,000 \\
23,790\end{array}$ & $\begin{array}{l}44,400 \\
35,700\end{array}$ & $\begin{array}{l}50,625 \\
39,000\end{array}$ \\
\hline Field & $C_{1}$ & $\mathrm{C}_{2}$ & $\mathrm{C}_{3}$ & $\mathrm{C}_{4}$ \\
\hline $\begin{array}{l}V_{D C} \\
A_{D C}\end{array}$ & 500 & $\begin{array}{r}36 \\
540\end{array}$ & $\begin{array}{r}40 \\
550 \\
\end{array}$ & $\begin{array}{r}48 \\
850\end{array}$ \\
\hline $\begin{array}{l}V_{A C} \\
A_{A C}\end{array}$ & $\begin{array}{r}340 \\
65\end{array}$ & $\begin{array}{r}335 \\
80\end{array}$ & $\begin{array}{r}300 \\
80\end{array}$ & $\begin{array}{l}350 \\
130\end{array}$ \\
\hline $\begin{array}{l}V_{A C} \times A \\
V_{D C} \times A\end{array}$ & $\begin{array}{cc}\text { AC } & 22,100 \\
D C & -\end{array}$ & $\begin{array}{l}26,800 \\
19,440\end{array}$ & $\begin{array}{l}24,000 \\
22,000\end{array}$ & $\begin{array}{l}45,500 \\
40,800\end{array}$ \\
\hline
\end{tabular}

$V_{D C}=$ Direct current voltage

ADC $=$ Direct current amperage

$V_{A C}=$ Altermating current voltage

$A_{A C}=$ Alternating current amperage 


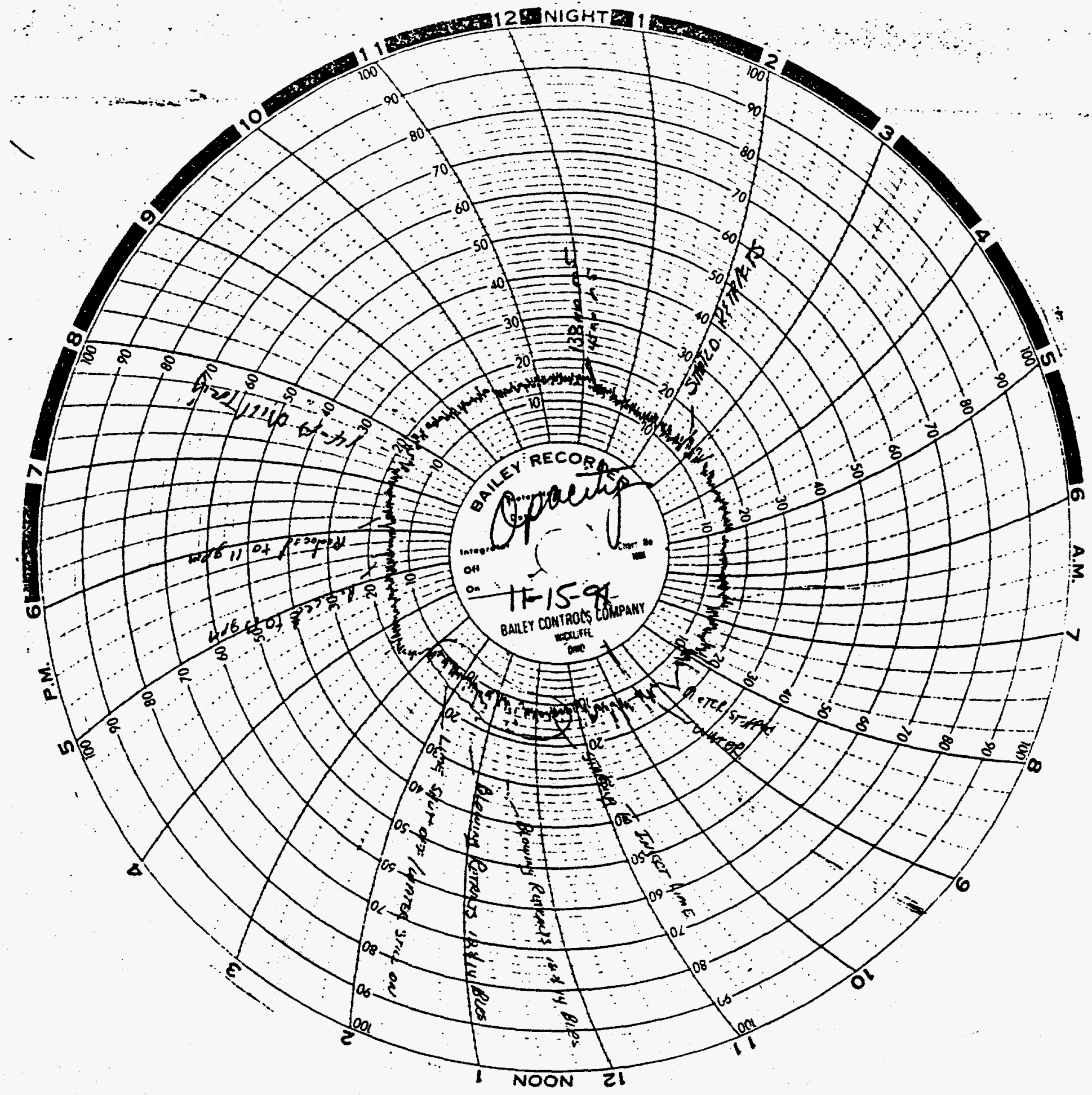

Figure 4-20 Recording of Opacity on November 15, 1991 


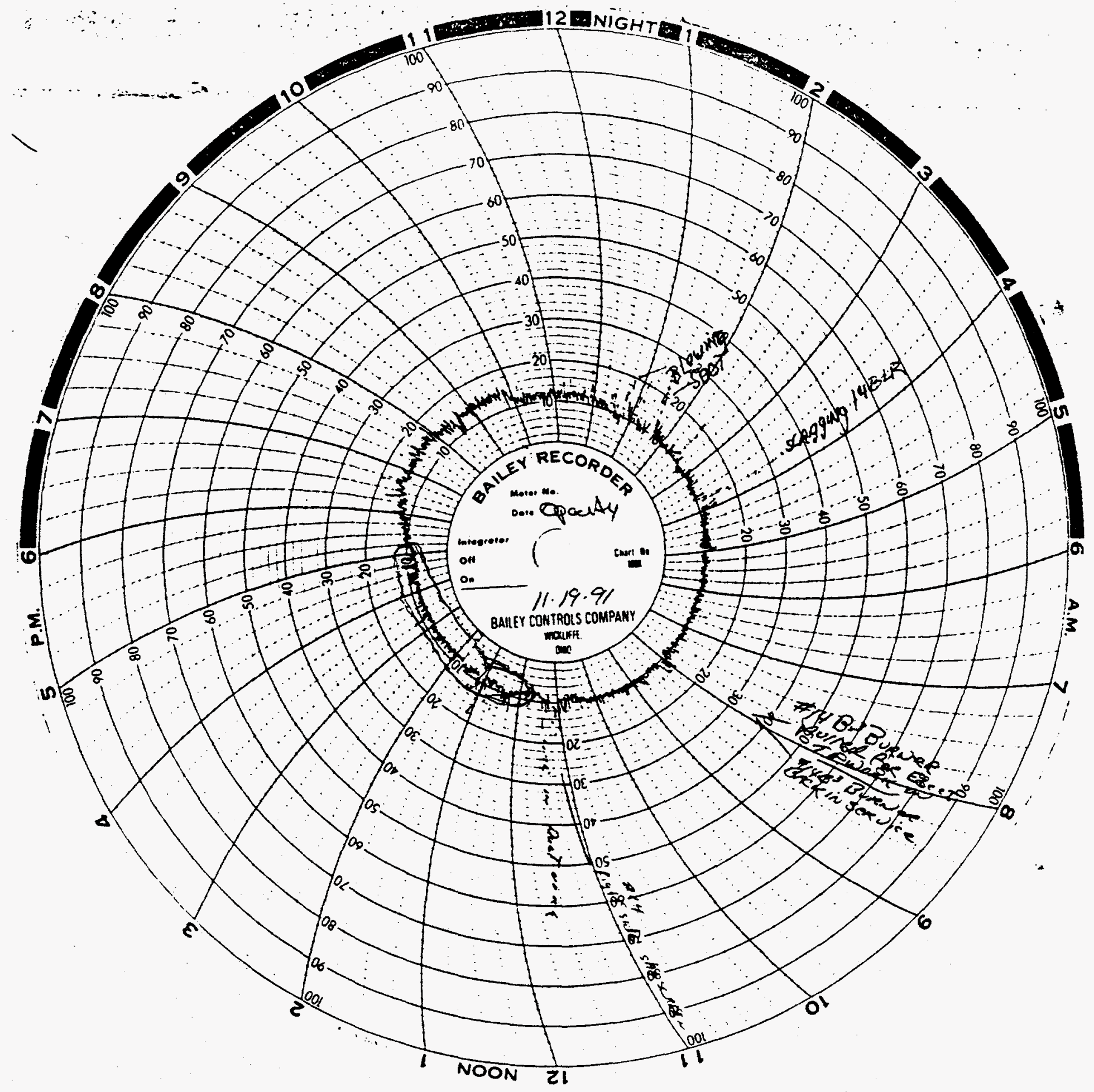

Figure 4-21 Recording of Opacity on November 19, 1991 
In a few cases, a higher opacity was observed during the lime slurry injection. Sometimes this was caused by mechanical or electrical failure of the Buell ESP, such as a broken ground wire connection or broken discharge wires that created a short circuit in the ESP. Once these problems were diagnosed and corrected, they disappeared.

At other times when the problem persisted, an ESP specialist, Mr. Ted Schafebook of General Electric Environmental Systems, was consulted. Mr. Schafebook has been involved with Buell's ESP from the time it was installed at Seward Station. He visited the station in October and December 1992 and gathered precipitator performance data related to the CZD operation. In January 1993, he also inspected the ESP, its collecting plates, and its discharge wires when the unit was down. Mr. Schafebook made the following observations:

- There is a net positive effect of lime slurry injection into the duct as long as all the solids are dried before encountering the ESP. The combined positive effects of increased humidity and decreased temperature on decreasing cake resistivity should more than offset the negative effect of lime addition to the cake, which tends to increase the cake resistivity. When lime slurry injection is terminated, humidity decreases and temperature increases almost immediately while it may take some hours for the lime-entrained cake to be rapped off the plates. The result is an immediate worsening in precipitator performance, followed by a gradual improvement in performance.

- Once lime slurry or water in the liquid phase begins to pass through the ESP, the cake will begin to cling to the plates so persistently that no amount of rapping or time will remove it. At some point, the degradation in performance will be so great that continued operation is only possible by reducing the gas temperature and increasing the gas humidity (water injection does both at the same time). It is probable that in this operating condition, any deviation from humidity, temperature, or cake consistency or layering, will result in an immediate negative effect on the ESP performance. 
- Operating the ESP with abnormally low flue gas temperatures below the acid dew point could cause an increase in the amount of cake, which would be difficult to remove by rapping. If this occurs, a complete wash-off of the precipitator plates is recommended. Otherwise, a return to normal higher flue gas temperatures could lead to worse ESP performance due to drying out of the cake.

- Future operation of the CZD system should avoid operation that would result in wet lime entering the precipitator (whether planned or upset). If wet lime enters the precipitator, the resultant cake will probably not be removable by any amount of rapping and will require a wash-off of the plates.

\subsection{AUTOMATED CONTINUOUS OPERATION}

Once the CZD system is set in operation, monitoring the condition of equipment and the changing of system setpoints can occur remotely at the control room. Remote monitoring and control of the CZD process from the control room are provided by the existing combustion management control system (MCS) and are supplemented by the process control view station. Additional plant and process operating information is available from Leeds \& Northrup (L\&N) recorders located in the ESP control room and in the B duct shack.

On automatic control, the injection rate (lime slurry or water) is automatically regulated to maintain the lowest temperature in Section $C$ at a chosen setpoint. As temperature or flow rate of the flue gas to the CZD system varies, the automatic controls vary the injection rate to maintain this set temperature.

The automatic controls have provided excellent operability and availability during the CZD system continuous demonstration period. For example, Figure 4-22 shows the CZD performance summary for the period October 17 to November 16, 1992 with online availability for 744 hours (100\%). It is remarkable that the automated and integrated CZD systems were online $100 \%$ of the time during this one-month period. 
ON-LINE AVAILABILITY 744 HOURS (100\%)

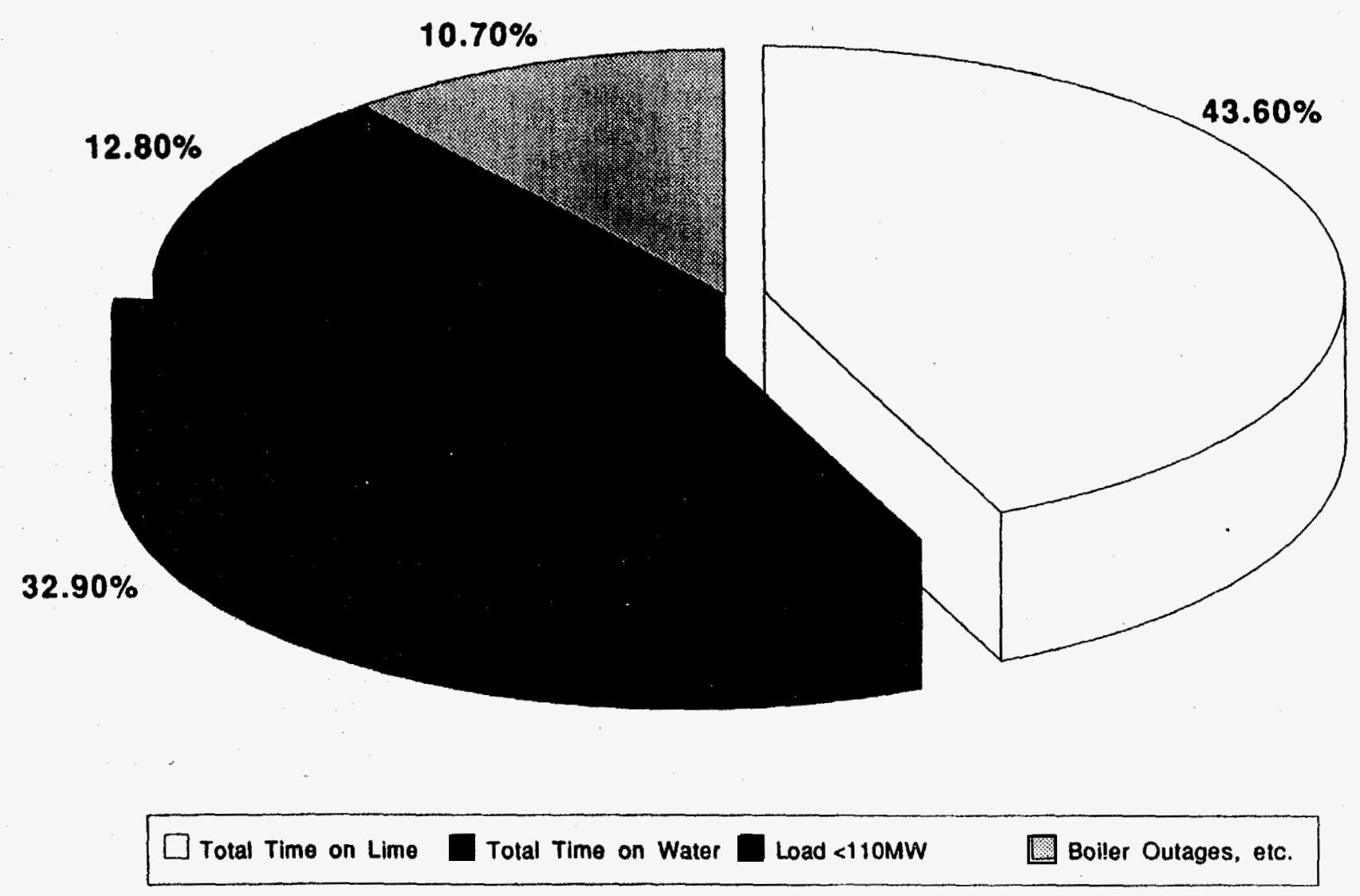

Figure 4-22 CZD Performance Summary - October 17 to November 16, 1992 


\section{Section 5}

\section{CRITICAL COMPONENT FAILURE REPORT}

\subsection{LIME SLURRY PREPARATION SYSTEM}

\subsubsection{Failure Identification: Drive Belts for Lime Silo Blower}

Description of Failure

During normal operation of the blower, two out of the three drive belts wore through and snapped. These belts drive the compressor that supplies the sparging air for the lime in the lime silo. Without this air, the system had to be temporarily shut down as no lime could be extracted from the silo.

\section{Disposition of Failed Item}

All three belts were replaced with a new, matched set of belts, and the system was returned to service.

\section{Action Taken}

These belts were added to the plant's preventative maintenance list.

\section{Remarks}

This was the first time that the belts were replaced since the installation of the silo and blower system. There were no additional failures during the demonstration program.

\subsubsection{Failure Identification: Lime Silo Screw Conveyor}

\section{Description of Failure}

The feed screw for the conveyor was scraping and banging the sides of the trough. The screw itself is approximately 12 feet long and comprises two 6-foot sections, coupled in the middle. The wooden bearing that supports the coupled area of the screw had worn away causing the screw to sag in the middle. Consequently, the blades on the screw became bent and damaged. Without this screw, no lime slurry could be produced because there was no way for the lime to be transferred from the silo to the sump. 


\section{Disposition of Failed Item}

The entire screw assembly, including the wooden bearing, was replaced and the system was returned to service.

Action Taken

The wooden bearing has been added to the plant's preventative maintenance list.

Remarks

No other problems with this system have occurred since the screw assembly was replaced.

\subsubsection{Failure Identification: Pipe Elbow on Recirculation Line}

\section{Description of Failure}

A pinhole size leak developed in a 45 degree elbow on the recirculation line in the slurry preparation area. The cause of the leak was the abrasive slurry (prior to being degritted) eroding through the wall of the Schedule 40 pipe elbow.

\section{Disposition of Failed Item/Action Taken}

The Schedule 40 pipe elbow was replaced with a similar elbow of greater wall thickness (Schedule 80).

\section{Remarks}

No further problems have been noted. In the future, all elbows will be made from Schedule 80 (or greater) piping. Also, the use of fiberglass reinforced plastic (FRP) may prevent the premature wearing of the elbows in the slurry lines.

\subsection{LIME SLURRY STORAGE AND HANDLING SYSTEM}

\subsubsection{Failure Identification: Lime Slurry Transfer Pump}

\section{Description of Failure}

The wear plate and stuffing box for slurry transfer pump P-102B developed a small crack during normal operations. This crack allowed lime slurry to leak through the wear plate/stuffing box and created a pinhole leak in the pump 
casing. The leak was not discovered until the slurry was observed leaking out of the hole in the pump casing.

Disposition of Failed Item/Action Taken

The wear plate and stuffing box were replaced by the manufacturer, Lawrence Pumps. The manufacturer determined that the failure was attributable to a factory defect. The pinhole in the pump's casing was patched.

\section{Remarks}

There were no additional failures during the demonstration program.

\subsubsection{Failure Identification: Gum-Rubber Sleeve for Control Valves FCV-10 and LCV-25}

\section{Description of Failure}

The gum-rubber sleeve for control valve FCV-10 typically lasted 4 to 6 months before wearing out during the course of normal operations. The sleeve for control valve LCV-25 lasted approximately one year before needing replacement. This sleeve is used in a pinch-type valve application and therefore is in constant contact with flowing lime slurry and experiences pressure drops of up to 50 to 60 psi. Once the wall of the sleeve has been worn through, the valve responds very erratically and cannot be relied upon for proper flow or level control.

\section{Disposition of Failed Item}

The damaged gum rubber sleeves were removed and replaced with new sleeves.

\section{Action Taken}

The gum-rubber sleeves have been added to the plant's preventative maintenance list and are routinely checked by the system operators.

\section{Remarks}

The sleeve for valve LCU-25 had no additional failure during the demonstration program. The sleeve for control valve FCV-10 has had to be replaced two times within the past year. The downtime associated with this changeout is costly to the project because the system must be taken offline in order to make the change. 
We are therefore looking into the use of ceramic-type valves for our flow control needs in future installations.

\subsection{SOOTBLOWING SYSTEM - ROTARY AND RETRACTABLE SOOTBLOWERS}

The project has encountered numerous problems with the Copes-Vulcan rotary and retractable sootblowers. Most of the problems can be attributed to oversights in their design for this application and to defects during the manufacturing process. The original parts for these blowers did not come from the usual manufacturing plant, which probably contributed to many of the problems. Copes-Vulcan has worked very closely with us in resolving all these problems.

As there were many failures associated with these blowers, only the major ones are discussed below.

\subsubsection{Failure Identification: Limit Switches for Retractable Sootblowers}

\section{Description of Failure}

Water was constantly getting into the switches and destroying the contacts. This water intrusion was initially thought to be the result of loose conduit fittings. However, once the conduit fittings were tightened and the switch cover gaskets were checked for proper sealing, water continued to accumulate in the switches. It was concluded that the moisture resulted from condensation migrating from the motor starter cabinet down through the cable insulation to the limit switch.

\section{Disposition of Failed Item/Action Taken}

To correct this problem, new NEMA $4 \mathrm{X}$ hermetically sealed limit switches were installed with pre-wired inlet cables. The cables were run in a way to ensure that no moisture could migrate into the wires. Also, the gaskets on the motor starter cabinets were replaced to prevent any condensation from getting into the cabinets. Desiccant was also placed in the cabinets for added protection. 


\section{Remarks}

It was the failure of the original type limit switches that led to a majority of the other problems encountered with the sootblowers. Since their replacement, there were no additional failures of these switches during the demonstration program. The replacement type switch (NEMA $4 X$, hermetically sealed) should be used on future installations.

\subsubsection{Failure Identification: Sootblower Mechanical Stops}

\section{Description of Failure}

Each of the four retractable sootblowers has a top and bottom mechanical stop in order to prevent the carriage from traveling beyond its intended range of motion. On one occasion, the failure of the bottom limit switch allowed the carriage to hit the bottom mechanical stop. It broke the stop and consequently destroyed the traveling carriage and steam lance.

\section{Disposition of Failed Item/Action Taken}

The mechanical stop was initially made out of 7/8-inch square bar. Copes has said that the problem with the bar may have been the extra weight of the lance and traveling carriage with the blower in the vertical position, as is the case at Seward. The stops and their mounting bolts were redesigned by Copes and installed on each of the blowers.

\section{Remarks:}

No further problems with the stops have been noted.

\subsubsection{Failure Identification: Sootblower Drive Chain}

\section{Description of Failure}

The drive chain for three of the four retractable blowers has broken numerous times. The failure of the chains was directly related to the limit switch failures, allowing the unit to drive into the mechanical stop. Sometimes the chain would break immediately; at other times breakage would occur later in the cycle, sending the carriage and lance assembly crashing downward. 


\section{Disposition of Failed Item/Action Taken}

Initially, the chain breakage problem was associated with the failure of the limit switches, and the chain was replaced with stronger, pre-stressed chain.

Subsequently, when some of these stronger chains broke, the limit switch problem was discovered.

\section{Remarks}

Since the limit switches were replaced, no additional chain failures have occurred.

\subsubsection{Failure Identification: Traveling Carriage}

\section{Description of Failure}

Each retractable blower has a traveling carriage that guides the stream lance into and out of the duct. The traveling carriage also provides a means for the steam lance to rotate $360^{\circ}$ as it enters and exits the duct. This carriage was destroyed along with the power pack that drives the carriage when the limit switches failed. The sootblower had to be taken out of service.

Disposition of Failed Item/Action Taken

The carriage and power pack assembly was all replaced by Copes-Vulcan.

\section{Remarks}

There were no additional carriage failures during the demonstration program.

\subsubsection{Failure Identification: Steam Valves for Rotary Sootblowers}

\section{Description of Failure}

All 10 steam valves for the 10 rotary sootblowers have had to be replaced since their original installation. The problem was that the valve would stick in the open position and could not be closed. With the valve stuck open, the system could never be fully pressurized, thus limiting the effectiveness of the system. Also, with the steam valve always open, steam was alsways being introduced into the duct, condensing out, and creating undesirable conditions inside the duct. 
The failure of the valves is attributable to both the poor quality of the original part (manufactured at a plant not typically used for such work) and possibly the introduction of ash deposits into the valve as a result of an upset condition of the boiler. It is hard to believe that the sootblowers could not accept a normal plant upset condition without being damaged in such a way as to require repair to internal valving.

\section{Disposition of Failed Item/Action Taken}

The damaged valves were all cleaned and reseated, although a few of them had irreparable damage and had to be replaced altogether. The manufacturer then recommended that forced air (seal air) be added to the blowers to prevent any ash deposits from accumulating inside the sootblowers. Since these modifications were made, only routine maintenance, such as tightening or replace packing, has been required, and the blowers have been operating satisfactorily.

\section{Remarks}

There were no additional problems with these valves since their replacement.

\subsubsection{Failure Identification: Air/Steam Check Valves for Rotary Sootblowers}

\section{Description of Failure}

The check valves in the air supply line for the seal air port experienced repeated failure. When these valves failed, ash filled the seal of the sootblower, preventing the rotation of the blower and making it necessary to remove the sootblower from the duct for cleaning and repacking. Also, the introduction of steam in the air line destroyed the air line filter and pressure regulator on each affected line.

\section{Disposition of Failed Item/Action Taken}

All the affected check valves were either cleaned or replaced. The manufacturer attributed the failure of these valves to the one-time upset condition in the duct (when the duct pressure went positive for a brief instance), but the quality of the original part was also suspect. Since the valves have been cleaned/replaced, no further instances of failure have been noted. 
Remarks

There were no additional problems with these valves during the demonstration program.

\subsection{LEEDS \& NORTHRUP (L\&N) CHART RECORDERS}

\subsubsection{Failure Identification: Chart Recorders}

\section{Description of Failure}

Major problems with the chart recorders were encountered during the entire period of their use. They were never reliable and would constantly have to be fiddled with or adjusted to make them work properly. Because of their failure, hours and sometimes days of valuable data were lost. The recorders also complicated the CZD system operation because they often failed to update the process information required for system operations. They would neither send nor receive signals to and from the control room.

The failure of the communications system was attributed to a combination of causes: the recorders themselves; the wiring linking the recorders with the Bailey Net 90 Control System and the other recorders in the system; and the custom communications software used for communicating between the L\&N recorders and the Bailey Control System. The trouble with the recorders was their failure to receive and transmit information when required. The major problem with the communication lines was the large amount of noise and interference generated by the R-C ESP, along with other plant equipment, that disrupted the signal. Finally, the software never performed as expected.

\section{Disposition of Failed Item}

The system was substantially improved by replacing the wiring between the recorders themselves and between the recorders and the Bailey in the control room. Fiberoptic cable was used to replace the wiring between the recorders and the control room. This type of cable is unaffected by electrical noise and interference. In addition, the recorders are now only used as "slaves" (for display only). They are no longer relied upon to transmit information and are also no longer used to perform basic process calculations. 


\section{Action Taken}

The recorders are now used only to display plant and process information. They are not used to collect or transmit data or to perform any calculations.

\section{Remarks}

Since these changes were made, the recorders have performed well and no problems have been noted. Since future installations will use fiberoptic communications, the use of this type of recorder would be acceptable.

\subsection{CONTINUOUS EMISSIONS MONITORING SYSTEM (CEMS)}

\subsubsection{Failure Identification: Lear Siegler In Situ Monitors}

\section{Description of Failure}

After the B Duct inlet and outlet $\mathrm{SO}_{2}, \mathrm{NO}$, and $\mathrm{O}_{2}$ monitors began operation in October 1991, several problems were discovered using this type of system with the CZD process:

- Reducing the flue gas temperature (by injecting lime slurry into the B Duct) adversely affected the operation of the outlet $\mathrm{SO}_{2}$ and $\mathrm{NO}$ monitors.

- Reducing the concentrations of $\mathrm{SO}_{2}$ in the flue gas interfered with the measurement of $\mathrm{NO}$ at the outlet $\mathrm{NO}$ monitor.

- The oxygen monitors at the inlet and outlet of the B Duct exhibited problems with calibration.

- The inlet NO monitor values increased when water was injected into the B Duct.

\section{Disposition of Failed Item/Action Taken}

Based on a recommendation from Penelec's Environmental Group, the system was substantially improved by replacing the Lear Siegler In Situ Monitoring System with a dilution probe type monitoring system. This system measured $\mathrm{SO}_{2}, \mathrm{NO}_{\mathrm{x}}$ and $\mathrm{CO}_{2}$ (instead of $\mathrm{O}_{2}$ ). The advantages of this type of system are high reliability, low maintenance and good accuracy. These systems were already tested and certified downstream of wet limestone scrubbers, verifying their ability to operate in a wet, cooled environment similar to the CZD outlet 
location. In addition, the measurements of $\mathrm{SO}_{2}, \mathrm{NO}_{x}$, and $\mathrm{CO}_{2}$ occur independently so interference does not occur.

\section{Remarks}

Since the dilution probe type monitoring system was installed, reliable measurements of $\mathrm{SO}_{2}$ and $\mathrm{CO}_{2}$ have been obtained. NOx measurements were questionable and these values were not reported. Additional investigation into a suitable $\mathrm{NO}_{\mathrm{x}}$ analyzer for the CZD system is required. 


\section{RELIABILITY, AVAILABILITY AND MAINTAINABILITY ANALYSIS OF MAJOR EQUIPMENT}

\subsection{ATOMIZING SYSTEM}

\subsubsection{Plugging of the Atomizers}

Often, when starting the CZD system after a few days of inactivity, the operators experienced plugging of the lime slurry connections (feeders) to the atomizers.

Plugging of an individual atomizer's lime slurry connections results in a reduced overall lime slurry injection rate, an uneven dispersion of atomized slurry into the flue gas, uneven flue gas cooling, and reduced $\mathrm{SO}_{2}$ removal, all of which are apparent from the monitored data.

All the lime feeders were provided with isolating valves and pressure gauges. The plugged feeders were recognized as having higher-than-normal pressure and lacking vibrations. Removing the affected atomizer from the duct and then stripping revealed that the lime feeder plugging originates at the small orifice through which the lime slurry enters the atomizer.

It was postulated that when the CZD system is reactivated after a few days of inactivity, the lime slurry washes off some lime scale from the equipment wall that in turn blocks the atomizer slurry inlet orifices and plugs the lime feeders.

This problem was remedied by recirculating the feed slurry through the vibrating screen for several hours prior to its injection into the atomizers.

To help avoid plugging the atomizer feeders in the future, care must be taken to ensure that the entire slurry piping system is properly cleaned and flushed prior to periods of inactivity lasting more than a day. This flushing combined with recirculation through the vibrating screen prior to startup will minimize plugging problems. 


\subsubsection{Atomizer Tip Deposits}

During continuous testing, Bechtel test engineers observed deposits on the duct floor and the turning vanes. These deposits required manual removal during unscheduled boiler shutdowns and on some occasions resulted in discontinuing the lime injection until they were removed.

It was postulated that the slurry atomization was inadequate to produce entrainment of the lime droplets in the flue gas. Large drops fell out of the flue gas, forming floor deposits. Smaller drops that remained entrained in the flue gas were too large for complete evaporation of their water content. These wet particles impinged on and stuck to the turning vanes.

The performance of the atomizers was tested on water outside the duct at the test stand on the top of the lime feed tanks. At the test stand, the atomization of water resulted in the production of airborne mist which drifted away in the wind without precipitating any water.

Observation of the atomizers operating on the lime slurry inside the duct revealed rapid formation of deposits on the external atomizer tips. It was postulated that the atomized slurry discharged from the atomizer tip orifices agglomerated on these deposits, forming large droplets that caused the duct deposits.

When these atomizers were again tested on the test stand outdoors, their tips became wet with large water droplets forming on them. It was thought that, when wet, the tips may catch fly ash from the flue gas. Several tip shields were tested in an attempt to screen fly ash from the atomizer tips. None of the shields worked. Finally the tip design was modified using a proprietary design. The special tip was then tested in the duct on the lime slurry without forming deposits. All atomizers will be equipped with these proprietary design tips in forthcoming tests.

\subsection{SOOTBLOWER SYSTEM LIMITATIONS}

The sootblowing system consists of 10 rotary sootblowers operating just above the duct floor, and four retractable sootblowers operating between the duct 
turning vanes at the end of the straight test duct section - about 120 feet downstream from the atomizing nozzles.

For the parametric tests, the test duct was provided with six floor sootblowers that covered only about one-half of the first straight section of the test duct. However, when revamping the system for continuous operation, four more rotary sootblowers were added to cover 100 feet of the duct floor and four retractable, vertical sootblowers were added to keep the turning vanes clean.

The last 20-foot length of the duct floor is not covered by the floor sootblowers. This is the area where the turning vane deposits, removed by the traversing sootblowers, can accumulate if they are not reentrained in the flue gas.

The sootblowing system experienced numerous equipment failures that were corrected by its supplier, and it now operates satisfactorily.

\subsection{LIME SYSTEM}

\subsubsection{Surface Deposits}

It is an inherent property of lime slurries to deposit lime on all exposed equipment surfaces. This is know as the plating property. These surface deposits dry out when the equipment is drained, and then they are sloughed off these surfaces when the lime slurry handling equipment is reactivated. There is no known method of avoiding the formation of such deposits. However, if the lime equipment is always filled with lime slurry, and the pumps are recirculating this slurry through all the piping, or if the piping is left filled with water, then the sloughing of surface deposits can be minimized.

To avoid plugging the atomizer feeders, a prolonged interruption of the lime injections should be followed by refiltration of the lime slurry prior to its atomization. 


\subsubsection{Valve Failures}

The CZD system operates with high-pressure lime slurries and uses pinch valves to control their flows. These valves have gum-rubber sleeves that last 6 to 12 months before they are worn out.

Frequent inspection of the pinch valves and prompt replacement of worn-out sleeves is a convenient method of managing the pinch valve wear problems. In future installations, the use of pinch-type valves with gum rubber sleeves will be minimized. Control valves with ceramic internals should be specified for critical service.

\subsubsection{Pump Failures}

The lime feed pumps experienced some operating problems due to a faulty seal packing that caused lime slurry leakage and to a faulty wear plate that caused pump casing leakage.

Both problems were fixed by the pump vendor by repacking the pump seal with the proper packing and replacing the faulty wear plate.

Currently, all pumps work satisfactorily.

\subsection{FLUE GAS SYSTEM}

\subsubsection{Uneven Gas Flow}

\subsubsection{Non-Uniformity of Gas Velocity}

The discharge plenum from the first stage ESP has the shape of a truncated pyramid lying on its side and is not symmetrical on the longitudinal axis of the test duct. It was hypothesized that this may be the reason why the gas flow is not uniformly distributed across the duct cross section. Future installations will ensure uniformity of the gas flow by properly studying the flow using duct velocity traverses and modifying the ductwork as necessary to provide straight, uniform flow into the confined zone. 


\subsubsection{Non-Uniformity of Gas Temperature}

In addition to the uneven distribution of the flue gas flow, there is a significant temperature difference between the left and right sides of the duct inlet plenum in the direction of the gas flow. The Unit No. 5 boiler operates with Ljungstrom rotary recuperative air heaters. It is an inherent characteristic of these heaters to have an appreciable temperature difference across the width of the flue gas stream. Installations in the future with these types of air heaters may need to include some type of gas mixing device (baffles) to improve the uniformity of the gas temperature in the duct.

\subsubsection{Variation in the Cross-Sectional Temperature at Section $C$}

It was observed that whereas the flow of the flue gas in the test duct is in the turbulent region, there is not that much mixing of flue gas in the first straight section of the test duct. Good gas mixing occurs only after the first set of duct turning vanes downstream of section $C$.

\subsubsection{Duct Deposits}

Duct deposits were observed during both parametric and continuous testing. These deposits were of sufficient volume to warrant upgrading of the sootblowing system prior to continuous operation of the CZD system.

It is thought that by changing the atomizer tips to prevent the formation of atomizer deposits, the formation of duct deposits will be reduced or prevented. Providing uniform gas flow in the duct will also help minimize the formation of duct deposits.

\subsubsection{Opacity Problems}

The injection of the atomized lime slurry into the flue gas stream increases the workload of an electrostatic precipitator. However, cooling and humidification of flue gas by the injected lime slurry more than compensates for the increased solids loading, resulting in a reduction in the stack gas opacity. However, the entrained solids in the flue gas entering the precipitator must be dry to avoid wetting the electrodes. An interruption of the lime injection is likely to result in an opacity increase unless corrective action is taken. 


\subsubsection{Corrective Actions}

Opacity episodes can be avoided by following the lime injection with the injection of a small volume of atomized water. The water injection must continue until all absorption waste that adheres to the ESP electrodes is removed from the system.

\subsubsection{Current Status}

The CZD system design now incorporates automatic controls which prevent operating at a condition that would result in wet lime entering the ESP.

Therefore, the system is designated to operate without adverse effects on the performance of the existing electrostatic precipitators.

\subsection{CONTROLS AND INSTRUMENTATION - L\&N RECORDERS}

L\&N recorders were unsatisfactory and were converted to slave recorders. For details of these problems, see Section 5, Critical Components Failure Report. 


\section{Section 7}

\section{PLANT COST DATA AND ECONOMICS}

\subsection{DEMONSTRATION PROJECT}

The overall summary of the capital cost requirements for the Seward CZD demonstration unit is shown in Table 7-1. Additional details can be found in the Public Design Report.

The costs shown in Table 7-1 include everything required to provide a complete and operable CZD system at Seward Station. These costs include all proprietary or "business-sensitive" equipment such as atomizer lances (included as piping), nozzles, and associated headers, piping, instrumentation, and other parts of the slurry injection atomizer array system.

Since earlier CZD proof-of-concept work was done at Seward Station, certain items of equipment did not need to be purchased and installed. These included the lime slurry feed and storage tanks, the grit tanks, the vibrating screen, and the water booster pump. In addition, Seward Station had an existing lime silo and lime preparation sump, as well as space in its existing buildings for installation of air compressors and a receiver. The total plant cost of $\$ 4,367,400$ shown in Table 7-1 is based on utilization of the existing equipment and space where possible. If the existing equipment and space were not available, the cost of the Seward Station CZD installation would increase to $\$ 5,146,300$. The incremental cost increase of $\$ 778,900$ may be broken down as follows:

Air compressors and receiver - add building, piping, wiring, etc.

$\$ 115,500$

Lime slurry preparation - add silo, sump, building, etc.

272,700

Lime slurry feed area - add tanks, screen, etc.

Lime slurry injection area - add water booster pump

Balance of plant - connecting wiring, piping, instrumentation, etc.

$\underline{116,800}$

Total installed cost

$\$ 778,900$

It is expected that there will be some cost improvement in future plants, based on design maturity and plant operating experience, because the Seward Station CZD 
system is the first commercial installation. Although most of the CZD equipment is of standard off-the-shelf design, the atomizer nozzles are expensive, special prototypes. As the market for CZD installations develops and production quantities of nozzles are required, the nozzle cost will decrease.

Table 7-1 shows the total field cost, total home office costs, and grand total based on the total direct costs. Field distributables, which include small tools, expendable supplies, field office costs, and similar items, are added to direct costs to obtain total field costs. Home office costs, which include engineering, procurement, accounting, and other supporting groups, are added to the field cost to produce the grand total. No allowance for contingency or fee is included in the cost estimates.

\subsection{COMMERCIAL PROJECTIONS}

The CZD process may be scaled as necessary to fit a variety of plant capacity requirements. The lime slurry preparation and feed areas offer no scaleup problems, and the lime slurry injection scaleup is a function of the site-specific plant characteristics. If existing plant ductwork is inadequate to provide the residence time and cross sectional area needed, new ductwork can be designed, similar to the retrofit at Seward Station, so that the injection requirements can be met. Consequently, duct size and length can be adjusted to satisfy the lime injection rates necessary to achieve the desired level of $\mathrm{SO}_{2}$ removal.

A preliminary assessment has been made of the capital and operating costs for CZD installations at various unit capacities. The costs were derived from analysis of the retrofit cost for Seward Station. It was assumed that no existing equipment or space was available and a complete lime receiving, preparation, and storage system would need to be provided. An allowance was also made for replacement of an equivalent amount of ductwork, similar to Seward Station. Costs for larger or smaller units were factored using appropriate exponents for individual items of equipment. The individual costs were then summed to give the total direct costs. Appropriate percentages were then applied for field distributables, home office costs, fees, and paid-up royalties to arrive at the total capital costs. 
Table 7-1

CZD Demonstration Unit Cost Summary

\begin{tabular}{|c|c|c|c|c|c|c|c|c|c|c|}
\hline & AREA 1 & AREA 2 & AREA 3 & AREA 4 & AREA 5 & AREA 6 & AREA 7 & AREA : & AREA 9 & \multirow[t]{2}{*}{ TOTAL } \\
\hline & $\begin{array}{c}\text { ATOMEZNG } \\
\text { AP } \\
\text { OONPFESSOR }\end{array}$ & $\begin{array}{l}\text { LME SUAPY } \\
\text { PFEPAPAION } \\
\text { APEA }\end{array}$ & $\begin{array}{l}\text { LME SUUPRY } \\
\text { FEED } \\
\text { AFEA }\end{array}$ & $\begin{array}{l}\text { LMESULPFY } \\
\text { MECTION } \\
\text { AFEA }\end{array}$ & $\begin{array}{l}\text { DUCT AND } \\
\text { SOOT. } \\
\text { DOWEPS }\end{array}$ & $\begin{array}{l}\text { WINTER } \\
\text { IZATION }\end{array}$ & $\begin{array}{l}\text { NSTRUMEN } \\
\text { TATION }\end{array}$ & EECTAICAL & $\begin{array}{l}\text { PPNNG AND } \\
\text { MECOWNICAL }\end{array}$ & \\
\hline MNOAEQAPMENT & 5339,013 & $\$ 52,735$ & $\$ 90.031$ & $\$ 108,742$ & $\$ 466,932$ & 50 & $\$ 312,876$ & $\$ 39,211$ & $\$ 22,825$ & $\$ 1,432,365$ \\
\hline BUKM MATERULLS & so & so & $\$ 1.022$ & 50 & 50 & $\$ 0$ & 50 & $\$ 0$ & $\$ 0$ & $\$ 1.022$ \\
\hline DRECT LABOA & 50 & $\$ 62.247$ & $\$ 97,351$ & $\$ 43,382$ & $\$ 140,613$ & $\$ 0$ & $\$ 2,706$ & $\$ 31,641$ & $\$ 41,511$ & $\$ 419,451$ \\
\hline SugCoNIfACTs & $\$ 253.610$ & $\$ 0$ & $\$ 0$ & $\$ 42,343$ & $\$ 376.291$ & $\$ 121.162$ & $\$ 30,095$ & $\$ 0$ & $\$ 0$ & $\$ 823.501$ \\
\hline SUBTOTAL & $\$ 592.623$ & $\$ 114,983$ & $\$ 188,404$ & $\$ 194.467$ & $\$ 983,837$ & $\$ 121,162$ & $\$ 345,678$ & $\$ 70,852$ & $\$ 64,336$ & $\$ 2,676,341$ \\
\hline & & & & & & & & & & \\
\hline SIPPNG & $\$ 1,150$ & $\$ 1,175$ & $\$ 1,401$ & $\$ 1.077$ & $\$ 1,329$ & so & $\$ 10,877$ & $\$ 1,587$ & $\$ 862$ & $\$ 19,467$ \\
\hline $\operatorname{tax}$ & $\$ 13.078$ & $\$ 301$ & $\$ 69$ & $\$ 474$ & 56 & $\$ 0$ & $\$ 15,408$ & $\$ 971$ & $\$ 209$ & $\$ 30,516$ \\
\hline & & & & & & & & & & \\
\hline TOTAL DARECT COST & $\$ 606,861$ & $\$ 116.459$ & $\$ 189,873$ & $\$ 196,019$ & $\$ 985,172$ & $\$ 121.162$ & $\$ 371,961$ & $\$ 73.409$ & $\$ 65,407$ & $\$ 2,726,323$ \\
\hline FEID DSTRIBUTABAF & $\$ 37,961$ & $\$ 7,285$ & $\$ 11,877$ & $\$ 12,262$ & $\$ 61,626$ & $\$ 7,579$ & $\$ 23,267$ & $\$ 4,592$ & $\$ 4,091$ & $\$ 170,540$ \\
\hline & & & & & & & & & & \\
\hline TOTNL FELD COST & $\$ 644,822$ & $\$ 123.744$ & $\$ 201,750$ & $\$ 208,281$ & $\$ 1,046,798$ & $\$ 128.741$ & $\$ 395,228$ & $\$ 78,001$ & $\$ 69,498$ & $\$ 2,896,863$ \\
\hline & & & & & & & & & & \\
\hline EGGNeBRANG & $\$ 247.380$ & $\$ 47.473$ & $\$ 77.400$ & $\$ 79.905$ & $\$ 401.594$ & $\$ 49.390$ & $\$ 151,625$ & $\$ 29.924$ & $\$ 26,662$ & $\$ 1,111,353$ \\
\hline PROAFEvent & $\$ 15,266$ & $\$ 7,637$ & $\$ 12,450$ & $\$ 12,853$ & $\$ 64,600$ & $\$ 7,945$ & $\$ 24,390$ & $\$ 4.814$ & $\$ 4,269$ & $\$ 178,772$ \\
\hline OTHERHOME OFFICE COSTS & $\$ 15,266$ & $\$ 7.706$ & $\$ 12,563$ & $\$ 12,970$ & $\$ 65,185$ & $\$ 8,017$ & $\$ 24,611$ & $\$ 4,857$ & $\$ 4,328$ & $\$ 180,390$ \\
\hline & & & & & & & & & & \\
\hline TOTN HOME OFFKCE COSTS & $\$ 277,912$ & $\$ 62,816$ & $\$ 102,413$ & $\$ 105,728$ & $\$ 531,370$ & $\$ 65,352$ & $\$ 200,626$ & $\$ 39,595$ & $\$ 35,279$ & $\$ 1,470,515$ \\
\hline & & & & & & & & & & \\
\hline GAAND TOTAL & 5922,734 & $\$ 186.560$ & $\$ 304.163$ & $\$ 314.009$ & $\$ 1,578.177$ & $\$ 194,093$ & $\$ 595,854$ & $\$ 117.596$ & $\$ 104.777$ & $54.367,378$ \\
\hline
\end{tabular}

NOTE: TOTAL COST DOES NOT NGLUDE COST OF ALPEAOY EXISTMG EQUUPMENT; COSTS WOUD MCREASE TO \$5, 146,300 F THESE WERE NCLUDED. 
Table 7-2 contains the design basis for the estimates. The details of the estimate for a $500 \mathrm{MW}$ generic unit are shown in Table 7-3. Figure 7-1 shows the variation of capital costs, in dollars per kilowatt, for a generic retrofit of CZD on units of various sizes. The total capital cost for plants in the range $150 \mathrm{MW}$ to $500 \mathrm{MW}$ varies from about $\$ 38 / \mathrm{kW}(500 \mathrm{MW})$ to $\$ 62 / \mathrm{kW}(150 \mathrm{MW})$. The capital costs rise sharply below $150 \mathrm{MW}$.

Figure 7-2 shows the projected operating and maintenance (O\&M) costs for CZD, expressed as dollars per ton of $\mathrm{SO}_{2}$ removed, versus the unit size in megawatts. The O\&M costs are shown both as 30-year levelized costs and as annual costs. The levelized costs were derived using EPRI's Technical Assessment Guidelines (TAG). The annual costs are on the same basis, but exclude any capital charges and represent the actual costs before application of carrying charges and levelization factor.

As shown in Figure 7-2, the annual O\&M costs for a plant burning 4\% sulfur coal vary from $\$ 332$ per ton of $\mathrm{SO}_{2}$ removed from a $50 \mathrm{MW}$ unit, to $\$ 185$ per ton of $\mathrm{SO}_{2}$ removed from a $500 \mathrm{MW}$ unit. Similarly, the levelized costs vary from $\$ 486$ per ton of $\mathrm{SO}_{2}$ removed from a $50 \mathrm{MW}$ unit, to $\$ 240$ per ton of $\mathrm{SO}_{2}$ removed from a 500 MW unit.

For both the capital and O\&M costs, unit size refers to a single unit and should not be confused with plant size or capacity. For example, a plant having a capacity of $600 \mathrm{MW}$ may consist of four $150 \mathrm{MW}$ units. In this case, capital costs should be determined from Figure 7-1 by referring to the cost for a $150 \mathrm{MW}$ unit and multiplying by 4 to determine the total plant cost. Costs determined in this manner will be very conservative, because they do not reflect the economies of multiple units. For example, a single lime preparation plant could service multiple CZD units. Similarly, the O\&M costs would be determined from Figure 7-2 by reference to the proper unit size (no multiplication necessary). 
Table 7-2

Design Basis

\begin{tabular}{|lr|}
\hline Technical \\
\hline Plant Capacity Factor, \% \\
Plant Heat Rate, Btu/ $\mathrm{kW}$ & 65 \\
Flue Gas Flow, scfm/MW & 9,800 \\
Coal HHV, Btu/lb & 2,400 \\
Moisture in Coal, \% & 11,200 \\
Sulfur in Coal, Dry Basis, \% & 12.0 \\
Flue Gas SO, Concentration, ppmv & 3.9 \\
SO 2 Removal, \% & 2,000 \\
\hline Economic & 50 \\
\hline Construction Labor Rate, \$/hr & 39.80 \\
Operating Labor Rate, \$/hr & 20.00 \\
Delivered Quicklime (CaO) Cost, \$/ton & 55.00 \\
Incremental Waste Disposal Cost, \$/ton & 6.00 \\
\hline
\end{tabular}


Table 7-3

Cost of $\mathrm{SO}_{2}$ Removal with CZD

(500 MW Plant Size)

Total Capital Requirements

Decrease in $\mathrm{SO}_{2}$ emissions

Increase in operating costs
$\$ 21.87 \mathrm{MM}$

7.4 ton $\mathrm{SO}_{2} / \mathrm{hr}$

$\$ 185.11$ per ton $\mathrm{SO}_{2}$ removed

\begin{abstract}
Steam Cycle Data
$\Delta$ Sulfur Dioxide Captured, tons $/ \mathrm{hr}$

Capital Cost Delta, \$MM

Boiler Efficiency, \%

CZD Treated Flue Gas, lb $\mathrm{SO}_{2} / \mathrm{MM}$ Btu

ECONOMIC EVALUATION

Carrying Charges

(30 yr book life, 20 yr tax life)

Levelization factor ( $0 \%$ real escalation)

Capital Recovery, $\$ M M / y r$

O\&M Cost of Removal, $\$ \mathrm{MM} / \mathrm{yr}$ at $80 \%$ capacity factor at $72 \%$ capacity factor at $65 \%$ capacity factor
\end{abstract}

Raw, Untreated Flue Gas, $\mathrm{lb} \mathrm{SO}_{2} / \mathrm{MM}$ Btu

Total cost of $\mathrm{SO}_{2}$ removal, $\$ /$ ton $\mathrm{SO}_{2}$

at $80 \%$ capacity factor at $72 \%$ capacity factor at $65 \%$ capacity factor

\begin{tabular}{|l|c|c|c|c|}
\multirow{2}{*}{ escalation) } & \multicolumn{2}{|c|}{30 Year Analysis } & \multicolumn{2}{c|}{10 Year Analysis } \\
\cline { 2 - 5 } & Constant \$ & Current \$ & Constant \$ & Current \$ \\
\hline & 0.106 & 0.165 & 0.127 & 0.189 \\
& 1 & 1.613 & 1 & 1.265 \\
& 2.32 & 3.61 & 2.78 & 4.13 \\
& & & & \\
& & & & \\
& 9.64 & 15.55 & 9.64 & 12.19 \\
& 8.68 & 13.99 & 8.68 & 10.97 \\
& 7.83 & 12.63 & 7.83 & 9.91 \\
& & & & \\
& & & & \\
& & & & \\
& 229.62 & 367.87 & 238.40 & 313.53 \\
& 234.57 & 375.57 & 244.37 & 322.35 \\
& 239.90 & 383.86 & 250.75 & 331.85
\end{tabular}

Backup for cost of $\mathrm{SO}_{2}$ removal

\section{Total Capital Requirement \\ Plant Power \\ Capital}

Material Balance Information

Coal, HHV

Capacity factor

Average input to boiler

Average coal usage

Heat Rate

Coal Usage @ full load

Moisture in coal

Sulfur in coal (dry)

Sulfur in coal (wet)

Average $S$ in coal
$\$ 37.70$ per $\mathrm{kW}$
$500 \mathrm{MW}$
$\$ 18.85 \mathrm{MM}$

$\begin{array}{rl}11,200 & \mathrm{Btu} / \mathrm{lb} \\ 65 \% & \\ 3,185 & \mathrm{MM} \mathrm{Btu} / \mathrm{hr} \\ 142.19 & \text { ton } / \mathrm{hr} \\ 284,375 & \mathrm{lb} / \mathrm{hr} \\ 9,800 & \mathrm{Btu} / \mathrm{kW} \\ 34.83 \% & \\ 218.75 & \text { ton } / \mathrm{hr} \\ 437,500 & \mathrm{lb} / \mathrm{hr} \\ 12 \% & \\ 3.86 \% & \\ 3.40 \% & \\ 4.83 & \text { ton } / \mathrm{hr} \\ 9,660 & \mathrm{lb} / \mathrm{hr} \\ 42,309 & \text { ton } / \mathrm{yr}\end{array}$


Table 7-3 (Cont'd)

$S$ in coal @ full load

Average $\mathrm{SO}_{2}$ produced

$\mathrm{SO}_{2}$ produced @ full rates

$\mathrm{SO}_{2}$ Removal rate

Average $\mathrm{SO}_{2}$ removed

$\mathrm{SO}_{2}$ removed @ full rates

\section{Total Capital Requirement}

Total Plant Investment

Prepaid Royalties (covered under capital)

Inventory Capital

Cost of lime (pebble quicklime)

(shipping included in cost of lime) Total

Lime utilization

Lime purity and slaking loss

Average lime consumption

Lime consumption @ full rates

Lime inventory 30 days @ full rates

Preproduction/Startup Costs (4 mo)

Labor

Consumables (lime)

Power

Total

Total Capital Requirement

Fixed O\&M Costs

Operating Labor @ $1 \mathrm{man} / \mathrm{shift}$

Maintenance @ $5 \%$ of PFI

Total Fixed

Variable O\&-M Costs

Lime (from above)

Waste Disposal

Power

Air compressor

Pumps, agitators, lighting, etc.

Power costs

Total O\&M Costs

Total Variable

Cost per ton of $\mathrm{SO}_{2}$ removed
7.43 ton $/ \mathrm{hr}$

$14,861 \mathrm{lb} / \mathrm{hr}$

$19,319 \mathrm{lb} / \mathrm{hr}$

$29,722 \mathrm{lb} / \mathrm{hr}$

$50.00 \%$

$9,660 \mathrm{lb} / \mathrm{hr}$

4.83 ton $/ \mathrm{hr}$

42,309 ton $/ \mathrm{yr}$

$14,861 \mathrm{lb} / \mathrm{hr}$

7.43 ton $/ \mathrm{hr}$

$\begin{array}{rl}\$ 18.85 & \mathrm{MM} \\ \$ 0.00 & \$ / \mathrm{kW} \\ \$ 0.00 & \mathrm{MM} \\ \$ 55 & \mathrm{per} \text { ton for chem } \\ \$ 0 & \text { per ton for ship } \\ \$ 55 & \\ 40 \% & \\ 92 \% & \\ 22,968 & \mathrm{lb} / \mathrm{hr} \\ 100,599 & \text { ton } / \mathrm{yr} \\ 35,335 & \mathrm{lb} / \mathrm{hr} \\ 17.67 & \text { ton } / \mathrm{hr} \\ 12,721 & \text { tons } \\ \$ 0.70 & \mathrm{MM} \\ & \\ \$ 0.37 & \mathrm{MM} \\ 33,533 & \text { tons } \\ \$ 1.84 & \mathrm{MM} \\ \$ 0.10 & \mathrm{MM} \\ \$ 2.32 & \mathrm{MM} \\ \$ 21.87 & \mathrm{MM} \\ & \\ \$ 20.00 & \mathrm{per} \mathrm{hr} \\ \$ 0.18 & \mathrm{MM} \\ \$ 0.94 & \mathrm{MM} \\ \$ 1.12 & \mathrm{MM} \\ & \\ \$ 5.53 & \mathrm{MM} \\ \$ 0.88 & \mathrm{MM} \\ 1500 & \mathrm{hp} \\ 300 & \mathrm{hp} \\ 1800 & \mathrm{hp} \\ 1341 & \mathrm{~kW} \\ 40 & \mathrm{mills} / \mathrm{kW} \\ \$ 0.31 & \mathrm{MM} \\ \$ 6.71 & \mathrm{MM} \\ \$ 7.83 & \\ \$ 185.11 & \mathrm{per} \text { ton } \\ & \\ & \\ & \\ & \\ & \end{array}$




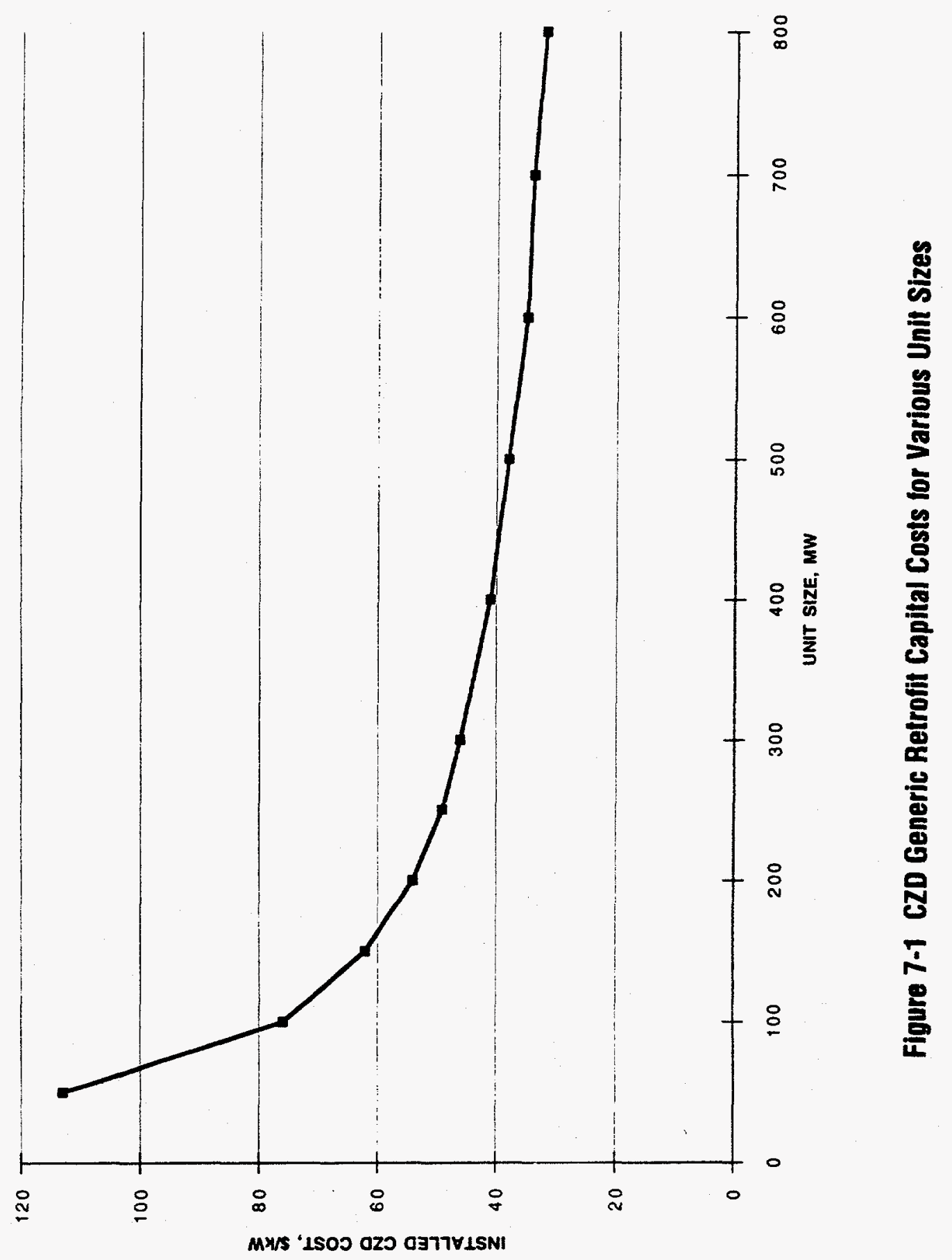




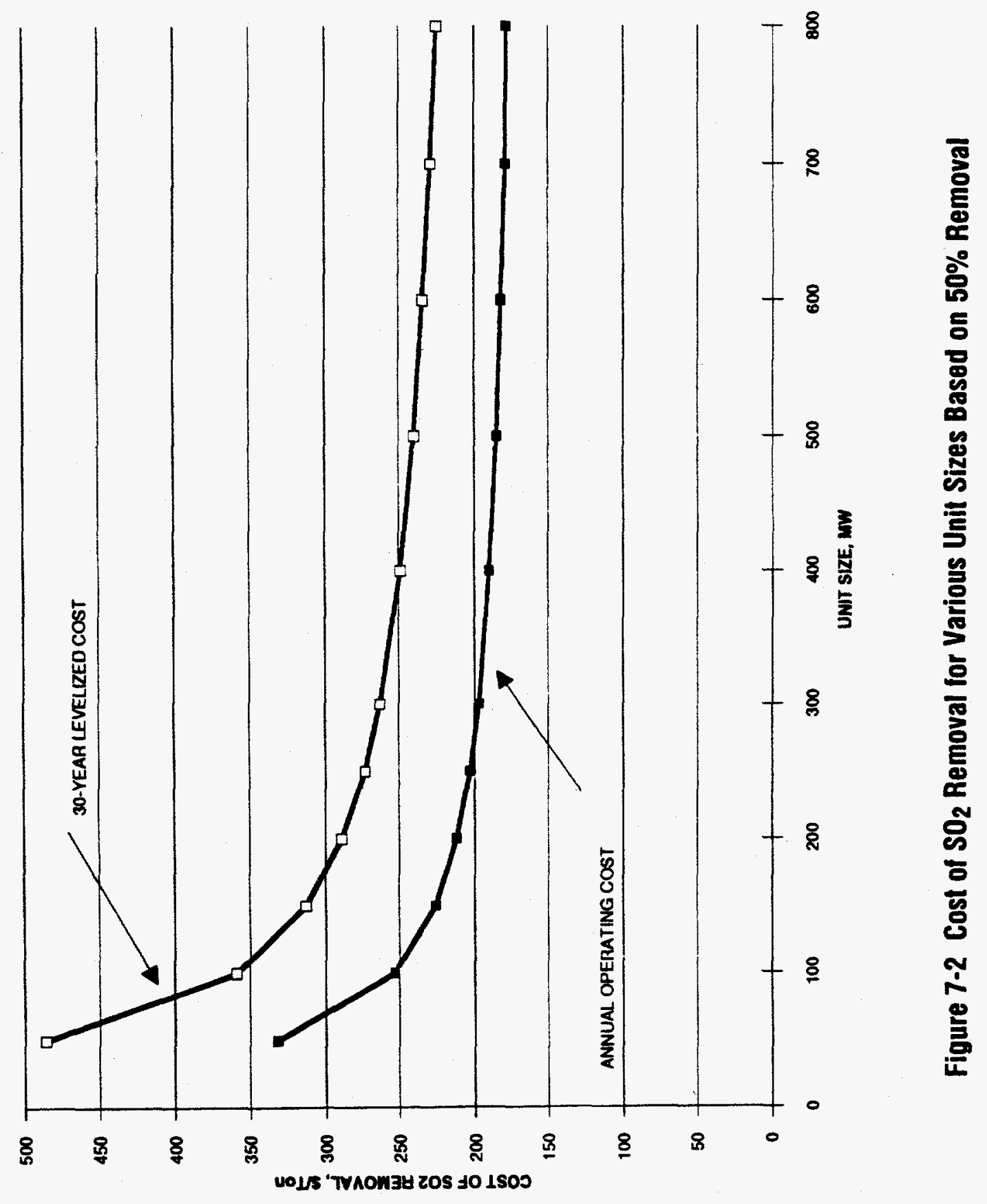




\subsection{COMPARISON WITH COMPETING TECHNOLOGIES}

The CZD-FGD process is capable of removing $50 \%$ of $\mathrm{SO}_{2}$ emissions from coal fired boilers. It is applicable to every size of industrial and utility boiler and is particularly suited for retrofit applications where it is necessary to reduce annual $\mathrm{SO}_{2}$ emissions. When successfully demonstrated, this project will establish an alternative process technology to conventional wet and dry FGD processes while requiring less physical space and lower capital and operating and maintenance costs.

However, technologies that will compete with CZD are likely to be those that also have limited $\mathrm{SO}_{2}$ removal capability. These technologies, along with $\mathrm{CZD}$, fall under a broad category called sorbent injection. The sorbent injection processes are generally divided into two subcategories: furnace-injection processes and duct-injection processes. Furnace-injection processes involve the injection of sorbent materials directly into the combustion zone. Duct-injection technologies, on the other hand, inject sorbent materials in the ducting immediately following the furnace.

Sorbent injection technologies have been demonstrated at the pilot plant scale; however, full-scale applications are limited. The limited technical and economic data available at this time on these processes preclude any meaningful direct comparisons with the CZD process.

One furnace-injection process, Limestone Injection into the Furnace and reActivation of Calcium (LIFAC), has been in commercial operation since 1988 and has also been selected for a demonstration under the Clean Coal Technology 3 program. In the LIFAC process, pulverized limestone is pneumatically injected into the upper region of the boiler. There, some $\mathrm{SO}_{2}$ is absorbed, and the limestone is calcined to calcium oxide. The calcium oxide removes additional $\mathrm{SO}_{2}$ in a downstream humidification reactor. An ESP then separates sorbent and fly ash from flue gas prior to exhaust.

The limestone-injection multistage burners (LIMB) process, developed by Babcock \& Wilcox (B\&W), is another furnace-injection process. The LIMB process uses low-NO $\mathrm{NO}_{x}$ burners to keep $\mathrm{NO}_{x}$ emissions below $0.5 \mathrm{lb} / \mathrm{MMBtu}$, and a 
lignosulfonate-doped, hydrated calcite lime is used as the reagent. The system has been operating as a demonstration unit since 1987. Humidification is required to maintain particulate emission control.

The Coolside process, developed by CONSOL, Inc., is a duct-injection process that takes place downstream of the air pre-heater. Hydrated lime is injected into the ducting, and shortly downstream, water sprays humidify the flue gas to nearly adiabatic saturation. Spent sorbent is removed in dry form, along with fly ash, in the existing particulate collector. The Coolside process was demonstrated at the 105 MW level by CONSOL, Inc. with DOE funding at Ohio Edison's Edgewater Station.

The features that distinguish the Bechtel CZD process from other similar injection processes are the following:

- Injection of an alkaline slurry directly into the duct. Other processes use injection of dry solids into the duct ahead of the particulate collector.

- Use of an ultrafine calcium/magnesium hydroxide, Type S PHDL. This commercially available product is made from plentiful, naturally occurring dolomite.

- Low residence time, made possible by the highly effective surface area of the Type $S$ lime.

- Localized dispersion of the reagent. Slurry droplets contact only part of the gas, while the droplets are drying, to remove up to 50 percent of the $\mathrm{SO}_{2}$. 


\section{Section 8}

\section{FUTURE PLANS AND MARKETING PROGRAM}

At the conclusion of the DOE-funded CZD demonstration project at Seward Station, reliable operation of the CZD process when integrated with a power station was demonstrated, but longer term continuous operation at higher $\mathrm{SO}_{2}$ removals was not. Bechtel and Penelec will continue to cooperate in the CZD demonstration to achieve continuous operation at $\mathrm{SO}_{2}$ removals of $50 \%$. Bechtel intends to commercialize the CZD process when the demonstration is successfully concluded.

Once commercially proven, the CZD-FGD process will provide an economical and technically acceptable means for the removal of $\mathrm{SO}_{2}$. The minimal space requirements and the competitive capital and O\&M costs make this technology attractive for retrofit applications for utility and industrial coal-fired boilers. The CZD-FGD process consists largely of proven, commercially available equipment, such as ductwork, atomizers, air compressors, tanks, pumps, etc.

The CZD-FGD process is particularly suited for retrofitting onto existing boilers and is not dependent on boiler type, age, size, type of coal burned or sulfur content of the coal. Conventional wet scrubbers for new sources are typically designed to remove $90 \% \mathrm{SO}_{2}$. The CZD-FGD process, however, which only removes $50 \% \mathrm{SO}_{2}$, is more suited to the retrofit market where the emphasis is on the annual reduction of $\mathrm{SO}_{2}$ and minimizing the cost to achieve this annual quota.

The CZD-FGD technology requires less equipment space requirements and lower capital and O\&M costs than conventional systems. The total cost per ton of $\mathrm{SO}_{2}$ removed, including capital and operating costs, is projected to be less than $\$ 300 /$ ton for a $500 \mathrm{MW}$ unit burning a $4 \%$ sulfur coal.

The acid rain provisions of the 1990 Clean Air Act Amendments (CAAA) give utilities the option to select the most cost-effective approach to control $\mathrm{SO}_{2}$ emissions to their required levels. There are a large number of candidate plants in the United States suitable for application of the CZD process. There is also a 
significant international marketing potential. Many areas, such as Central Europe, could benefit from a low capital cost method of reducing $\mathrm{SO}_{2}$ emissions.

While most utilities have preliminary CAAA compliance plans in place, the final outcome is uncertain. Estimates of the amount of scrubbing, especially for Phase I, have fallen substantially as confidence has grown with regard to the availability of adequate quantities of low-sulfur coal at reasonable cost.

Estimates for Phase II scrubber retrofits range from 25,000 to 50,000 MW. These will likely be phased in over a long period of time - perhaps until 2005 and beyond - as utilities use emission allowance credits to delay retrofits.

The potential for CZD retrofits is less than it was when the CZD demonstration project started, but it is still substantial. Dry scrubbing and injection technologies could capture 10 to $15 \%$ of the Phase II FGD capacity. CZD retrofits are likely to obtain a good share of this because CZD is cost-effective at those locations with limited compliance options and at some medium- and low-sulfur coal-fired plants.

Following a successful CZD demonstration, Bechtel will initiate business discussions with domestic utilities, including Penelec, which might potentially benefit from CZD. After the CZD system is commercialized in the United States, commercialization in Eastern Europe and developing countries will be pursued.

Bechtel intends to be flexible in its CZD marketing approach. We will not only license the process but will undertake the design, procurement, and construction of CZD systems. We will also participate in own/operate arrangements as we have done in several large cogeneration projects. To recover our investment in CZD installations, we would offer to process flue gas according to a tolling formula with unit revenues derived for each ton of $\mathrm{SO}_{2}$ removed or for a share of the emission allowance credits generated.

For additional information on the CZD technology, please contact the Manager, Emission Control, Research and Development, Bechtel Group, Inc., 50 Beale Street, San Francisco, CA 94105-1895 [telephone (415) 768-1234]. 


\section{Section 9}

\section{CONCLUSIONS AND RECOMMENDATIONS}

The following conclusions and principal findings can be drawn from the results of the CZD demonstration:

- The integration of the fully automated system with the power plant operation proved that the CZD process responds very well to automated control operations.

- CZD system availability and mechanical operation of the process are very good. For example, during the period October 17 to November 16, 1992, the automated systems were on line $100 \%$ of the time -744 hours.

- Overall $\mathrm{SO}_{2}$ removals above $50 \%$ are possible under favorable boiler operating conditions when the inlet flue gas temperature is above $300^{\circ} \mathrm{F}$. However, demonstration of sustained operation at $\mathrm{SO}_{2}$ removal rates of $50 \%$ was not accomplished during this program.

- Lime utilization is inversely related to lime slurry concentration and it decreases significantly as concentrations rise above $10 \%$. Lime utilizations of $50 \%$ are possible with lime concentrations of $5 \%$, but fall off to the low 30 s when concentrations increase to $10 \%$.

- The injection of atomized lime slurry in a large duct can be controlled in a confined zone which minimizes duct deposition while enhancing $\mathrm{SO}_{2}$ removal performance. Temperature profiles of the duct cross section during injection can be used to define the shape of the confined zone.

- Injected lime slurry has to dry before contacting any surfaces inside the duct; otherwise, deposits will form. It is critical to ensure that slurry injection rates high enough to cause wet deposits be avoided since it is not possible to remove such deposits by sootblowing, and a unit shutdown is necessary for removal.

- During normal CZD operations, no deposits of fly ash and reaction products took place in the flue gas duct. Equipment failures that would cause deposits were identified as follows: 
- A power failure on the air compressor supplying the compressed air to the lime slurry atomizers

- Breakage of the ceramic tips, causing coarse sprays

- Leakage of the lime slurry atomizers around their flanges and spray tips, causing the formation of deposits on the atomizer tips

- At Seward Station, stack opacity is not detrimentally affected by the CZD system.

- Results of the demonstration indicate that the CZD process can achieve costs of $\$ 300 /$ ton of $\mathrm{SO}_{2}$ removed when operating a $500 \mathrm{MW}$ unit burning $4 \%$ sulfur coal. Based on a $500 \mathrm{MW}$ plant retrofitted with CZD for a $50 \%$ rate of $\mathrm{SO}_{2}$ removal, the total capital cost is estimated at less than $\$ 30 / \mathrm{kW}$.

Additional testing is required to further explore the limits of the lime injection rate and $\mathrm{SO}_{2}$ removal, to clarify performance of $\mathrm{CL}$ and PHDL under continuous operation, and to more thoroughly assess the effect of long-term, continuous lime injection on ESP performance.

It is recommended that Bechtel and Penelec continue the continuous operation portion of the CZD demonstration project and bring it to a successful conclusion. 


\section{BIBLIOGRAPHY}

Bechtel Corporation. Confined Zone Dispersion Project Public Design Report. San Francisco, California, August 1993.

- Confined Zone Dispersion Flue Gas Desulfurization Demonstration. Quarterly Report No. 1 For the Period November 1, 1990 to January 30, 1991. San Francisco, California.

. Confined Zone Dispersion Flue Gas Desulfurization Demonstration. Quarterly Report No. 2 For the Period February 1, 1991 to April 30, 1991. San Francisco, California.

- Confined Zone Dispersion Flue Gas Desulfurization Demonstration. Quarterly Report No. 3 For the Period May 1, 1991 to July 31, 1991. San Francisco, California.

. Confined Zone Dispersion Flue Gas Desulfurization Demonstration. Quarterly Report No. 4 For the Period August 1, 1991 to October 31, 1991.

. Confined Zone Dispersion Flue Gas Desulfurization Demonstration. Quarterly Report No. 5 For the Period November 1, 1991 to January 31, 1992.

- Confined Zone Dispersion Flue Gas Desulfurization Demonstration. Quarterly Report No. 6 For the Period February 1, 1992 to April 30, 1992.

- Confined Zone Dispersion Flue Gas Desulfurization Demonstration. Quarterly Report No. 7 For the Period May 1, 1992 to August 16, 1992.

. Confined Zone Dispersion Flue Gas Desulfurization Demonstration. Quarterly Report No. 8 For the Period August 17, 1992 to November 16, 1992.

Confined Zone Dispersion Flue Gas Desulfurization Demonstration. Quarterly Report No. 9 For the Period November 17, 1992 to February 16, 1993.

Report No. 10 For the Period February 17, 1993 to May 31, 1993.

Electric Power Research Institute. Technical Assessment Guide. Electricity Supply 1993. EPRI TR-102276-V1R7. June 1993. 


\section{Appendix A}

This appendix shows the typical chemical analysis of lime used during the CZD project (see Table A-1) and the ultimate analyses for normal and higher sulfur coal (see Table A-2).

Table A-1

Typical Chemical Analysis of Lime Used During the CZD Project

\begin{tabular}{|l|c|c|c|}
\hline Component, \% & $\begin{array}{c}\text { Pressure } \\
\text { Hydrated } \\
\text { Dolomitic Lime }\end{array}$ & $\begin{array}{c}\text { Hydrated } \\
\text { Calcitic Lime }\end{array}$ & Quicklime* \\
\hline Silica, $\mathrm{SiO}_{2}$ & 0.66 & 0.92 & 1.35 \\
Iron Oxide, $\mathrm{Fe}_{2} \mathrm{O}_{3}$ & 0.20 & 0.29 & 0.25 \\
Aluminum Oxide, $\mathrm{Al}_{2} \mathrm{O}_{3}$ & 0.50 & 0.46 & 0.30 \\
Calcium Oxide, $\mathrm{CaO}$ & 44.50 & 73.00 & 95.63 \\
Magnesium Oxide, $\mathrm{MgO}$ & 28.22 & 0.65 & 1.40 \\
Carbon Dioxide, $\mathrm{CO} 2$ & 1.80 & 0.40 & 0.95 \\
Total Water & 23.60 & 0.50 & \\
Loss On Ignition, $\mathrm{LOI}$ & 24.67 & & \\
Available $\mathrm{Ca}(\mathrm{OH})_{2} \cdot \mathrm{Mg}(\mathrm{OH})_{2}$ & 94 & & \\
Available $\mathrm{Ca}(\mathrm{OH})_{2}$ & 93 & & \\
\hline
\end{tabular}

* Used to prepare the freshly slaked lime 
Table A-2

Ultimate Analyses for

Normal and Higher Sulfur Coal

\begin{tabular}{|l|c|c|}
\hline \multicolumn{1}{|c|}{ Component } & $\begin{array}{c}\text { Normal Sulfur Coal } \\
\text { (Wt. \%) }\end{array}$ & $\begin{array}{c}\text { Higher Sulfur Coal } \\
\text { (Wt. \%) }\end{array}$ \\
\hline Moisture & 6.39 & 4.84 \\
Carbon & 67.73 & 67.63 \\
Hydrogen & 3.92 & 3.95 \\
Nitrogen & 1.21 & 1.23 \\
Sulfur & 1.50 & 2.30 \\
Ash & 15.32 & 17.77 \\
Oxygen & 3.88 & 2.28 \\
Heating Value Range (Btu/lb) & $11,500-12,400$ & $11,600-11,900$ \\
\hline
\end{tabular}

